\title{
Fluorite (U-Th-Sm)/He thermochronology
}

\author{
Dissertation \\ zur Erlangung des mathematisch-naturwissenschaftlichen \\ Doktorgrades \\ "Doctor rerum naturalium" \\ der Georg-August-Universität Göttingen \\ im Promotionsprogramm Geowissenschaften \\ der Georg-August University School of Science (GAUSS)
}

vorgelegt von
Reinhard Wolff
aus Spaichingen

Göttingen, 2015 
Betreuungsausschuss

Dr. István Dunkl, Sedimentologie, GZG, Georg-August-Universität Göttingen

Prof. Dr. Hilmar von Eynatten, Sedimentologie, GZG, Georg-August-Universität Göttingen

Mitglieder der Prüfungskommission

Referent: Prof. Dr. Jonas Kley, Strukturgeologie, GZG, Georg-August-Universität Göttingen

Korreferent Prof. Dr. Gerhard Wörner, Geochemie, GZG, Georg-August-Universität Göttingen

2. Korreferent: Prof. Dr. Gregor Markl, Petrologie, Eberhard Karls Universität Tübingen

Weitere Mitglieder der Prüfungskommission:

Prof. Dr. Andreas Pack, Isotopengeologie, GZG, Georg-August-Universität Göttingen

Tag der mündlichen Prüfung: 3.9.2015 
Hiermit erkläre ich an Eides statt, die vorliegende Arbeit selbstständig angefertigt zu haben und dabei keine anderen als die von mir angegebenen Quellen und Hilfsmittel benutzt zu haben. Ferner erkläre ich, dass ich nicht anderweitig versucht habe, eine Dissertation einzureichen.

Göttingen, den 27.07.2015

Reinhard Wolff 
Wenn eine Idee zu Beginn nicht absurd erscheint, dann ist sie es nicht wert, weiterverfolgt zu werden. Albert Einstein 


\section{Table of Contents}

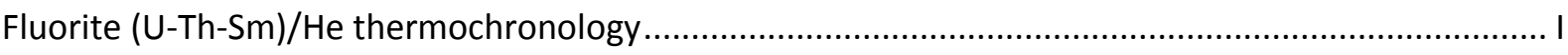

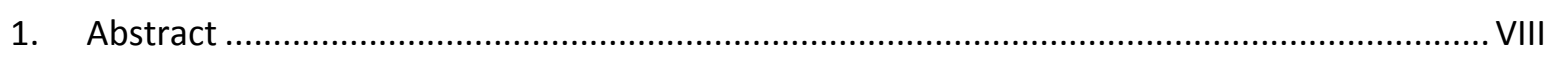

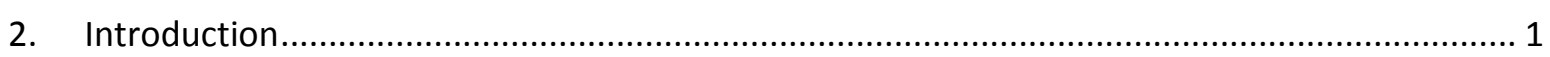

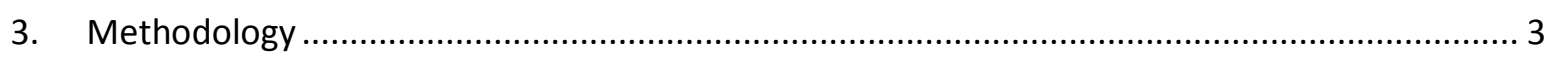

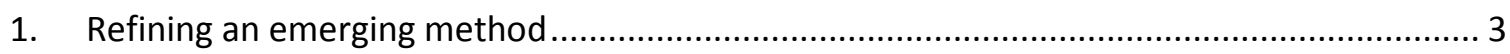

2. Fluorite (U-Th-Sm)/He thermochronology ..................................................................... 4

3. Refining the step heating diffusion measurements .......................................................... 5

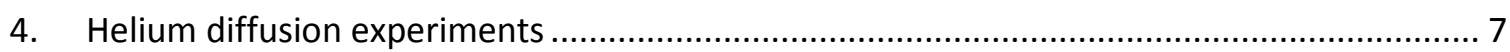

4. Superposition of burial and hydrothermal events: post-Variscan thermal evolution of the

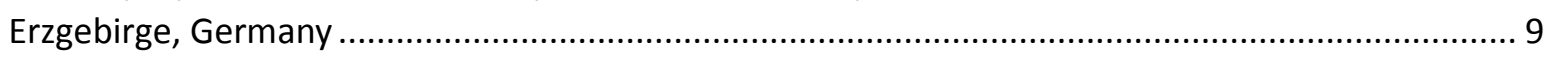

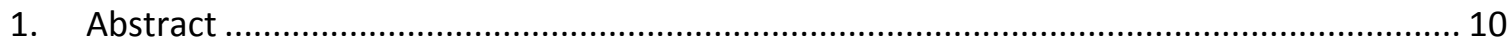

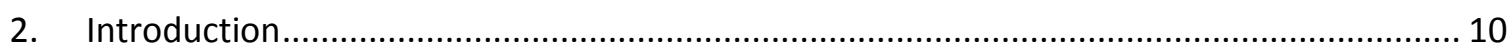

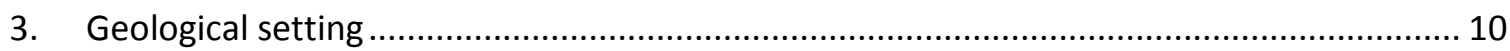

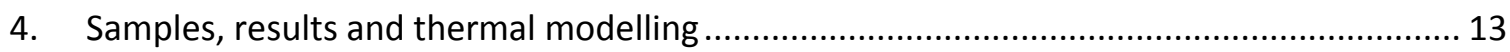

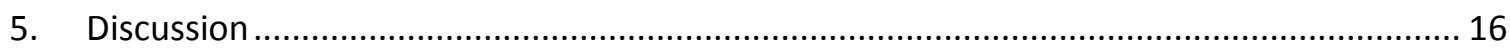

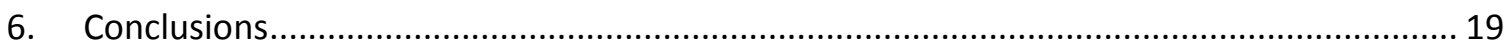

5. The age of the latest thermal overprint of tin and polymetallic deposits in the Erzgebirge, Germany: constraints from fluorite (U-Th-Sm)/He thermochronology ........................................ 21

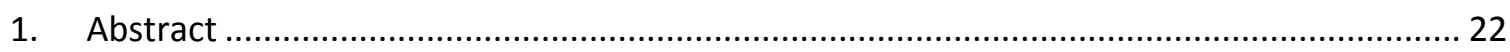

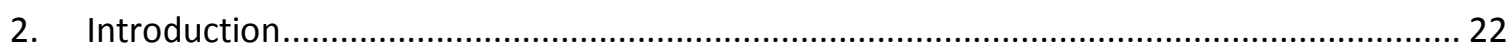

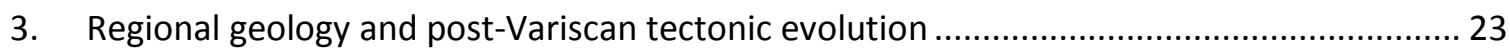

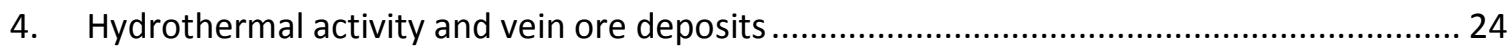

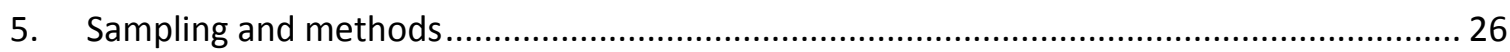

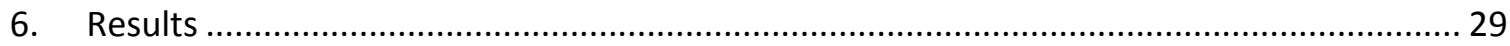

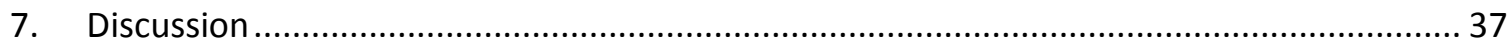

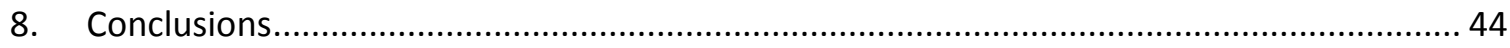

6. Variable helium diffusion characteristics in fluorite ............................................................ 46

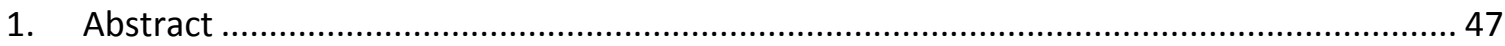

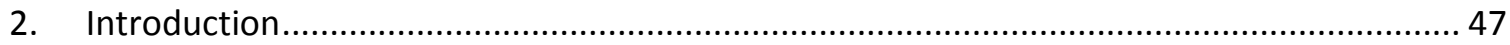

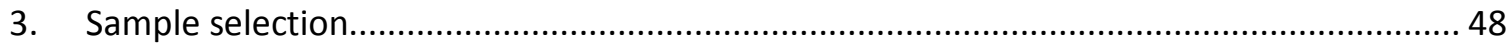

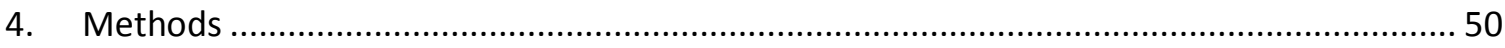

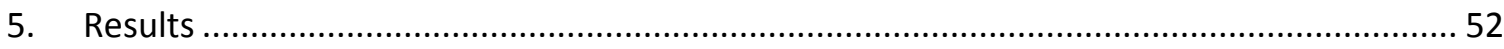

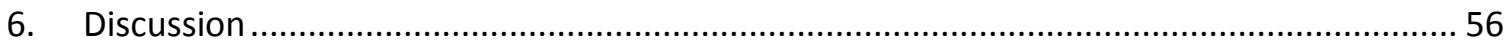

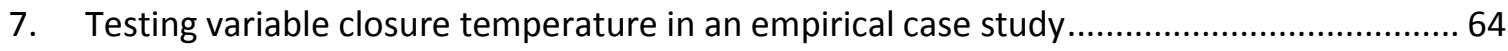




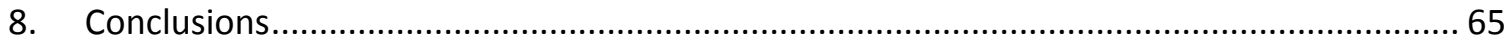

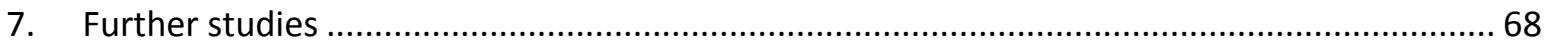

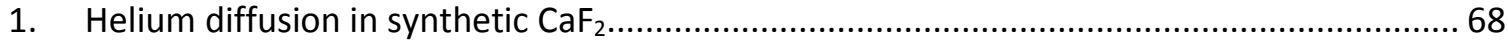

2. Fluorite classification based on rare earth element systematics ................................. 73

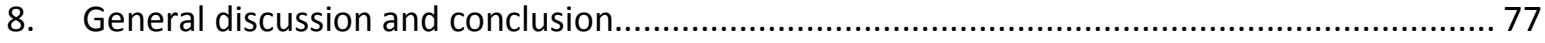

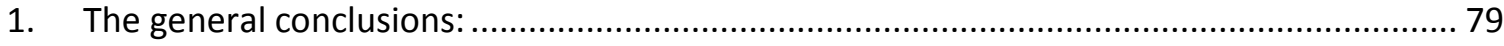

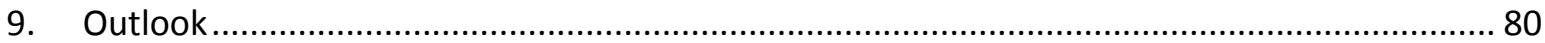

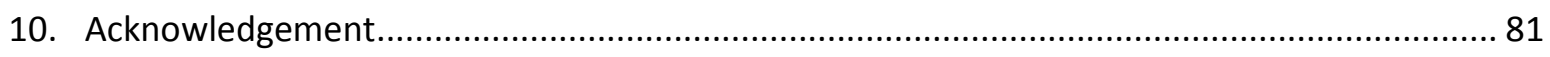

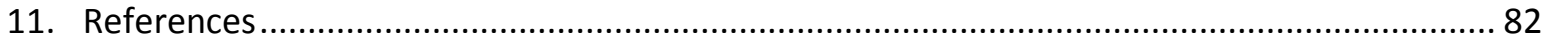




\section{Preface}

The structure of this thesis follows a development and validation strategy of the fluorite (U-Th-Sm)/He method. Abstract and introduction summarise the results and point out the aims and strategy of the chosen approach, respectively. The methodology chapter contains the logbook of improving the analytical technique of an emerging and promising method and details on the procedures elaborated in the methodical article. Further methods applied are explained in the relevant articles or at the corresponding chapter. The articles included in this cumulative thesis are presented next. The full references of the three articles are listed below. The chapter further studies contains experiments and studies supporting the main thesis that are not included in the articles mentioned above. At the end a general discussion and conclusion and outlook are given.

This study was funded by the German Research Foundation (DFG grant DU373/6).

List of articles included in this thesis:

Wolff, R., Dunkl, I., Lange, J.-M., Tonk, C., Voigt, T. von Eynatten, H., 2015. Superposition of burial and hydrothermal events: post-Variscan thermal evolution of the Erzgebirge, Germany. Terra Nova, 27(4), 292-299.

Wolff, R., Dunkl, I., Kempe, U. von Eynatten, H., 2015. The age of the latest hydrothermal overprint of tin and polymetallic deposits in the Erzgebirge, Germany: constraints from fluorite (U-Th-Sm)/He thermochronology. Economic Geology, 110, 2025-2040.

Wolff, R., Dunkl, I., Kempe, U., Stockli, D. F., Wiedenbeck, M. von Eynatten, H., 2016. Variable helium diffusion characteristics in fluorite. Geochimica et Cosmochimica Acta, 188, 21-34. 


\section{Abstract}

The aim of my thesis is to establish an emerging and novel method in low-temperature thermochronology based upon the mineral fluorite. The new and until now rarely applied method, fluorite (U-Th-Sm)/He thermochronology (FHe), is validated in two ways: by (A) analytically estimating the helium diffusion which controls the closure temperature $\left(T_{c}\right)$ by step heating experiments and $(B)$ comparing it to well-established thermochronometers in an empirical case study. Regarding the first, the diffusion experiments indicate a thermally activated process with the physical crystal as the diffusion domain. Moreover, the diffusion data allows one to draw the conclusion that the closure temperature is variable. Hereby, the calculated closure temperature of the fluorite thermochronometer varies between $46 \pm 14^{\circ} \mathrm{C}$ and $169 \pm 9{ }^{\circ} \mathrm{C}$, considering a $125 \mu \mathrm{m}$ fragment size. $\left(\log D_{0} / a^{2}=0.30 \pm 0.27\right.$ to $7.27 \pm 0.46 \mathrm{~s}^{-1}$ and $E_{a}=96 \pm 3.5$ to $\left.182 \pm 3.8 \mathrm{~kJ} / \mathrm{mol}\right)$. In this thesis I establish that minor substitutions of calcium by rare earth elements and yttrium $(R E E+Y)$ and related charge compensation by sodium, fluorine, oxygen and/or vacancies in the fluorite crystal lattice have a significant impact on the diffusivity of helium in the mineral. With increasing $R E E+Y$ concentrations $F$ vacancies are reduced and key diffusion pathways are narrowed. Consequently, a higher closure temperature is to be expected. Therefore, the REE+Y content can be used for estimating the $T_{c}$. An empirical case study in the Erzgebirge, Germany confirms this variability: The complex post Variscan thermal history of the Erzgebirge is established with apatite and zircon (U-Th)/He and apatite fission track thermochronology. It is the result of Mesozoic sedimentary burial, exhumation in Cenomanian times and superimposed Cretaceous hydrothermal activity. The present-day surface of the Erzgebirge was exhumed to a near-surface position after the Variscan orogeny. Thermal modelling reveals a Permo-Mesozoic burial up to temperatures of 80 to $100{ }^{\circ} \mathrm{C}$ while the sedimentary cover thins out towards the north resulting in maximum burial temperatures less than $40^{\circ} \mathrm{C}$. This thermal pattern was modified locally by Cretaceous hydrothermal activity that resets the zircon (U-Th)/He thermochronometer along ore veins. In line with the empirical case study, 233 fluorite aliquots taken from 38 samples at 7 localities from two mineralisation types ( $\mathrm{Sn}-\mathrm{W}$ mineralisation of Late Carboniferous to Early Permian age and a polymetallic vein mineralisation of probably Mesozoic age; they can be distinguished by La-Er-Gd using linear discriminant analysis) have been dated. Six deposits yield Cretaceous FHe ages (112 \pm 10 to $79 \pm 10 \mathrm{Ma}$ ) independent of their paragenesis, while samples from the Sadisdorf Sn-W deposit yields $234 \pm 16 \mathrm{Ma}$. The younger ages are interpreted as cooling ages indicating the time when the last thermal overprint, including possible hydrothermal activity, in the Erzgebirge ceased. The oldest, Triassic fluorite ages at Sadisdorf still carry a memory of the late Variscan mineralisation because Mesozoic thermal overprint performed partial reset only. The Triassic FHe ages are thus considered as mixed ages. Thermal modelling based on FHe ages and He diffusion parameters in fluorite yields thermal histories comparable to the results from the well-established apatite- and zircon-based thermal modelling. Empirical observation of two fluorite samples from the same deposit (Horni Krupka, Czech Republic) with ca. $170^{\circ} \mathrm{C}$ and ca. $43^{\circ} \mathrm{C} \mathrm{T}_{\mathrm{c}}$ yield highly different (UTh-Sm)/He ages of $290 \pm 10 \mathrm{Ma}$ and $79 \pm 10 \mathrm{Ma}$, respectively. Accordingly, the fluorite sample with the high $T_{c}$ could have quantitatively retained helium since the formation of the fluorite-bearing ores in the Permian, despite subsequent Mesozoic burial and associated regional hydrothermal heating. In 
contrast, the fluorite with the low $T_{c}$ yields a Late Cretaceous age close to the apatite fission track and apatite (U-Th)/He ages from the same locality. 



\section{Introduction}

The (U-Th)/He thermochronology of accessory minerals like apatite and zircon provides excellent constraints on low temperature thermal histories (Farley, 2000; Reiners et al., 2002). However, the use of this method is limited to rocks that contain these minerals. Especially in the vicinity of some rare metal ore deposits (e.g. greisen), apatite is often lacking due to the typically low $\mathrm{pH}$ of the ore bearing fluids. In contrast, fluorite is a common constituent in high- to low-temperature hydrothermal veins, as accessory phase in granitoids, pegmatites, carbonatites and alkaline intrusives, in stratabound deposits, and as authigenic phase in sandstones. In particular, hydrothermal veins occur in a wide range of geological settings which are frequently not well suited for apatite and zircon dating. The need to determine the age of ore deposits led to the development of isotopic techniques for fluorite geochronology using the Sm/Nd (Chesley et al., 1991; Chesley et al., 1994) and U-Th-Pb (Hofstra et al., 2000) approaches. Later, fluorite low-temperature thermochronology was introduced by Evans et al. (2005) and rarely applied (Pi et al., 2005; Siebel et al., 2009). The published diffusion parameters of helium in fluorite (Evans et al., 2005; Pi et al., 2005) are inconsistent and its systematics are still insufficiently understood. Evans et al. (2005) published diffusion data on $200-350 \mu \mathrm{m}$ diameter fragments that correspond to a $\mathrm{T}_{\mathrm{c}}$ of $60^{\circ} \mathrm{C} \pm 5^{\circ} \mathrm{C}$. In contrary, Reiners' diffusion experiments (published in Pi et al., 2005) reveal a $\mathrm{T}_{c}$ of $200{ }^{\circ} \mathrm{C}$. Therefore, precise and extensive analysis of these parameters is crucial to establishing this new thermochronometer as a method of choice in dating ore deposits. Furthermore, multi-method chronology using several minerals including fluorite with different thermal sensitivities to cover the entire thermal history in combination with thermal modelling is even more accurate for revealing complex thermal histories.

To validate the closure temperature of the emerging fluorite (U-Th-Sm)/He (FHe) method in my thesis I follow a twofold strategy (Fig. 2.1). (A) The diffusion behaviour of helium in fluorite has been studied analytically by step heating experiments yielding the activation energy $E_{a}$ and the diffusivity $D_{0} / a^{2}$ that can be used to calculate a $T_{c}$. To thoroughly characterise the diffusion of helium in fluorite mineralogic, crystallographic, and geochemical parameters need to be known too. In particular, the very good cleavage of fluorite can result in the breaking of crystals during diffusion experiments due to thermal stress. This would decrease the diffusion domain size and the integrity of the mineral during the experiment would not be given any more. This decrepitation and its dependency on temperature is addressed in separate experiments. Further, the zonation patterns of the fluorites are analysed by cathodoluminescence. An influence due to the substitution for calcium by the incorporation of rare earth elements and yttrium (REE+Y), sodium, and other cations is monitored by ICP-MS measurements. The anions that might be involved in a related charge compensation are monitored by SIMS. Raman spectroscopy is extensively applied as a proxy for a change in lattice ordering due to substitution. The results of the analytical diffusion measurements and their dependency on the REE $+Y$ content is published in the third article (Wolff et al., 2016; Variable helium diffusion characteristics in fluorite. Geochimica et Cosmochimica Acta, 188, 21-34.) together with a comparison to the empirical case study. 


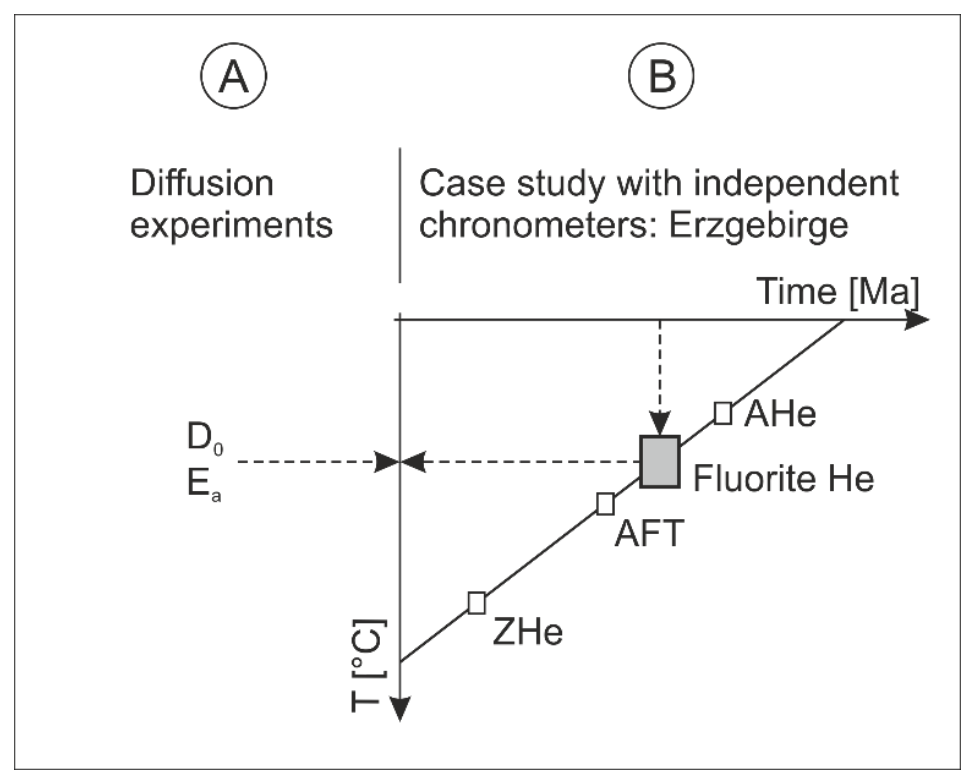

Fig. 2.1: Twofold strategy demonstrated by a simplified time-temperature plot showing the determination of the closure temperature for fluorite $(\mathrm{U}-\mathrm{Th}-\mathrm{Sm}) / \mathrm{He}$. On the right hand side the FHe thermochronology is combined with an empirical case study which is revealed by apatite and zircon (U-Th)/He and fission track. And on the left hand side FHe thermochronology is established analytically by helium diffusion experiments in fluorite yielding the diffusivity and the activation energy that can be converted to a $T_{c}$.

(B) These analytical results on the closure temperature of $\mathrm{FHe}$ are compared to an empirical case study. Therefore, $\mathrm{FHe}$ is applied in a regional case study in the Erzgebirge and the results are compared to and integrated in a multi-method thermochronological history together with well-established thermochronological methods. The Erzgebirge is well suited for the field study, because it is well known for its various fluorite occurrences, the ore deposits and the possibility to apply further low temperature thermochronometers. After the thermal history including burial, exhumation, and hydrothermal activity is established, the FHe ages can be included in the resulting time-temperature path and information about the FHe system can be gained, e.g. the closure temperature can be extracted. Subsequently, the post-Variscan thermal history of the Erzgebirge is characterised and discussed in the first article (Wolff et al., 2015b; Superposition of burial and hydrothermal events: postVariscan thermal evolution of the Erzgebirge, Germany, Terra Nova, 27(4), 292-299) using thermal modelling of zircon and apatite (U-Th)/He, apatite fission track and vitrinite reflectance. In the second article (Wolff et al., 2015a; The age of the latest thermal overprint of tin and polymetallic deposits in the Erzgebirge, Germany: constraints from fluorite (U-Th-Sm)/He thermochronology, Economic Geology, 110, 2025-2040) about 233 single fluorite (U-Th-Sm)/He ages from almost the entire Erzgebirge are presented and included in the thermal history of this area. The results of the thermal modelling based on FHe data are compared to the time-temperature paths published in Wolff et al. (2015b).

Afterwards, further studies linked to the thesis are presented. They cover helium diffusion experiments in synthetic pure and doped $\mathrm{CaF}_{2}$ crystals for comparison to natural fluorite. This was done using soaking experiments in Piston cylinders to incorporate helium in synthetic fluorite beforehand. Moreover, a fluorite classification based on rare earth elements systematics is refined by statistical treatment of the huge amount of data on fluorites analysed herein. 


\section{Methodology}

\section{Refining an emerging method}

Establishing a measurement routing for a new mineral for low temperature thermochronology needs several adjustments due to its chemical and physical properties. The measuring protocol at the noble gas mass spectrometer, the acid digestion protocol and the isotope dilution-solution measurement at the inductively coupled mass spectrometer (ICP-MS) had to be modified and adjusted by myself for fluorite. In a first step sufficient temperatures for a total degassing of fluorite have been estimated. Already at the first glowing of the platinum capsule a convenient low re-extract of helium is reached, and, in personal communication, Evans suggested not to overshoot the fluorite because uranium and thorium might be mobilized. I also tested different metals for wrapping the crystals to be able to degas a bigger amount of fluorite than possible in the platinum capsules used for apatite and zircon. Niobium is not flexible enough, after bending it relaxes abruptly leading to a loss of the encapsulated crystal. Copper foil is the best choice because it does not weld and melt. But it does not glow at low laser intensities and therefore the glow intensity cannot be used for estimating the temperature. Due to the insufficient coupling to the laser, the laser energy is too low to heat up bigger amounts of copper foil. Concluding, I use the Platinum capsules which are also suited for apatite and zircon and the maximum sample size is limited to $c a .250 \mu \mathrm{m}$. Nevertheless, at the diffusion experiments copper foil is used for fixing the crystals in the platinum capsules to the thermo-element.

The acid digestion of fluorite can be done using $\mathrm{HNO}_{3}$ and $\mathrm{HClO}_{4}(3: 1)$ with open digestion (Evans et al., 2005) or $\mathrm{H}_{2} \mathrm{SO}_{4}$ and $\mathrm{HNO}_{3}$ (Richardson and Blenkinsop, 1989). The first approach has been applied in 4 digestion sessions. But $\mathrm{HClO}_{4}$ has to be handled very carefully and the digestion was not successful, some steps had to be repeated in closed vessels until total digestion. The second approach has been tested, also, but $\mathrm{H}_{2} \mathrm{SO}_{4}$ turned out to be very impure in respect of $\mathrm{U}$ and $\mathrm{Th}$, which results in high blank values. Additional, I tested "superpure" $\mathrm{HCl}(9 \mathrm{~N})$ for digestion. The use of $\mathrm{HCl}$ was straight forward, no precipitation was found using the microscope and uranium and thorium stayed stable in the liquid phase (proven by blank tests). The $\mathrm{HCl}$ blank has been analysed three times at every ICP-MS session. Because the fluorite samples yield a low amount of uranium and thorium and the sensitivity of the Perkin Elmer ICP-MS for $U$ and Th is about pg level I had to reduce the blank level drastically (Fig. 3.1, EA3.1). The highly electrostatic Savillex Teflon ${ }^{\circledR}$ vials are cleaned carefully following 12 steps with additional ultra-sonic cleaning. The acid digestion and drying takes place in a temperature controlled filtered-air Teflon inlay build in the workshop of the University of Göttingen. The memory effect of Teflon with $\mathrm{HCl}$ and $\mathrm{HNO}_{3}$ is below the detection limit (EA3.1). 


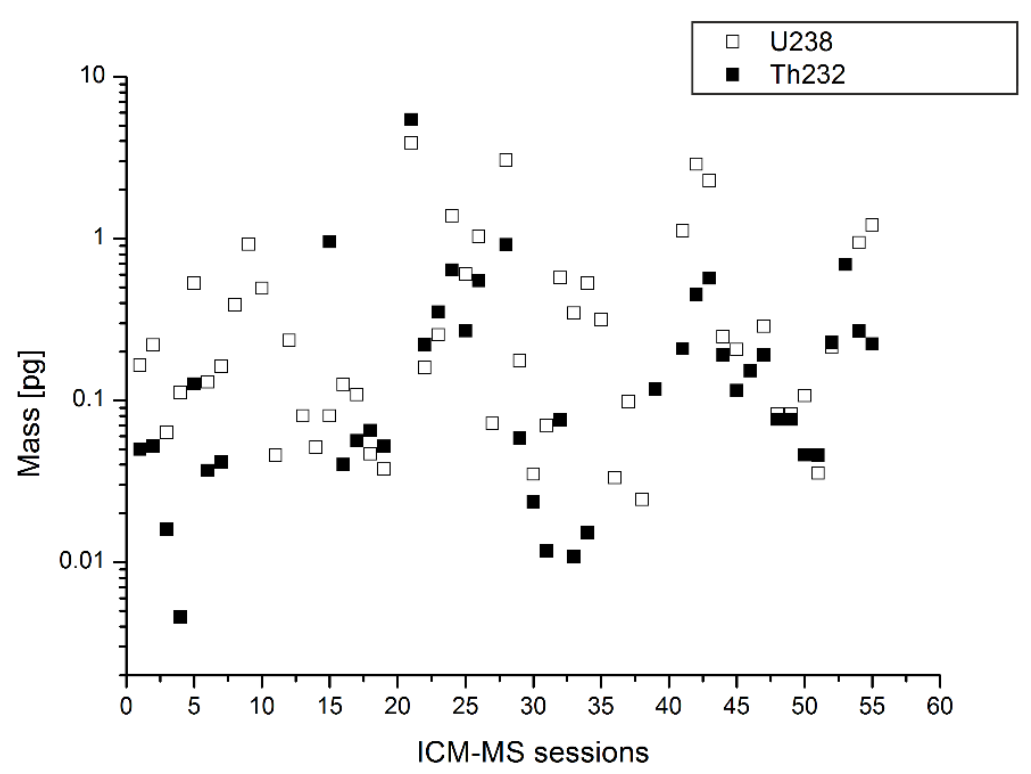

Fig. 3.1: ${ }^{238} \mathrm{U}$ and ${ }^{232}$ Th blank measurements of 60 ICP-MS sessions.

I tested the stability of the solutions of dissolved fluorites $(3 \% \mathrm{HCl})$ by measuring them again after 10 month storage in a refrigerator at ca. $8^{\circ} \mathrm{C}$. The discrepancy between the first and repeated measurements can be neglected (EA3.2). At the ICP-MS the solution is diluted to $4 \% \mathrm{HCl}$ "superpure" and analysed with APEX and later using only the peristaltic pump to obtain an optimized signal stability. $4 \% \mathrm{HNO}_{3}$ and $0.05 \% \mathrm{HF}$ as ICP-MS carrier acid is also suitable. A fluorite specific external multi element standard solution has been created and used in order to match the matrix of the digested fluorite samples, especially the high amount of $\mathrm{Ca}$.

\section{Fluorite $(\mathrm{U}-\mathrm{Th}$-Sm)/He thermochronology}

The fluorite $(\mathrm{U}-\mathrm{Th}-\mathrm{Sm}) / \mathrm{He}$ method is based on the He accumulation from the radioactive decay of ${ }^{147} \mathrm{Sm}$ as well as that which accumulates from the ${ }^{238} \mathrm{U},{ }^{235} \mathrm{U}$ and ${ }^{232} \mathrm{Th}$ decay chains. The alpha-ejection correction (Farley et al., 1996) was not applied, because fragments from the outer surface of the crystals had been excluded from the analyses. We dated only single-fragment aliquots; the crystal fragments were wrapped in ca. 1×1 mm-sized platinum capsules and degassed in high vacuum by heating with an infrared diode laser. The extracted gas was purified using a SAES Ti-Zr getter at $450^{\circ} \mathrm{C}$. The chemically inert noble gases and a minor amount of other rest gases were then expanded into a Hiden triple-filter quadrupole mass spectrometer equipped with a positive ion counting detector. Crystals were checked for degassing of helium by sequential reheating and helium measurement. Following degassing, samples were retrieved from the gas extraction line, unpacked and spiked with calibrated ${ }^{230} \mathrm{Th}$ and ${ }^{233} \mathrm{U}$ solutions. The fluorites were then dissolved in Savillex Teflon ${ }^{\circledR}$ vials using ultrapure $30 \% \mathrm{HCl}$ at $75{ }^{\circ} \mathrm{C}$ for 24 hours (until total drying). The solution process was monitored by a stereo microscope and the last step was repeated until the total digestion. The digested samples were dissolved in $4 \% \mathrm{HCl}$ (recently at $4 \% \mathrm{NHO}_{3}$ and $0.005 \% \mathrm{HF}$ ) and the solutions were analysed using a Perkin Elmer Elan DRC II ICP-MS equipped with an APEX micro-flow nebulizer. The actinide concentrations were determined by isotope dilution method and the Sm by external calibration. The level of detections (LoD) was between 1 and 2 pg, slightly variable in the different ICP-MS sessions. 


\section{Refining the step heating diffusion measurements}

The step heating set up with three PID controlled cells for diffusion measurements is build following Farley et al. (1999) and optimized during this work. Two cells with less volume have been installed instead of the former ones in order to increase the signal by decreasing the volume. I estimated the relative volume of the cells using the proportions of helium determined during expansion into several volumes of the diffusion part (EA3.3). Beforehand, the linearity of the mass spectrometer was proven by repeated expansion experiments into the same volume. The volume is between 0.219 and $0.181 \%$ of the main volume. This knowledge was even more important during the first measurement period while the helium analysis was based on alternating ${ }^{4} \mathrm{He}$ standard measured in the MIX and diffusion cell volume. During the second period the measurements are based on ${ }^{3} \mathrm{He}$ standard measured synchrony in the same volume. The installation of a valve between the cell and the getter in the diffusion cell fastens the cleaning schedule after each sample change by $c a$. one day. A stack has been created by the workshop which is able to carry several fans, the light bulb itself, and an aluminium cone to focus the light and heat. After testing several halogen bulbs I chose the Osram HLX Xenophot ${ }^{\circledR}$ because a convenient temperature is reached, the life span is acceptable and the heat can be focused by the aluminium cone. Further, the gold coating does reflects the heat only in the direction of the sample. The adjustment of the focus together with convenient amount of cooling fans is necessary to keep the temperature of the diffusion cell itself low because it is sensitively coupled with the helium blank of the measurements. Therefore, cold and hot blank measurements for every single cell have been performed and every diffusion cycle starts with a $1 \mathrm{~h}$ cold blank. The hot blank of the used diff cell varies between 0.005 and $0.009 \mathrm{ncc} /$ hour helium in the range of 280 to $520^{\circ} \mathrm{C}$ (Fig. 3.2, EA3.4).

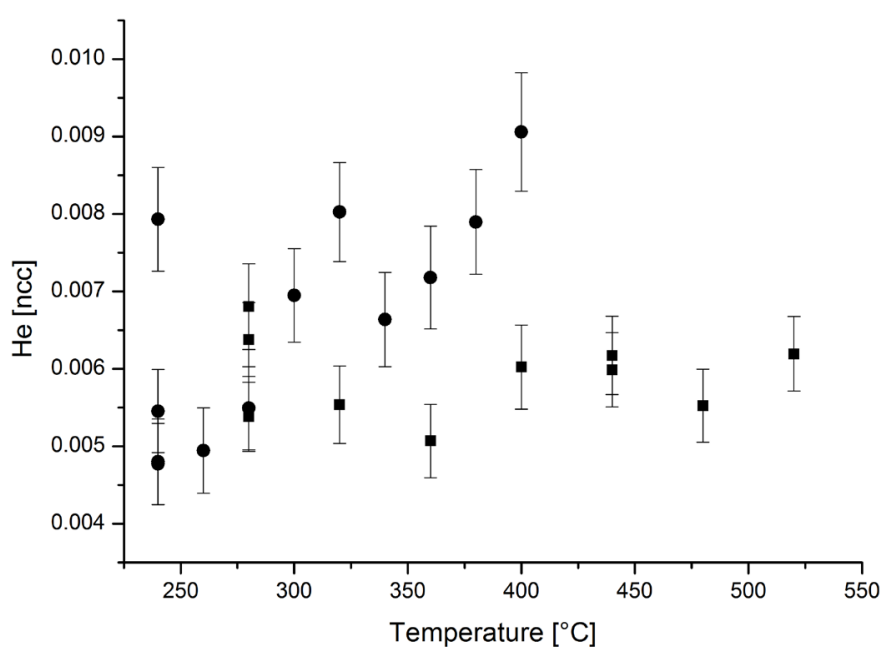

Fig. 3.2: Hot blank measurements of helium in the diffusion cells (circle first, squares second run).

The temperature is controlled using PIDs by Newport-Omega. I have optimized the setting to reach the temperature as fast as possible without overshooting and holding the temperature within $0.1{ }^{\circ} \mathrm{C}$. The temperature set point can be chosen by PC via a local area network.

I have done the calculation of the diffusion parameters $E_{a}$ and $D_{o} / a^{2}$ by Matlab/Octave and Excel using the equation 5a-c of Fechtig and Kalbitzer (1966) and the closure temperature $T_{c}$ in the sense of Dodson (1973) with the assumptions of a sphere geometry and $10^{\circ} \mathrm{C} / \mathrm{Ma}$ cooling rate as following: 
Calculation of the diffusion constant $D$ of every single diffusion step $i$ following Fechtig and Kalbitzer (1966):

$$
D_{i+1}=\frac{R^{2}}{\pi^{2}\left(t_{i+1}-t_{i}\right)} *\left\{-\frac{\pi^{2}}{3}\left(F_{i+1}-F_{i}\right)-2 \pi\left(\sqrt{1-\frac{\pi}{3} F_{i+1}}-\sqrt{1-\frac{\pi}{3} F_{i}}\right)\right\}
$$

This equation is based on Fick's fist law. Here, the solution for conduction of heat in solids is now adapted by Carslaw and Jaeger (1959) for fractional losses of gas given as a function of time (Eq. 3.1). With $i$ as number of diffusion step in which a cumulative fractional loss $F_{i}$ happened within the time $t_{i}$, and a diffusion constant $D_{i} . R$ is the ideal gas constant. This equation is slightly varied for losses below $10 \%$ and above $90 \%$. The general assumptions are (i) diffusion is temperature dependent (ii) no increase of helium due to radioactivity with time (iii) a sphere (iv) a homogeneous helium distribution in the crystal (v) no back diffusion into the crystal.

If this diffusion process is exponentially activated by temperature the overall temperature dependence can be described by a linear Arrhenius relationship:

$$
D=D_{0} \exp \left(-\frac{E_{a}}{R T}\right)
$$

Hereby, $T$ is the temperature, $E_{a}$ the activation energy in the sense of Arrhenius, and $D_{0}$ the diffusivity at infinite high temperatures (frequency factor) (Eq. 3.2). Transforming the equation to the form $y=$ $m * x+b$ and including the diffusion domain radius $a$ we get:

$$
\ln \left(\frac{D}{a^{2}}\right)=-\frac{E}{R} * \frac{1}{T}+\ln \left(\frac{D_{0}}{a^{2}}\right)
$$

The slope and the $y$-axis intercept of the linear Arrhenius relationship yield the activation energy and the diffusivity divided by the diffusion domain radius, respectively (Eq. 3.3). These coefficients are constant over the analysed temperature interval. Further, they can be used for thermal modelling by extrapolating to lower temperatures and geological timescales. For better comprehension, the closure temperature $T_{c}$ in the sense of Dodson (1973) can be calculated iteratively using Dodson (1973):

$$
T_{c}=\frac{E}{R * \ln \left(\frac{A * R * T_{c}^{2} * \frac{D_{0}}{a^{2}}}{E * \frac{d T}{d t}}\right)}
$$

With a numerical constant $A$ depending on the geometry and the ratio of $\frac{\lambda}{\tau}, \tau$ is a time constant (Eq. 3.4). E.g. for a sphere $A$ is 55 . Further, $\frac{d T}{d t}$ is the cooling rate.

The results of the calculation have been carefully compared to published results, calculations by Stöckli (pers. com) and by a cross calibration to the Matlab/Octave code by Goldsmith and Stöckli (version 2, pers. com.). The comparison is yielding a $R^{2}$ of 0.9994 (Fig. 3.3, EA3.5). For regression and uncertainties of the diffusion parameters and the $T_{c}$ Monte Carlo inversion has been applied with 5000 repetitions assuming a Gaussian distribution using the Matlab code mentioned above. 


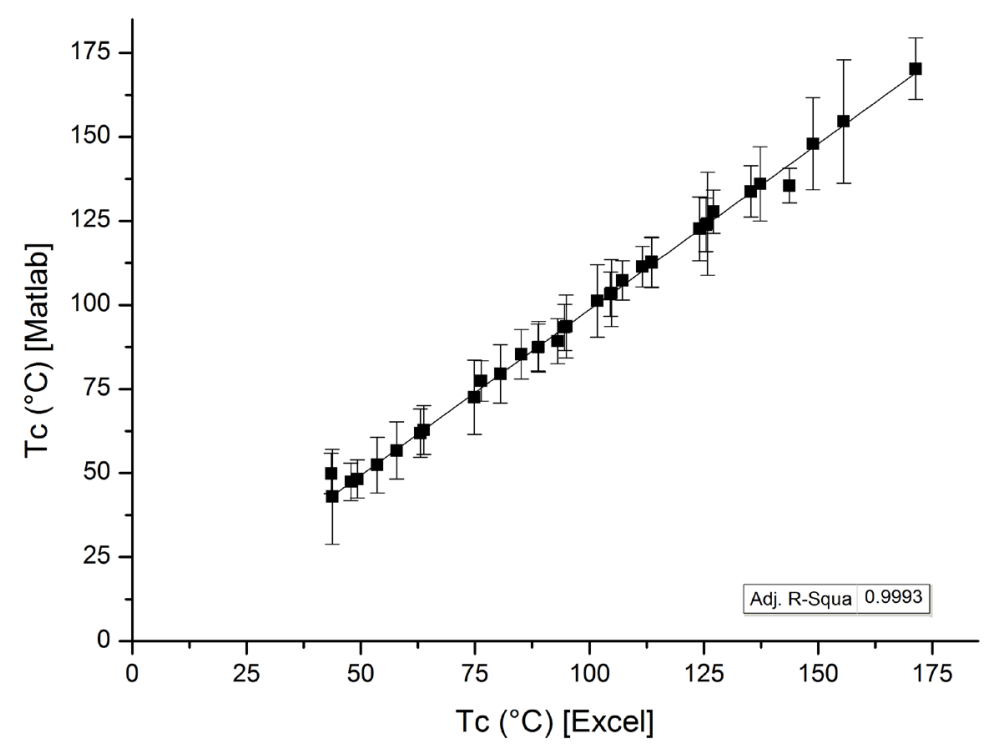

Fig. 3.3: Cross calibration of $T_{c}$ calculated by Matlab including a regression with Monte Carlo inversion for uncertainty (Goldsmith, pers com.) and Excel based on own calculations (Fechtig and Kalbitzer, 1966).

\section{Helium diffusion experiments}

The outer surface of the euhedral crystal or crystal fragments were stained, and the samples were carefully crushed. Only intact, inclusion free shards derived from the interior of the crystals were selected. Both size and shape parameters of the crystal fragments were determined by multiple microphotographs. The average fragment size used for diffusion experiments was between 100 and $400 \mu \mathrm{m}$ and the radius value used for calculation of diffusion parameters refers to the maximum insphere dimension that can be constructed based on such photographs.

I have performed step heating experiments in two laboratories using slightly different instruments and degassing schedules (University of Göttingen and Jackson school of geoscience, University of Texas in Austin). In both laboratories the helium diffusion experiments are based on the apparatus for stepwise degassing (Farley 1999). The single- and multi-fragment aliquots were wrapped in ca. $1 \times 1 \mathrm{~mm}$-sized platinum capsules and stepwise degassed in high vacuum. The procedures applied in the two laboratories are slightly different. (i) In the Göttingen laboratory the heating was performed by PIDcontrolled low voltage halogen lamps. The steps were assigned for the samples individually according to the former dating experiments in order to provide convenient amounts of He through the entire degassing procedure. I developed the idea to hold the samples at the respective temperature reached between the single steps to avoid thermal stress of the crystals and reduce the thermal hysteresis. Mainly, the temperature was risen from 280 to $520^{\circ} \mathrm{C}$ in $20^{\circ} \mathrm{C}$ steps. Temperature cycling experiments have been used to investigate whether complex heating schedules yield comparable results to monotonic increasing temperature steps. In these cases after the first sequence a decrease and increase in $40{ }^{\circ} \mathrm{C}$ steps for two hours was chosen (for detailed heating schedule see EA6.4). The extracted gas was purified and analysed according to the bulk degassing experiments described below. Following the step wise degassing, the Pt capsules were totally degassed by reheating with the infrared diode laser. The dissolution, spiking and actinide measurements were identical to the procedure applied for the (U-Th-Sm)/He dated crystals. (ii) In the Austin laboratory the heating was performed with a halogen lamp and total cooling was applied between the heating steps while the extracted gas was purified in a cryo trap. At least two heating cycles between $150^{\circ} \mathrm{C}$ and $550^{\circ} \mathrm{C}$ in $10^{\circ} \mathrm{C}$ steps were 
performed. The purified gas was analysed by a Pfeiffer mass spectrometer. The actinide and Sm content of the dissolved $\left(\mathrm{HCl}\right.$ and $\left.\mathrm{HNO}_{3}\right)$ and spiked solution was measured with an Element 2 mass spectrometer. 


\section{Superposition of burial and hydrothermal events: post-Variscan thermal evolution of the Erzgebirge, Germany}

The following first case study revealing the geochronology of the Erzgebirge frames the FHe study combining the FHe data to the thermal history of the Erzgebirge. This paper is published 2015 in TerraNova, 27(4), 292-299, Doi: 10.1111/ter.12159

License Number for reuse permission: 3658700150397

Wolff, R. ${ }^{1}$, Dunkl, I. ${ }^{1}$, Lange, J.-M. ${ }^{2}$, Tonk, C. ${ }^{2}$, Voigt, T. ${ }^{3}$, von Eynatten, H. ${ }^{1}$

Corresponding author: Reinhard Wolff, University of Goettingen, Geoscience Center, Goldschmidtstr. 3, 37077 Goettingen, Germany, rwolff@gwdg.de

${ }^{1}$ University of Goettingen, Geoscience Center, Goldschmidtstr. 3, 37077 Goettingen, Germany

${ }^{2}$ Senckenberg Natural History Collections of Dresden, Museum for Mineralogy and Geology, Section Petrography, Koenigsbruecker Landstr. 159, 01109 Dresden, Germany

${ }^{3}$ Friedrich Schiller University of Jena, Institute of Geosciences, Burgweg 11, 07749 Jena, Germany

Short title: Burial and hydrothermal effects in the Erzgebirge

Keywords: Erzgebirge, thermochronology, ore-deposits, hydrothermal activity, Variscides 
4. Superposition of burial and hydrothermal events: post-Variscan thermal evolution of the Erzgebirge, Germany

\section{Abstract}

The post-Variscan thermal history of the Erzgebirge (Germany) is the result of periods of sedimentary burial, exhumation and superimposed hydrothermal activity. Timing and degree of thermal overprint have been analysed by zircon and apatite (U-Th)/He and apatite fission track thermochronology. The present-day surface of the Erzgebirge was exhumed to a near-surface position after the Variscan orogeny. Thermal modelling reveals Permo-Mesozoic burial up to temperatures of 80 to $100{ }^{\circ} \mathrm{C}$ while the sedimentary cover thins out towards north resulting in maximum burial temperatures less than $40{ }^{\circ} \mathrm{C}$. This thermal pattern was modified locally by Cretaceous hydrothermal activity that reset the zircon (U-Th)/He thermochronometer along ore veins. The thermal models show no significant regional exhumation during Cenozoic times indicating that the peneplain-like morphology of the basement is a Late Cretaceous feature.

\section{Introduction}

The Erzgebirge (Saxonian Ore Mountains) forms part of the Saxo-Thuringian unit of the Variscan mountain belt, located at the northern margin of the Bohemian Massif (Fig. 4.1a). It exposes mainly metamorphic rocks intruded by Carboniferous and Permian felsic igneous rocks (e.g. Kossmat, 1925; Romer et al., 2010a). Numerous studies deal with the Variscan evolution of the Erzgebirge (e.g. Kempe et al., 1999; Förster et al., 2007; Seifert, 2008; Linnemann and Romer, 2010; Romer et al., 2010a), however, its thermal history during Mesozoic and Cenozoic times is still insufficiently understood, as the post-Variscan sedimentary record is incomplete or missing. Locally the thermal history was influenced by ore-generating hydrothermal fluids. Thus, the thickness of the eroded cover suggested by available apatite fission track (AFT) data are a matter of debate (Schröder and Peterek, 2001; Ventura and Lisker, 2003; Lange et al., 2008). In this study we present results of zircon and apatite (U$\mathrm{Th}) / \mathrm{He}$ (ZHe and AHe, respectively) and AFT thermochronology obtained on basement rocks and Permian strata of the Erzgebirge. The applied methods yield detailed information on the thermal history of the Variscan basement below $200{ }^{\circ} \mathrm{C}$ (e. g. Flowers et al., 2009; Gautheron et al., 2009; Guenthner et al., 2013) at regional scale (Erzgebirge). This case study serves as an example for basement blocks in which the regional thermal structure is perturbed by local hydrothermal anomalies.

\section{Geological setting}

The structure of the Erzgebirge is dominated by an antiform exposing high- to medium-grade metamorphic rocks in the core surrounded by low-grade metamorphic units mainly composed of micaschists and phyllites. This Variscan metamorphic assemblage was intruded by late- and postVariscan granitoids and partly covered by rhyolites (Romer et al., 2007; see Fig. 4.1b). The postVariscan sedimentary cover of the region starts with Late Carboniferous to Early Permian continental deposits (Fig. 4.2a), later in Triassic times the area formed the margin of the Central European Basin (Ziegler, 1990) and experienced subsidence (Voigt, 1995). West, north and east of the Erzgebirge thin Permian to Triassic sequences are preserved (Fig. 4.1a), but the thickness of the former cover on the currently exposed Erzgebirge is still a topic of debate (Schröder, 1976; Brause, 1988; Götze, 1998; Voigt, 2009). Schröder (1987) estimated a cover thickness of $1.5 \mathrm{~km}$, while Dudek et al. (1991) postulated a post-Variscan denudation of at least $2.5 \mathrm{~km}$. 


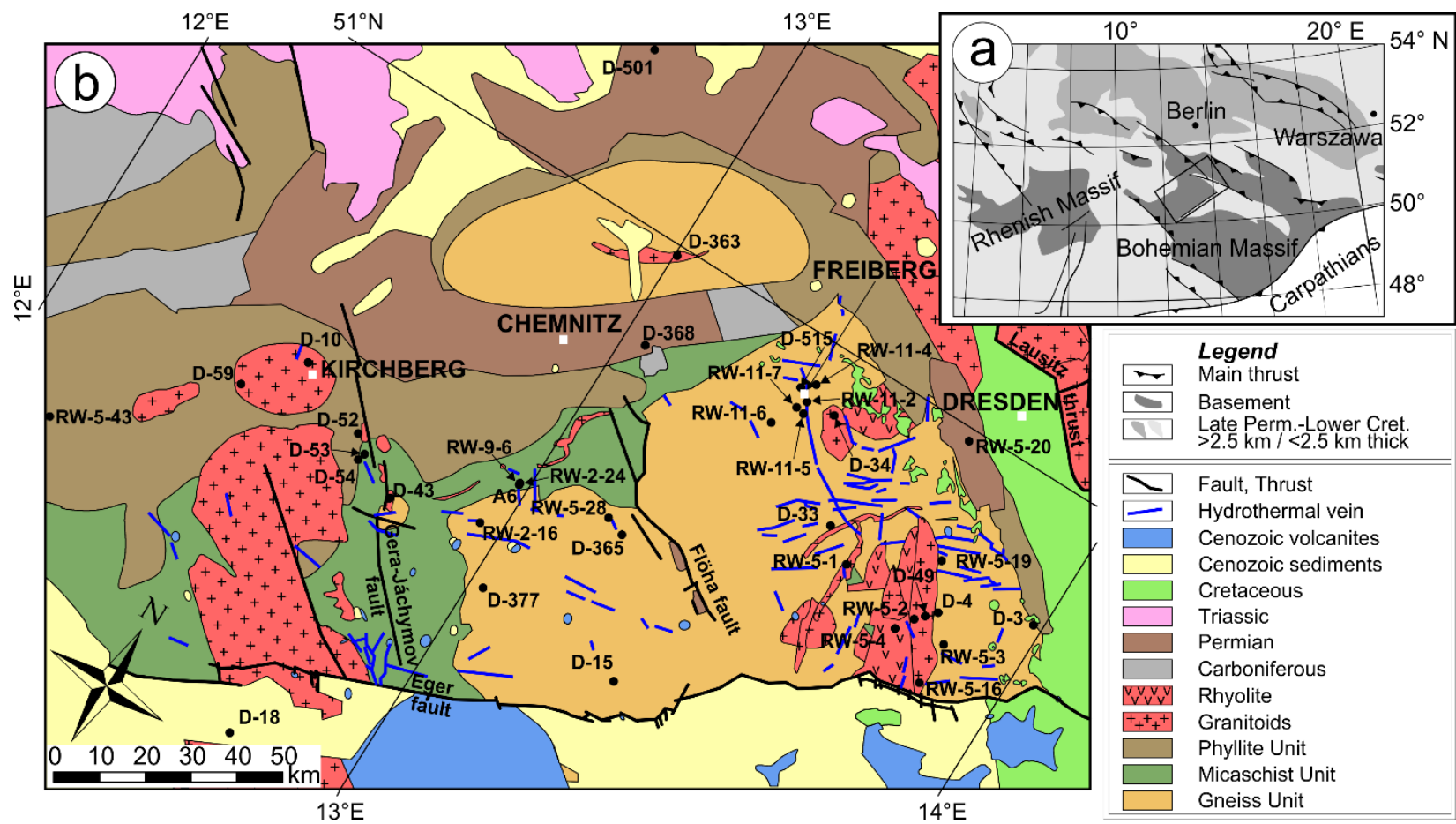

Fig. 4.1: (a) Position of the Erzgebirge within the European Variscides and surrounding Permo-Mesozoic basins. Rectangle represents the position of the study area magnified in Figure b (modified after Kley, 2013). (b) Geological map of the Erzgebirge (simplified after Wolf et al., 1992) with sample localities.

The Erzgebirge is dissected by the Gera-Jáchymov and Flöha faults (Fig. 4.1b). These northwestsoutheast striking major fault zones were active in Mesozoic time (Kley, 2013). Further northeast across the Lausitz Thrust, sedimentological data and cooling ages of the Lausitz Massif reveal significant exhumation during Late Cretaceous basin inversion (Voigt, 2009; Danišík et al., 2010).

In the north-eastern part of the Erzgebirge Cenomanian to Coniacian sediments transgressively overlie the Variscan basement (e.g. Pietzsch, 1913; Kossmat, 1925; Wolf et al., 1992; Voigt, 1995). A palaeoriver delivered these sediments into the northern part of the Bohemian Cretaceous Basin during the Middle Cenomanian (Voigt, 1998; Schröder and Peterek, 2001; Voigt, 2009). Gravel composition reveals that during this time the Triassic sedimentary cover had already been removed. During Turonian and Coniacian time the area of the later eastern Erzgebirge was buried, as is indicated by the occurrences of marl and limestone layers preserved at the Eger Graben (Voigt, 2009).

Today, the Erzgebirge has a relatively flat relief, slightly tilted towards northwest. Palaeo-soil occurrences and kaolinite deposits indicate deep tropical weathering associated with the development of a peneplain in the Erzgebirge. According to Migoń and Lidmar-Bergström (2001) this preserved peneplain formed after approximately 80-70 Ma (i.e. Campanian time). Final exhumation of the Erzgebirge in late Cenozoic times was associated to the European Cenozoic Rift System (Ziegler and Dèzes, 2007) and led to the removal of almost the complete Upper Cretaceous sedimentary cover (Fig. 4.2a). In the southern Erzgebirge the basement is partly covered by Eocene to Oligocene fluvial deposits (Knobloch and Konzalová, 1998; Mai and Walther, 2000) and locally by Oligocene and Early Miocene mafic lava sheets (Suhr, 2003). The lava flows filled palaeo-valleys, but form elongated hills today. The relief inversion allows estimating the post-Oligocene erosion to be less than $200 \mathrm{~m}$. 
4. Superposition of burial and hydrothermal events: post-Variscan thermal evolution of the Erzgebirge, Germany

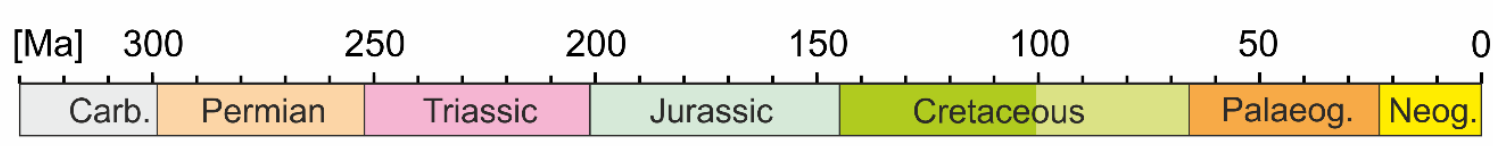

\section{a) Synopsis of major events}

\begin{tabular}{|l|l|}
\hline Magmatism & \\
\hline Sedimentation Permian - Jurassic & Cenom. (NE) \\
\hline Erosion / Exhumation \\
\hline Erosion of basement \\
\hline
\end{tabular}

b) Geochronology of ore deposits
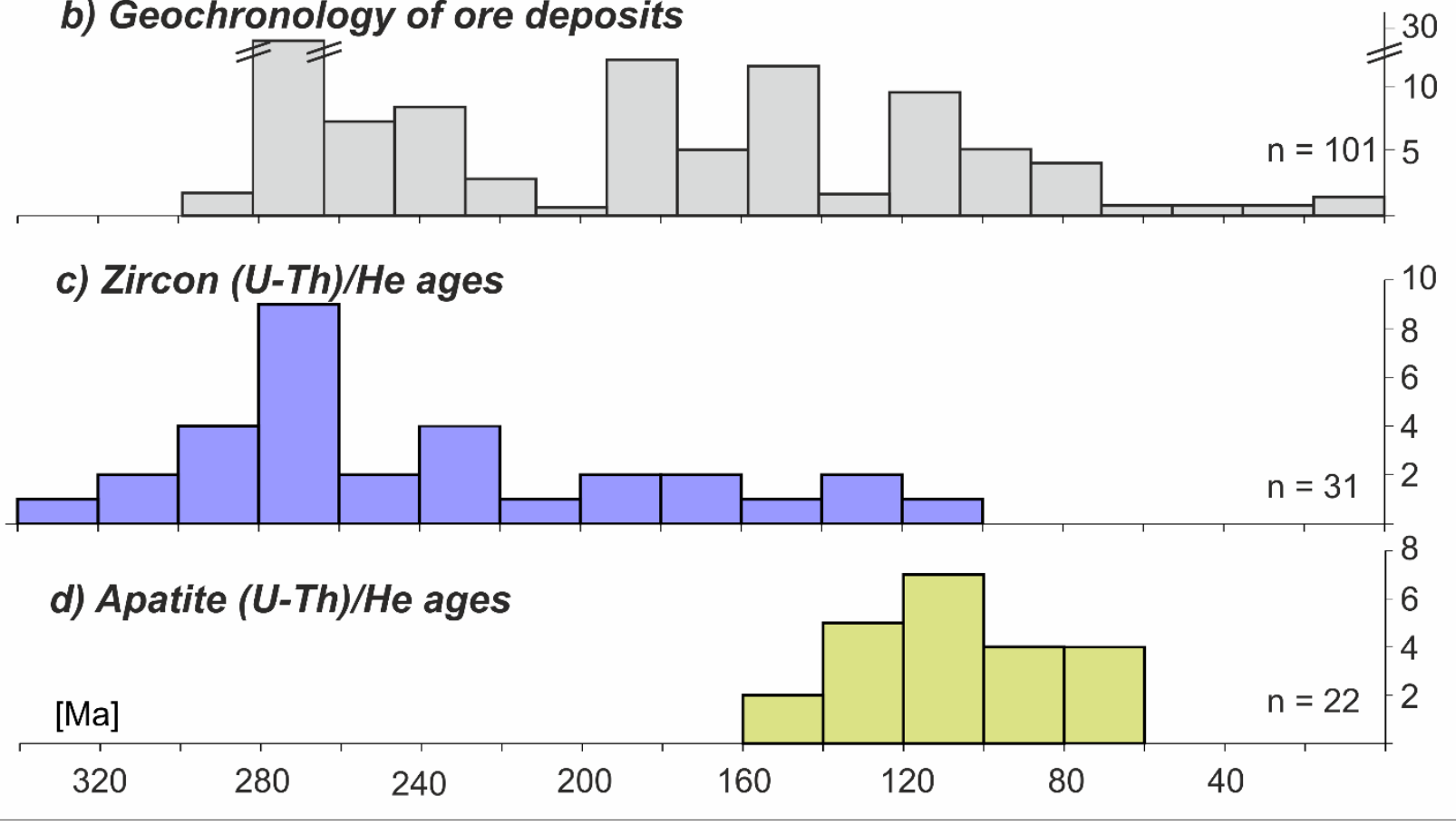

Fig. 4.2: (a) Synopsis of major events of the post-Variscan evolution of the Erzgebirge (for discussion and references, see chapter on Geological setting). (b) Compilation of geochronological data related to hydrothermal activity of the Erzgebirge (from Romer et al., 2010b). (c) and (d) New low-temperature thermochronological data presented herein. For geologic time scale, see e.g. Gradstein and Ogg (2004).

\subsection{Hydrothermal activity}

The Erzgebirge is famous for numerous ore deposits. Two major periods of hydrothermal activity were recognized. First, the late Variscan emplacement of granitoids and rhyolites were accompanied by increased hydrothermal activity generating mainly Sn-W and Mo-rich greisen and skarn deposits at around 280 Ma (e.g. Stemprok and Sulcek, 1969; Baumann et al., 2000). Second, long-lasting Mesozoic hydrothermal activity ( $c a .180-65 \mathrm{Ma}$ ) has generated ore veins at many sites in the basement (Fig. 4.1b and Fig. 4.2b; e.g. Romer et al., 2010b). The Mesozoic mineralisation consist of predominantly baritefluorite-sulphide and hematite-barite veins penetrating the metamorphic basement (e.g. Trinkler et al., 2005; Seifert, 2008; Romer et al., 2010b). 


\subsection{Thermochronology}

Ventura and Lisker (2003) presented apatite fission track data and modelled the thermal history from a borehole penetrating the basement in the south-western part of the Erzgebirge. Short track lengths (10.5 to $11.5 \mu \mathrm{m}$ ) combined with relatively old apparent AFT ages (151 to $89 \mathrm{Ma}$ ) imply a long residence in the apatite partial annealing zone (between ca. 120 and $60^{\circ} \mathrm{C}$, e.g. Gleadow et al., 1986) before final cooling. They suggested two episodes in which a thick cover layer was removed: (i) from Late Jurassic to Late Cretaceous (1.5 to $5.9 \mathrm{~km}$ ) and (ii) in late Cenozoic (2.1 to $5.6 \mathrm{~km}$ ). The two episodes were related to the Pangea breakup and the tectonic activity of the Eger Graben starting in the Oligocene, respectively (Ventura and Lisker 2003). However, the thickness of the eroded cover was questioned in later studies. Lange et al. (2008) presented AFT data covering the entire Erzgebirge and suggest a more complex exhumation pattern with less than $1 \mathrm{~km}$ of late Cenozoic erosion. Their AFT apparent ages range from 130 to $60 \mathrm{Ma}$, but in the central block of the Erzgebirge old ages up to $210 \mathrm{Ma}$ are preserved indicating limited post-Variscan burial and erosion.

\section{Samples, results and thermal modelling}

Apatite and zircon (U-Th)/He thermochronology (AHe and ZHe, respectively) was performed on the samples collected by Lange et al. (2008), on sample A6 of Kempe and Götze (2002), and on 17 new samples from the basement and the Permian (Fig. 4.1b). Details on the laboratory techniques are described in Wolff et al. (2012). The apatite $(\mathrm{N}=60)$ and zircon (N=99) (U-Th)/He single grain data are summarised as unweighted average ages in Tab. 4.1 and displayed on a simplified geological map together with the contour map of the apatite fission track ages from Lange et al. (2008) and the uppermost borehole sample of Ventura and Lisker (2003) (Fig. 4.3). The previously published AFT data from the Erzgebirge were completed by three new ages and track length measurements determined on apatite crystals of uniform uranium content (Fig. 4.3 and Tab. 4.2, see details in the Electronic Appendices). 
4. Superposition of burial and hydrothermal events: post-Variscan thermal evolution of the Erzgebirge, Germany

\begin{tabular}{|c|c|c|c|c|c|c|c|c|}
\hline $\begin{array}{c}\text { Sample } \\
\text { No. }\end{array}$ & $\begin{array}{l}\text { Latitude } \\
\text { North }\end{array}$ & $\begin{array}{c}\text { Longitude } \\
\text { East }\end{array}$ & $\begin{array}{l}\text { Elevation } \\
\text { [m a.s.l.] }\end{array}$ & Lithology & $\begin{array}{c}\text { ZHe [Ma] } \\
\text { unweighted } \\
\text { aver. }\end{array}$ & s.e. & $\begin{array}{c}\text { AHe [Ma] } \\
\text { unweighted } \\
\text { aver. }\end{array}$ & s.e. \\
\hline$\overline{A 6}$ & 50.64394 & 12.98133 & 365 & granite & & & 140.1 & 5.6 \\
\hline D-3 & 50.83378 & 13.98092 & 400 & granite & 276.5 & 6.5 & & \\
\hline D-4 & 50.78441 & 13.80945 & 500 & granitoid & 307.0 & 16.6 & & \\
\hline D-10 & 50.63186 & 12.50243 & 380 & granite & 232.2 & 24.8 & 124.8 & 18.6 \\
\hline D-15 & 50.49707 & 13.34174 & 500 & gneiss & 276.1 & 8.9 & & \\
\hline D-18 & 50.18681 & 12.75712 & 600 & granite & 168.3 & 11.4 & 122.3 & 6.2 \\
\hline D-33 & 50.80493 & 13.54003 & 600 & rhyolite & 302.1 & 5.9 & 88.1 & 4.0 \\
\hline D-34 & 50.92311 & 13.43227 & 370 & granite & 124.2 & 6.0 & 91.2 & 4.8 \\
\hline D-43 & 50.54140 & 12.77551 & 500 & granite & 143.1 & 21.3 & & \\
\hline D-49 & 50.77181 & 13.79174 & 550 & rhyolite & 226.4 & 17.4 & 73.5 & 3.1 \\
\hline D-52 & 50.59003 & 12.65937 & 570 & granite & 134.2 & 25.2 & & \\
\hline D-53 & 50.57223 & 12.69173 & 410 & granite & 188.0 & 14.7 & 114.3 & 1.0 \\
\hline D-54 & 50.56218 & 12.68657 & 470 & granite & 186.2 & 19.1 & & \\
\hline D-59 & 50.56464 & 12.41329 & 430 & granite & 111.9 & 3.5 & 103.9 & 4.7 \\
\hline D-363 & 50.98751 & 13.00509 & 250 & granite & 208.7 & 20.7 & & \\
\hline D-365 & 50.65754 & 13.20331 & 540 & gneiss & & & 157.5 & 6.8 \\
\hline D-368 & 50.87239 & 13.04493 & 300 & gneiss & & & 103.8 & 32.7 \\
\hline D-377 & 50.51185 & 13.03078 & 720 & gneiss & & & 100.3 & 12.7 \\
\hline D-501 & 51.20099 & 12.74058 & 150 & rhyolite & 270.5 & 11.3 & & \\
\hline D-515 & 50.93058 & 13.34703 & 380 & gneiss & 288.7 & 16.4 & 89.8 & 11.8 \\
\hline RW-2-16 & 50.57613 & 12.95476 & 569 & gneiss & 275.1 & 9.2 & 92.3 & 11.0 \\
\hline RW-2-24 & 50.64394 & 12.98133 & 623 & granite & & & 134.9 & 6.5 \\
\hline RW-5-1 & 50.77468 & 13.60706 & 690 & rhyolite & 285.8 & 8.0 & 79.2 & 8.2 \\
\hline RW-5-2 & 50.76155 & 13.77623 & 688 & granite & 268.7 & 8.2 & 64.4 & 5.6 \\
\hline RW-5-3 & 50.75443 & 13.85205 & 586 & granite & 251.4 & 2.1 & & \\
\hline RW-5-4 & 50.73906 & 13.75453 & 817 & rhyolite & 276.1 & 20.5 & 79.6 & 7.8 \\
\hline RW-5-16 & 50.69792 & 13.85120 & 590 & gneiss & 226.9 & 13.7 & 102.9 & 9.1 \\
\hline RW-5-19 & 50.84130 & 13.76144 & 333 & gneiss & 234.5 & 22.7 & & \\
\hline RW-5-20 & 50.98494 & 13.68278 & 203 & rhyolite & 270.2 & 5.8 & 108.5 & 2.4 \\
\hline RW-5-28 & 50.66650 & 13.16324 & 623 & gneiss & 252.2 & 7.6 & 129.1 & 26.8 \\
\hline RW-5-43 & 50.39903 & 12.11844 & 478 & sandstone & 161.4 & 7.9 & & \\
\hline RW-9-6 & 50.64394 & 12.98133 & 623 & granite & & & 136.9 & 15.1 \\
\hline RW-11-2 & 50.91869 & 13.37285 & 340 & gneiss & 267.9 & 5.6 & & \\
\hline RW-11-4 & 50.94369 & 13.37018 & 340 & gneiss & 281.2 & 15.8 & 101.0 & 5.0 \\
\hline RW-11-5 & 50.90474 & 13.37862 & 340 & gneiss & 322.7 & 7.6 & & \\
\hline RW-11-6 & 50.87397 & 13.33489 & 340 & gneiss & 279.2 & 5.0 & & \\
\hline RW-11-7 & 50.90680 & 13.36069 & 340 & gneiss & 289.4 & 43.5 & & \\
\hline
\end{tabular}

Tab. 4.1: Zircon and apatite (U-Th)/He ages and sample locations of the Erzgebirge, Germany. For analytical details, see Electronic Appendices. Numbers in italics represent apatite samples where only one crystal yielded usable age information. D-samples are from the collection of the Dresden Fission Track Laboratory (DDSPsamples), A6 is from Kempe and Götze (2002). s.e. = $1 \sigma$ standard error. 


\begin{tabular}{cccccccccccccc} 
Sample & Cryst. RhoS & Ns & Rhol & Ni & RhoD & Nd & $\begin{array}{c}\text { Chi-sq. } \\
\text { P (\%) }\end{array}$ & $\begin{array}{c}\text { Central Age } \\
\text { Disp. }\end{array}$ & $\begin{array}{c}\text { Track length } \\
{[\mu \mathrm{Ma}, \pm 1 \mathrm{~s} . \mathrm{d} .]}\end{array}$ & $\begin{array}{c}\text { Dpar } \\
{[\mu \mathrm{m}]}\end{array}$ \\
\hline \hline A6 & 20 & 33.5 & $(1321)$ & 40.1 & $(1580)$ & 7.00 & $(2654)$ & 80 & 0.00 & $\mathbf{1 0 8} \pm 5.3$ & $13.6 \pm 1.4(76)$ & 1.9 \\
D-4 & 20 & 7.24 & $(1098)$ & 9.52 & $(1450)$ & 7.04 & $(2654)$ & 67 & 0.00 & $\mathbf{9 8 . 2}$ & \pm 4.1 & $13.4 \pm 1.3(73)$ & 2.1 \\
D-53 & 25 & 10.8 & $(988)$ & 16.4 & $(1503)$ & 7.02 & $(2654)$ & 73 & 0.00 & $\mathbf{8 5 . 3} \pm 3.7$ & $13.2 \pm 1.3(110)$ & 2.1
\end{tabular}

Tab. 4.2: Details of the apatite fission track analysis. Cryst.: number of dated apatite crystals. Track densities (Rho) for spontaneous (S), induced (I) and dosimeter (D) tracks are as measured (x105 tr/cm2); number of tracks counted $(N)$ shown in brackets. $P(\%)$ : probability obtaining Chi-squared value for $n$ degree of freedom (where $n=$ no. crystals-1). Disp.: Dispersion and Central age are calculated according to Galbraith and Laslett (1993). Number of measured horizontal confined tracks are indicated in brackets.

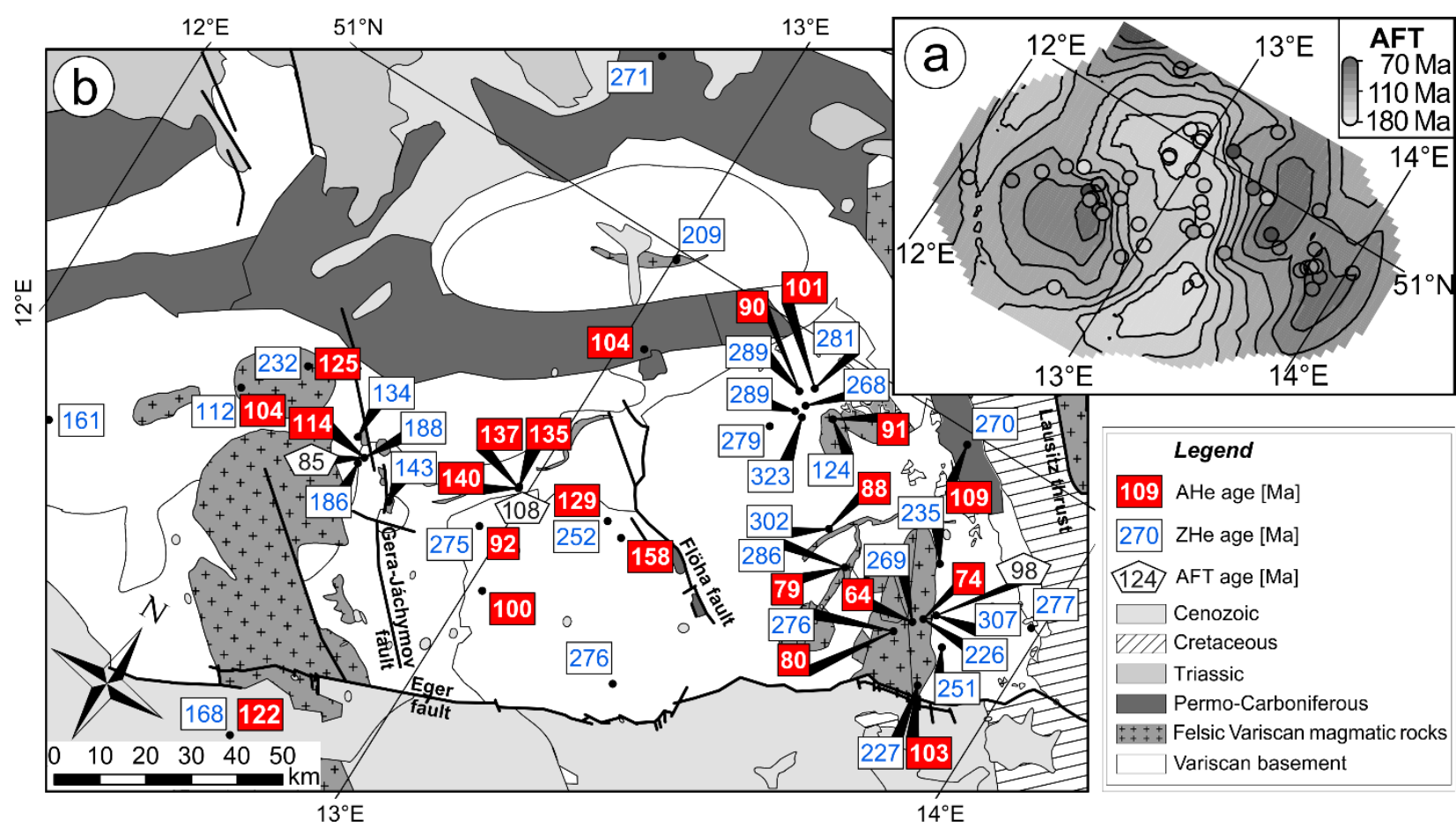

Fig. 4.3: (a) Apatite fission track isochron map generated by Kriging (Cressie, 1993) from the apparent AFT ages of Lange et al. (2008), the uppermost borehole sample of Ventura and Lisker (2003), and the AFT ages presented herein. (b) New (U-Th)/He and AFT ages plotted on the simplified geological map of the Erzgebirge.

The AFT age of sample A6 from the central tectonic block between the Gera-Jáchymov and the Flöha faults yields an age of $108 \mathrm{Ma}$ and a mean track length of $13.6 \mu \mathrm{m}$. It is older than D-4 and D-53 from the other two blocks with 98 and 85 Ma showing track lengths of 13.4 and $13.2 \mu \mathrm{m}$, respectively. Together they fit well into the existing AFT data set. The apparent AHe ages range from 158 to $64 \mathrm{Ma}$ (Fig. 4.2d). In the north-eastern Erzgebirge the AHe ages range between 109 and $64 \mathrm{Ma}$, while in the central and western Erzgebirge they are typically older than $100 \mathrm{Ma}$ (Fig. 4.3b). The apparent ZHe ages range from 323 to $112 \mathrm{Ma}$ with a prominent Permian age population and a broad Mesozoic age distribution (Fig. 4.2c). Permian ages dominate in the north-eastern and central part of the Erzgebirge while Jurassic to Cretaceous ages dominate in the south-western part (Fig. 4.3b). However, two localities do not match this pattern: sample D-34 yields $124 \mathrm{Ma}$, while six neighbouring samples at Freiberg (RW-11-X, D-515) give ZHe ages from 323 to $268 \mathrm{Ma}$. Similarly, we obtained ZHe ages of 112 and $232 \mathrm{Ma}$ for two samples close to each other in the Kirchberg granite (D-10 and D-59). The ZHe ages show a negative correlation with the actinide concentration mirroring an overall long stay in the helium 
4. Superposition of burial and hydrothermal events: post-Variscan thermal evolution of the Erzgebirge, Germany

partial retention zone (Fig. 4.4; e.g. Wolf et al., 1996). The alpha dose controlled partial reset is responsible for at least part of the observed wide intra-sample age scatter.

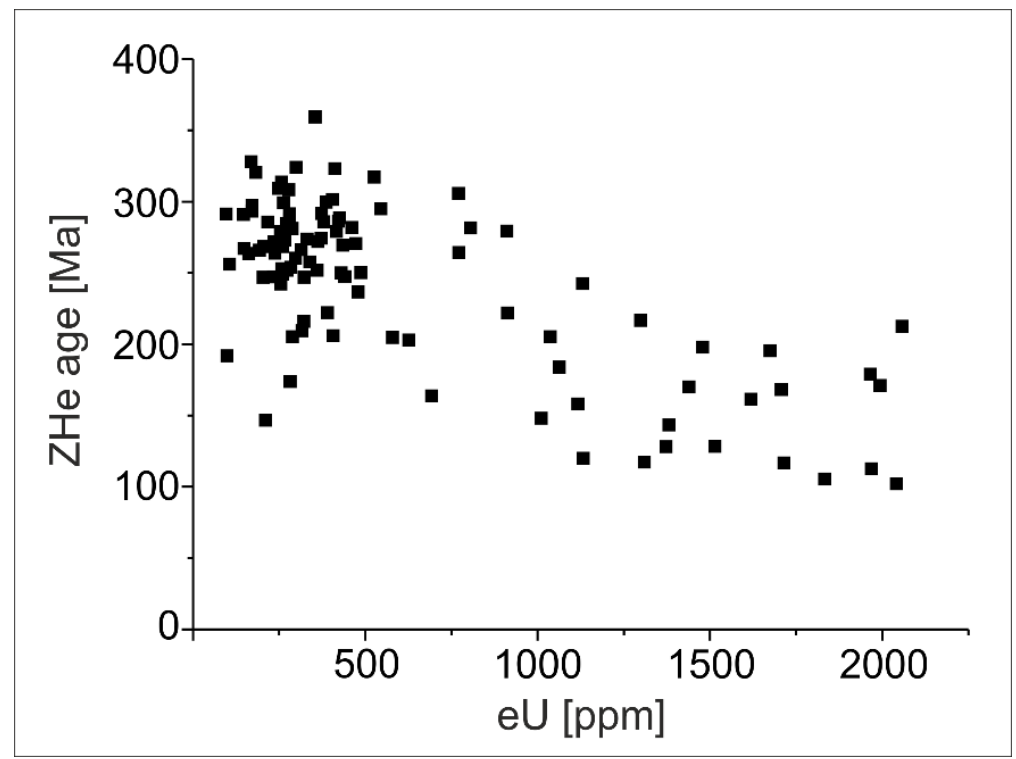

Fig. 4.4: Correlation of effective uranium concentration $\left([U]+0.235^{*}[T h]\right)$ and the $(U-T h) /$ He age of all dated zircon single crystals.

Five characteristic samples, which represent the three different tectonic blocks and a pair from the Freiberg ore district with highly different ZHe ages have been selected for thermal modelling. The HeFTy software of Ketcham (2005) was applied considering the RDAAM algorithm that includes the damage and annealing impact on helium diffusion (Flowers et al., 2009; Gautheron et al., 2009; Guenthner et al., 2013). Modelling is based on the new AHe, ZHe and AFT ages as well as AFT track length and Dpar measurements, on the dimensions of the dated crystals and on their actinide concentrations. The starting points of the time-temperature path for the basement samples were set after the cooling from Variscan metamorphic conditions ( $\mathrm{ca} .300 \mathrm{Ma}, 200^{\circ} \mathrm{C}$ ). For all samples, a good agreement between modelled time-temperature paths and measured data was obtained. The results of thermal modelling are displayed in Fig. 4.5 (for details, see Electronic Appendix 4.3).

\section{Discussion}

According to the areal distribution of the apatite low-T thermochronological data three blocks having different thermal histories can be identified (Fig. 4.3). The central block between the Gera-Jáchymov fault and the Flöha fault has considerably older AFT and AHe ages than the neighbouring blocks. This block was exhumed already in Early Cretaceous and remained in a near surface position since. Southwest of the Gera-Jáchimov fault the ZHe ages are significantly younger than in the central and NE blocks. However, the increased actinide concentration of these zircons indicates their less Heretentive character (Nasdala et al., 2004). Therefore, the apparent ZHe ages have to be evaluated carefully and thermal modelling is required to reveal the thermal histories of the different blocks.

The detected differences between the low-T ages of the three major blocks cannot be related to a difference in the rather flat topography of the study area, thus young vertical movements can be ruled out as reason for the obtained age pattern. We postulate that the pre-Late Cretaceous differential development of the Erzgebirge is responsible for the detected age pattern. The boundaries between 
these blocks coincide with the major northwest-southeast striking brittle structures of the region. The Gera-Jáchymov fault and Flöha fault are the prime candidates due to their prominent character and documented Mesozoic activity (Kley, 2013). The Flöha fault separates different units of high-grade and ultra-high-grade metamorphic formations of the Erzgebirge. Along this fault two Late Carboniferous to Early Permian intramontane basins were preserved indicating the significance of the vertical offset (Fig. 4.1b).

\subsection{Thermal history modelling}

The locally preserved onlapping Upper Carboniferous to Lower Permian sequences prove that the Erzgebirge basement cooled to near-surface temperatures shortly after the Variscan orogeny. The modelling results of samples D-53 and D-4 indicate that their Permo-Mesozoic minimum burial temperature reached 80 to $100{ }^{\circ} \mathrm{C}$ leading to a total reset of the AHe thermochronometer (Fig. 4.5). The Permian to Cretaceous thermal history is only loosely constrained for samples A6 and D-34 due to their relatively high temperatures reached in Early Cretaceous and therefore relatively young apparent AHe ages. Only in case of sample D-515 from the northernmost part of the study area the preCretaceous burial temperature remained below $80^{\circ} \mathrm{C}$ (Fig. 4.5). Because the incomplete relics of the Permo-Mesozoic sedimentary cover do not allow thickness estimates, this data provide the first evidence for limited Permo-Mesozoic burial in the northern part of the Erzgebirge. The relatively close sample D-34 does not show this effect for reasons given below. 
4. Superposition of burial and hydrothermal events: post-Variscan thermal evolution of the Erzgebirge, Germany

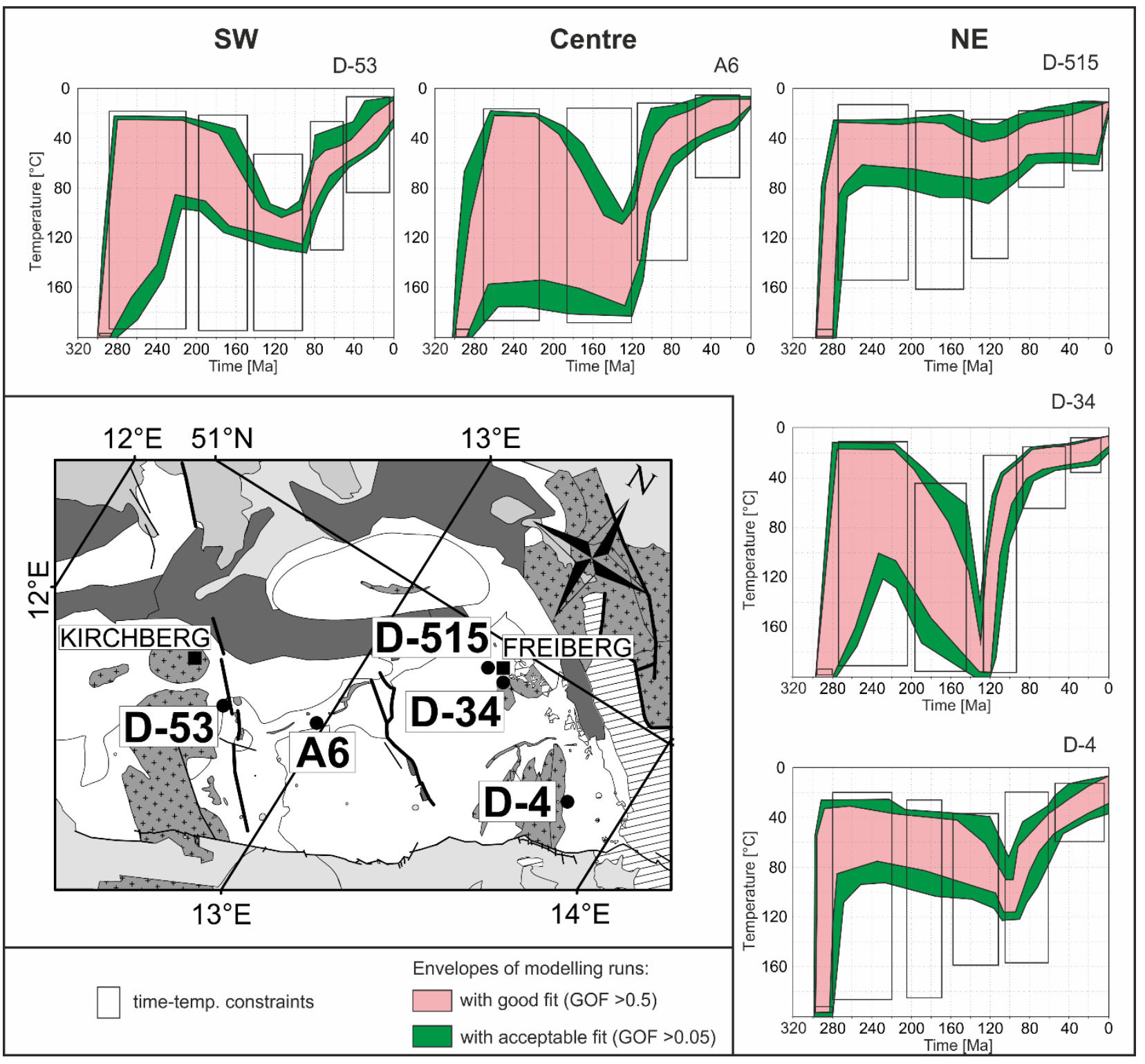

Fig. 4.5: Time-temperature paths obtained for selected localities of the Erzgebirge based on thermal modelling using HeFTy software (Ketcham, 2005). The top panels show the thermal histories from the three major tectonic blocks of the Erzgebirge (SW to NE). The right panels present the modelled thermal histories of neighbouring samples from the Freiberg ore district that experienced highly different Cretaceous thermal overprints.

The characteristic feature of all modelled thermal histories is the pronounced Cretaceous thermal climax (ca. 120 to $110 \mathrm{Ma}$ ) and the abrupt onset of cooling afterwards. We assume that rapid cooling was triggered by the cessation of the hydrothermal activity rather than by exhumation. The thickness of the removed Permo-Mesozoic sedimentary cover and basement cannot be determined exactly, but the composition of Cenomanian sediments indicate that the mid-Cretaceous erosion incised also into the basement (Voigt, 1998).

\subsection{Local reset of ZHe thermochronometer triggered by hydrothermal activity}

Modelled t-T-paths for the neighbouring samples D-515 and D-34 close to Freiberg are compared in Fig. 4.5 (top right). Given the local geological situation the contrast between the obtained thermal histories within a relatively short distance cannot be explained by faulting. Instead, the local abundance of Mesozoic hydrothermal veins suggest that the thermal event was triggered by the temperature of ore-forming fluids that is considered to have been $c a .250{ }^{\circ} \mathrm{C}$ as inferred from fluid inclusion studies (e.g. Trinkler et al., 2005). This temperature is sufficient to reset the ZHe 
thermochronometer even if the duration of the increased temperature is as short as $1 \mathrm{Myr}$ (calculated by Closure software; Ehlers et al., 2005). The temperature climax at ca. $120 \mathrm{Ma}$ in the thermal model is in good agreement with the Early Cretaceous ages recorded by other, independent geochronometers (Fig. 4.2b) of Komínek et al. (1994), Förster (1996), and Romer et al. (2010b).

In contrary to Freiberg the mineral veins in the Kirchberg granite were considered as late Variscan so far (Kempe, 2003), but the Cretaceous ZHe age (D-59) indicates a Mesozoic hydrothermal event affecting this ore district, too. For both samples D-34 and D-59 the AHe ages are roughly similar (91 and $104 \mathrm{Ma}$, respectively) indicating that the increased heat flow terminated in mid-Cretaceous time followed by rapid cooling below the helium partial retention temperature in apatite (Fig. 4.5, D-34).

\subsection{Preservation of pre-Cenozoic landforms}

The modelled thermal histories do not indicate significant re-heating or cooling during Cenozoic times which is in contrast to the significant young denundation of the Erzgebirge proposed by Ventura and Lisker (2003). According to the here presented multi-method thermochronological data set covering a large area, the characteristic peneplain-like morphology of the Erzgebirge and the weathering-related deposits have been preserved since Late Cretaceous.

\section{Conclusions}

1) According to thermal modelling of ZHe, AHe and AFT data, the Erzgebirge is dissected by two roughly NE-SW aligned fault zones leading to three structural blocks that experienced different post-Variscan thermal histories.

2) Basement rocks experienced cooling to near-surface temperature shortly after the Variscan orogeny and were then buried by Permian to Jurassic sediments. Thermal modelling of the northernmost sample suggests that the pre-Cretaceous burial was deeper in the southern to central parts of the Erzgebirge compared to its northern part.

3) Local thermal anomalies resetting all investigated thermochronometers were generated by Cretaceous hydrothermal ore-forming fluids at Freiberg and Kirchberg granite. For the latter this is the first indication for hydrothermal activity in Early Cretaceous times.

4) AHe data show no detectable regional exhumation or hydrothermal re-heating since Late Cretaceous. 
4. Superposition of burial and hydrothermal events: post-Variscan thermal evolution of the Erzgebirge, Germany

\section{Acknowledgments}

This study was funded by the German Research Foundation (DFG grant DU373/6). We thank Ulf Kempe (Freiberg) for the A6 apatite sample. We are indebted to Irina Ottenbacher and Judit Dunkl-Nagy for the careful mineral separation and for the measurements, and to the Central Metal Workshop for the maintenance of the GÖochron Laboratories. We thank Cécile Gautheron, Meinert Rahn, Klaus Mezger and an anonymous reviewer for their constructive and helpful comments. Thanks to Raimon TolosanaDelgado for statistical advice.

\section{Electronic Appendices}

EA 4.1: Details of the apatite and zircon (U-Th)/He results obtained on basement and Permian sedimentary samples of the Erzgebirge. Amount of helium is given in nanocubic centimeter in standard temperature and pressure. Amount of radioactive elements are given in nanograms. Ejection correct. (Ft): correction factor for alpha-ejection (according to Farley et al., 1996). Uncertainties of helium and the radioactive element contents are given as $1 \sigma$, in relative error \%. Uncertainties of the radioactive element concentrations are ca. $10 \%$ (due to the relatively high inaccuracy in the crystal mass estimation). Uncertainty of the single grain age is given as $1 \sigma$ and includes both the analytical uncertainty and the estimated uncertainty of Ft. Uncertainty of the sample average ages are in 1 standard error, as $(S D) /(n) 1 / 2$; where $S D=$ standard deviation of the age replicates and $n=n u m b e r$ of age determinations. When only two aliquots were measured the uncertainty of the sample average is expressed by 1 standard deviation.

Farley, K.A., Wolf, R.A. and Silver, L.T., 1996. The effects of long alpha-stopping distance on (U-Th)/He ages. Geochim. Cosmochim. Acta, 60, 4223-4229.

EA 4.2: Distribution of horizontal confined track lengths of the new apatite samples.

EA 4.3: Goodness of fit (GOF) values of the thermal modelling performed by HeFTy software (Ketcham, 2005). "-" indicates that the corresponding thermochronometer was not available. 


\section{The age of the latest thermal overprint of tin and polymetallic deposits in the Erzgebirge, Germany: constraints from fluorite (U-Th-Sm)/He thermochronology}

The following second article combines a high number of FHe data of variable localities and different types of mineralisation to the framework of the first paper (see above). It is published 2015 in Economic Geology, 110, 2025-2040, Doi: 10.2113/econgeo.110.8.2025

License for reuse permission received by mail.

Wolff, R. ${ }^{1}$, Dunkl, I. ${ }^{1}$, Kempe, U. ${ }^{2}$, von Eynatten, $\mathrm{H}^{1}$

${ }^{1}$ University of Goettingen, Geoscience Center, Sedimentology and Environmental Geology, Goldschmidtstr. 3, 37077 Goettingen, Germany

2 TU Bergakademie Freiberg, Institut für Mineralogie

Corresponding author: Reinhard Wolff, rwolff@gwdg.de

Short title: Fluorite thermochronology of tin and polymetallic deposits

Keywords: Erzgebirge, fluorite, thermochronology, ore-deposits, hydrothermal activity 
5. The age of the latest thermal overprint of tin and polymetallic deposits in the Erzgebirge, Germany: constraints from fluorite (U-Th-Sm)/He thermochronology

\section{Abstract}

The Erzgebirge region of Germany records two major episodes of hydrothermal activity, which includes a Late Carboniferous to Early Permian event associated with significant $\mathrm{Sn}-\mathrm{W}$ mineralisation that is related to late Variscan granite magmatism, and a Mesozoic episode of polymetallic vein mineralisation. In contrast to the first event, the age of the younger hydrothermal activity is poorly constrained. For the latter, various geochronological methods yielded a wide age range from Permian to early Tertiary. Here we apply fluorite (U-Th-Sm)/He thermochronology (FHe) on both types of mineralisation with a twofold goal: (i) to investigate the sensitivity and applicability of the new FHe method (Evans et al. 2005), and (ii) to constrain the thermal history of ore deposits in the Erzgebirge region. 233 aliquots from 7 mineralisation localities have been dated. Fluorite from six deposits yield Cretaceous FHe ages between 112 to $79 \mathrm{Ma}$, which are independent of their paragenesis. In contrast, fluorite from the Sadisdorf Sn-W deposit yield an age of $234 \mathrm{Ma}$. The younger ages are interpreted as cooling ages indicating the time of the last thermal overprint, including possible hydrothermal activity, in the Erzgebirge. The oldest, Triassic FHe ages at Sadisdorf indicate that the Mesozoic thermal overprint only partially reset the (U-Th-Sm)/He system of the late Variscan mineralisation. Thermal modelling based on FHe ages and He diffusion parameters in fluorite results in thermal histories comparable to the results from the well-established apatite-based thermal modelling. This study emphasizes the applicability of fluorite (U-Th-Sm)/He thermochronology, which is especially suited for ore deposits where apatite is lacking.

\section{Introduction}

Fluorite is a mineral commonly occurring (i) in hydrothermal deposits, (ii) as an accessory phase in granites, pegmatites, carbonatites and alkaline magmatites, (iii) in stratabound ore deposits, and (iv) as authigenic phase in sandstones. In particular, hydrothermal veins occur in a wide range of geological settings, which are not all well suited for the commonly used apatite thermochronology because apatite easily dissolves in the presence of acid fluids. The need to determine the age of such ore deposits has led to the development of isotopic techniques for fluorite geochronology such as the $\mathrm{Sm} / \mathrm{Nd}$ (Chesley et al., 1991; 1994) and U-Th-Pb methods (Hofstra et al., 2000). Fluorite lowtemperature (low-T) thermochronology using fission track technique was first attempted by Grønlie et al. (1990). Recently, the fluorite (U-Th-Sm)/He method (FHe) was introduced by Evans et al. (2005) and applied by Pi et al. (2005) and Siebel et al. (2010). According to these studies, the closure temperature of the (U-Th-Sm)/He fluorite system ranges between ca. $200{ }^{\circ} \mathrm{C}$ and $60^{\circ} \mathrm{C}$ (Evans et al., 2005; Pi et al., 2005), which is well suited for dating low-T thermal and hydrothermal events. To investigate the sensitivity and routine applicability of FHe thermochronology, we have performed a comprehensive study on fluorite from several ore deposits in the Erzgebirge (German Ore Mountains) (Fig. 5.1). The Erzgebirge is an ideal test area because it hosts numerous well-studied ore deposits of variable types often containing fluorite (e.g. Kempe et al., 2002). Moreover, the complex post-Variscan thermal history of the Erzgebirge is extensively studied by $\mathrm{K}-\mathrm{Ar}$ and $\mathrm{Ar}-\mathrm{Ar}$ studies on mica and hornblende (Werner and Lippolt, 2000), apatite fission track analysis (Ventura and Lisker, 2003; Lange et al., 2008) as well as zircon and apatite (U-Th-Sm)/He thermochronology (Wolff et al., 2015b). These studies suggest a significant Mesozoic sedimentary burial after the post-Variscan denundation and before the Variscan basement has been re-exhumed in Late Cretaceous times (Voigt, 2009). This thermal history is superimposed by hydrothermal activity. Our study, performed on fluorite from various sites in the Erzgebirge, demonstrates that FHe thermochronology serves as an excellent tool to constrain the minimum age of the latest thermal overprint in such a complex ore district. 


\section{Regional geology and post-Variscan tectonic evolution}

The Erzgebirge forms an antiform structure exposing high- to medium-grade metamorphic gneisses in the core surrounded by a sequence of low-grade metamorphic units, mainly composed of micaschists and phyllites. This metamorphic assemblage formed by crustal stacking during Carboniferous time (e.g. Werner and Lippolt, 2000) and was later intruded by late- to post-Variscan granitoids and locally covered by rhyolites (Kossmat, 1925; Romer et al., 2007; see Fig. 5.1b). The Erzgebirge is bordered in the east by the Lausitz thrust to the Cadomian basement of the Lausitz block (Linnemann and Romer, 2002). This fault is sealed by Cretaceous deposits that formed at the margin of the synsedimentary uplifting block in the east. The initially flexural margin was later transformed into a thrust (Linnemann and Romer, 2010). The Eger fault delimits the Erzgebirge towards the south (e.g. Kroner et al., 2007; Fig. 5.1b). The post-Variscan sedimentary cover of the region starts with Late Carboniferous to Early Permian continental deposits. In Triassic times, the area formed a marginal part of the Central European Basin and experienced some subsidence, as suggested by facies and thickness trends from surrounding Triassic deposits (Voigt, 1995). West, north and east of the Erzgebirge, the Permian to Triassic sequences are still preserved (Fig. 5.1a), but the thickness of the former cover on the currently exposed Erzgebirge is a matter of debate (Schröder, 1976; Brause, 1988; Götze, 1998; Voigt, 2009). Schröder (1987) estimates a thickness of $1.5 \mathrm{~km}$, while Dudek (1991) postulates a post-Variscan denudation of at least $2.5 \mathrm{~km}$. Thermal modelling reveals a Permo-Mesozoic burial temperature reaching $\mathrm{ca} .80$ to $100^{\circ} \mathrm{C}$ at the south, while the sedimentary cover thins out towards north (Wolff et al., 2015b).

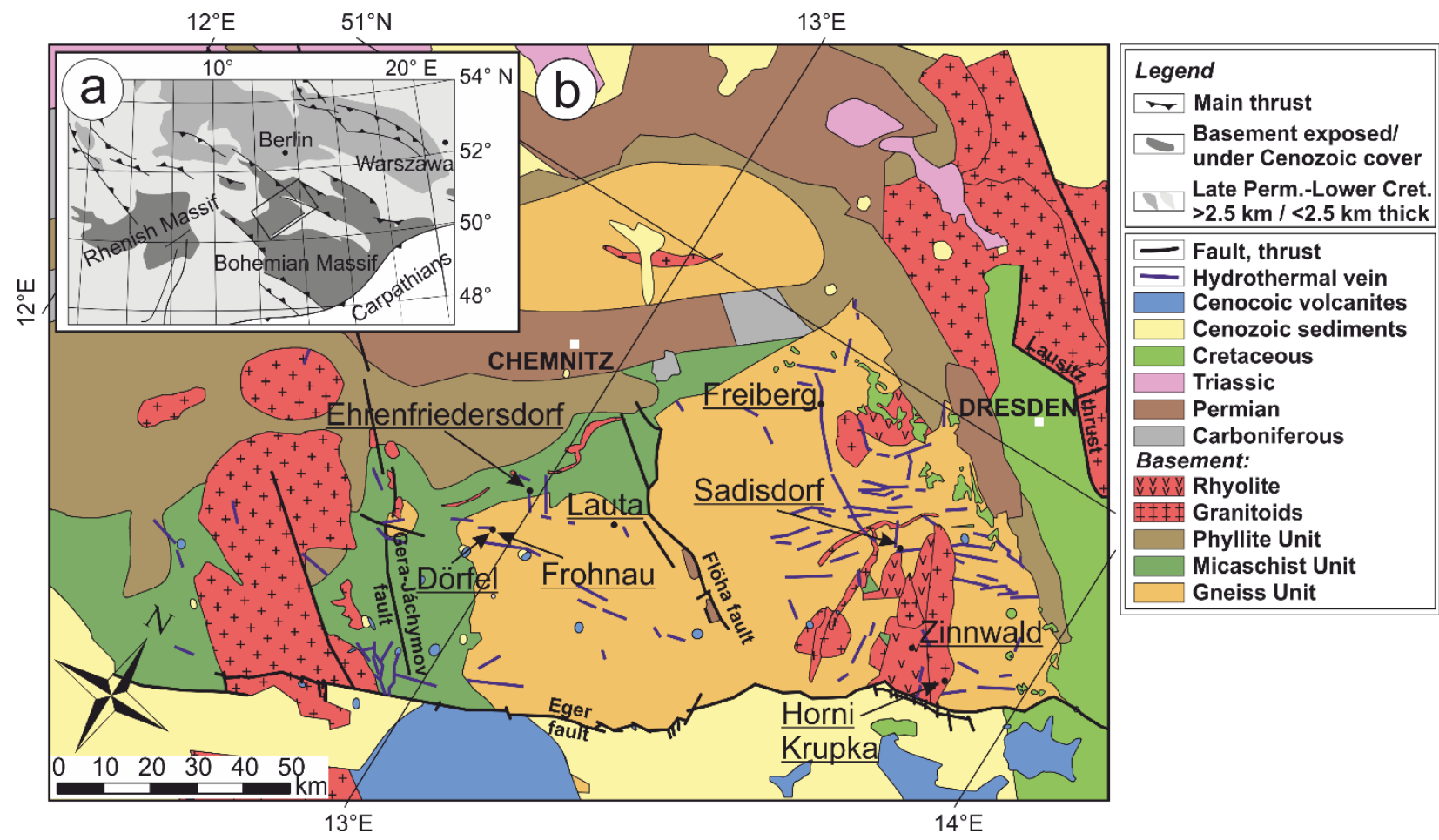

Fig. 5.1: (a) Position of the Erzgebirge (German Ore Mountains) in the European Variscides and surrounding Permo-Mesozoic basins (modified after Kley, 2013). Rectangle represents the position of the study area. (b) Geological map of the Erzgebirge (simplified after Wolf et al., 1992) with sample locations (underlined) and major fault zones.

In the eastern Erzgebirge, Upper Cretaceous (Cenomanian to Coniacian) sediments transgressively overlie the Variscan basement (e.g. Pietzsch, 1913; Kossmat, 1925; Wolf et al., 1992; Prazak, 1994; Voigt, 1995; Janetschke and Wilmsen, 2014). In Middle Cenomanian times, the Niederschöna paleo- 
5. The age of the latest thermal overprint of tin and polymetallic deposits in the Erzgebirge, Germany: constraints from fluorite (U-Th-Sm)/He thermochronology

river delivered sediments into the northern part of the Bohemian Cretaceous Basin (Kossmat, 1925; Voigt, 1998; Schröder and Peterek, 2001; Voigt, 2009). Gravel composition reveals that during this time, the Triassic sedimentary cover has already been removed. Final exhumation of the Erzgebirge and the entire northern Bohemian Massif in late Cenozoic times has led to almost complete denudation of the Upper Cretaceous sedimentary cover. Sedimentary data (Voigt, 2009) and cooling ages of the Lausitz Massif (Lange et al., 2008) reveal exhumation exceeding at least $4 \mathrm{~km}$ during Late Cretaceous Basin inversion (Voigt, 2009). In adjacent areas, similar amounts of Late Cretaceous inversion has been reported, for instance, from the Karkonosze Mts., Harz Mts., and Thuringian Forest (Thomson and Zeh, 2000; von Eynatten et al., 2008; Danišík et al., 2010).

In the western Erzgebirge the basement is partly covered by Eocene to Oligocene fluvial deposits (Knobloch et al., 1996) and locally by Oligocene and Lower Miocene mafic lava flows (Suhr, 2003). The lavas originally flowed in paleo-valleys, but now they are forming elongated hills representing the Neogene palaeosurface. Locally the relief inversion allows one estimating the post-Eocene erosion to be less than 200 m (Eissmann, 1997). However, Ventura and Lisker (2003) suggested a late Cenozoic denudation that removed a thick cover layer $(2.1 \mathrm{~km}$ to $5.6 \mathrm{~km})$ connected to the activity of the Eger graben in the Oligocene. This eroded thickness is debated. For instance, according to their apatite fission track data Lange et al. (2008) favored less than $1 \mathrm{~km}$ for late Cenozoic denudation. The minor Cenozoic denudation is also supported by the apatite (U-Th)/He thermochronological data of Wolff $e t$ al. (2015b).

\section{Hydrothermal activity and vein ore deposits}

The Erzgebirge is famous for its numerous vein ore deposits which have been extensively mined for centuries. There is a complex picture of relations between Variscan magmatism, tectonic setting, vein composition and the ore type for various mineralisation sequences ( $\mathrm{W}, \mathrm{Sn}-\mathrm{W}, \mathrm{Zn}-\mathrm{Pb}-\mathrm{Cu}, \mathrm{Ag}-\mathrm{Sb}, \mathrm{Bi}-\mathrm{Co}-$ $\mathrm{Ni}-\mathrm{U}$ etc.). Accordingly, there is a long-lasting debate on the genesis and timing of various types of mineralisations. Recently, two major periods of hydrothermal activity are commonly distinguished. The first is related to late Variscan granitoid magmatism, the second is assumed to be Mesozoic (Fig. 5.2a; Baumann et al., 2000; Seifert, 2008; Romer et al., 2010b). There are, however, conflicting views assuming that the second period is also late Variscan (e.g. Tischendorf et al., 1989). Depending on the approach used in various studies (with the mineral association, tectonic position, and/or relative age relations as the main classification criteria), mineralisation styles were assigned alternatively to the late Variscan or to the Mesozoic period (Baumann, 1967; Tischendorf et al., 1989; Baumann, 1994a, b; Höhndorf et al., 1994; Kuschka, 1996, 1997; Baumann et al., 2000; Seifert, 2008). Furthermore, mineralisation types belonging to different styles and periods may be superimposed within one single vein system as may be illustrated by the Ehrenfriedersdorf tin deposit investigated in more detail in this work (Kumann and Leeder, 1994; Hösel et al., 1994). There is, however, a consensus that (i) the typical Sn-W mineralisation belongs to the first, late Variscan period and (ii) the characteristic polymetallic or fluorite-barite mineralisation (so-called "fba") belongs to the second, post-Variscan period (referred to as "Mesozoic" in this work). 


\begin{tabular}{|c|c|c|c|c|c|c|} 
[Ma] $300,250,2$ & 200, & 150 & 100 & 50 & 0 \\
\hline Carb. & Permian & Triassic & Jurassic & Cretaceous & Paleog. & Neog. \\
\hline
\end{tabular}

a) Geochronology of ore deposits

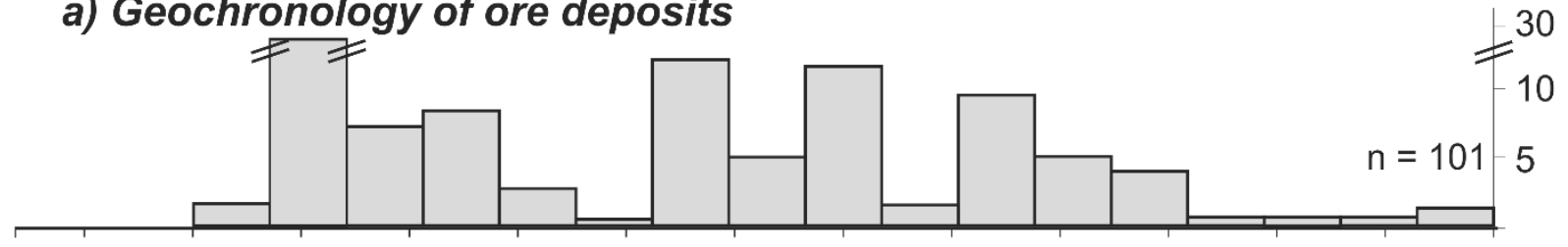

b) Fluorite (U-Th-Sm)/He ages

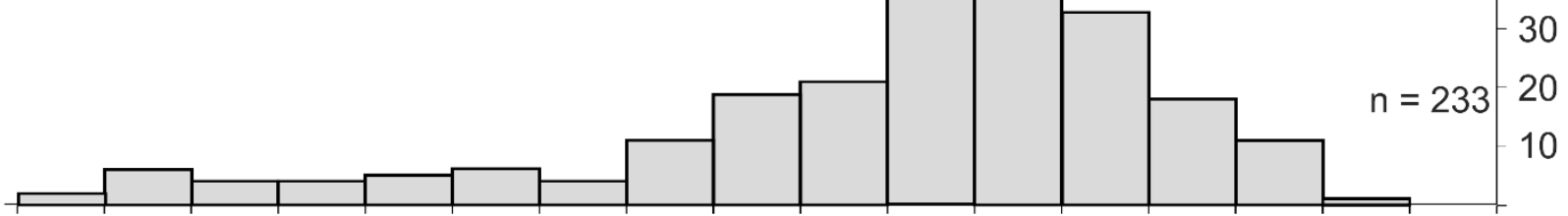

c) Apatite (U-Th-Sm)/He ages

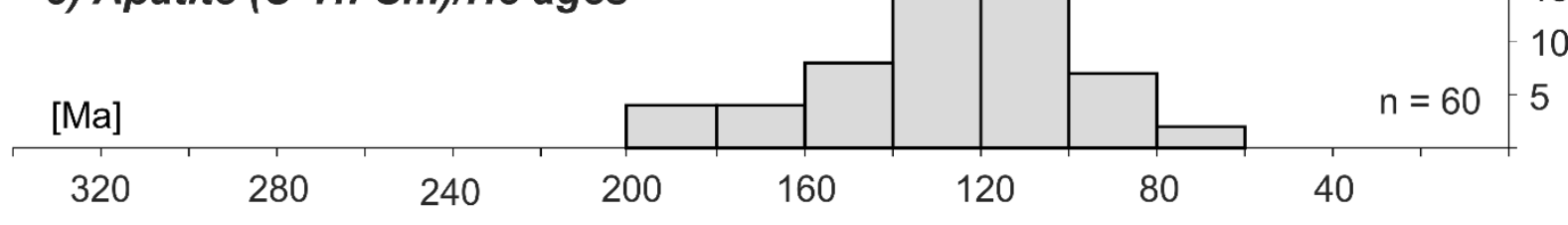

Fig. 5.2: (a) Compilation of geochronological data from the literature indicating a broad and diffuse age range from Permian to Tertiary for hydrothermal activity in the Erzgebirge (pitchblende U-Pb (mostly 260 to $280 \mathrm{Ma}$ ), muscovite and feldspar $\mathrm{K}$-Ar and Rb-Sr, fluorite $\mathrm{Sm}-\mathrm{Nd}$, and sphalerite Rb-Sr ages; lower and upper cretaceous are subdivided; from Romer et al., 2010b); (b) Fluorite (U-Th-Sm)/He thermochronological data (this work) and (c) AHe ages from Wolff et al. (2015b).

Early applications of isotope geochronology (pitchblende chemical U-Pb and $\mathrm{Pb} / \mathrm{Pb}$ dating and $\mathrm{K}-\mathrm{Ar}$ dating on altered wall rocks; see review by Baumann, 1967) indicated two main events of late Variscan and Mesozoic (180-80 Ma) ages, and a multiple remobilization of uranium in the related deposits starting from the late Variscan. The latter phenomenon was confirmed by more recent studies (Eikenberg, 1991; Förster and Haack, 1996).

The late Variscan emplacement of granitoids, rhyolites and lamprophyric dikes was accompanied by increased high-T hydrothermal activity and associated with Sn-W and Mo enrichment in greisen, vein and skarn deposits (e.g. Stemprok and Sulcek, 1969; Baumann et al., 2000; Dolejs and Štemprok, 2001; Seifert, 2008; Romer et al., 2010a). The age of this early mineralisation is now well constrained to a time interval between Late Carboniferous to Early Permian (e.g. Tischendorf and Förster, 1990; Baumann et al., 2000). Nevertheless, exact absolute age relations between magmatism and ore precipitation are a matter of considerable debates. For example, a Carboniferous or Permian age of tin mineralisation is highly controversial (Kempe et al., 2004; Romer et al., 2007; Romer et al., 2010a).

The Mesozoic mineral veins are predominantly polymetallic of barite-fluorite-sulfide and hematitebarite type hosted in the metamorphic basement rocks. Some veins contain anomalous concentrations of U, Ba-Sr, Bi-Co-Ni-As-Ag, Ge-Hg or Fe-Mn (e.g. Trinkler et al., 2005; Seifert, 2008). This second ore formation period may have been driven by major tectonic events affecting the European continent, such as the Triassic opening of the Tethys or Jurassic to Cretaceous opening of the Central and North 
5. The age of the latest thermal overprint of tin and polymetallic deposits in the Erzgebirge, Germany: constraints from fluorite (U-Th-Sm)/He thermochronology

Atlantic (Mitchell and Halliday, 1976; Halliday and Mitchell, 1984; Cathelineau et al., 1990; Baumann and Weber, 1996; Romer et al., 2010b). Tischendorf (1990) related the late vein-type deposits to the Alpine orogenesis that had a remote influence on the European Variscides. The relative age relationships of the Mesozoic vein systems are studied in detail by Seifert (1992), Baumann (1994b; 1994a), Kuschka (1996; 1997), Baumann (2000), Seifert (2008) and were recently reviewed by Romer et al. (2010b). The age of the second period is still poorly constrained and assigned mostly to Mesozoic time by recent workers (e.g. Höhndorf et al., 1994; Trinkler et al., 2005; Romer et al., 2010b; Fig. 5.2a). According to Klemm (1994), fluids from polymetallic mineralisations show chemical compositions typical of brines in deeply buried sedimentary basins.

\section{Sampling and methods}

We focused our study on fluorite samples from the two well-defined mineralisation types: from the late Variscan Sn-W and from the Mesozoic polymetallic deposits (so-called "fba-type" with fluorite and barite). Samples from Sn-W deposits were collected mainly from underground mines and from open pits (Horni Krupka, Zinnwald, Sadisdorf, Ehrenfriedersdorf, and Dörfel). Most of them were characterized in more details previously (Kempe et al., 2002; Monecke et al., 2011). Additional samples were collected from mine dumps and received from museums in Dörfel, Zinnwald and Ehrenfriedersdorf (Fig. 5.1b, Tab. 5.1). These samples belong mainly to the late Variscan Sn-W mineralisation. However, samples from Mesozoic mineralisations, which are also present at Ehrenfriedersdorf and Dörfel, were studied as well. The fluorite associated with Sn-W mineralisation is well characterized by specific rare earth element (REE) patterns displaying distinct negative and positive Eu anomalies, enrichment of heavy REE and often also the tetrad effect (Monecke et al., 2002, 2011). Fluorite samples from Mesozoic "fba" deposits (Freiberg, Lauta and Frohnau) were collected from mine dumps or obtained from museum collections. Fluorite of this type is often characterized by a conspicuous yellow to honey-brown color. Such typical color often occurs together with violet or greenish color in single fluorite crystals or aggregates. Moreover, such "fba" fluorites are typified by a hump-shaped REE distribution pattern with an enrichment of the middle REE and weak Eu anomalies (Trinkler et al., 2005). The characteristics described above may be used as a criterion to distinguish late Variscan Sn-W and Mesozoic ("fba") polymetallic samples when various fluorite types are present in a single deposit. To cover the full scale of specific fluorite types, samples covering a broad variety of colors have been selected from each locality. All samples investigated are listed in the Electronic Appendix 5.1. 


\begin{tabular}{|c|c|c|c|c|c|c|c|c|c|c|c|}
\hline \multirow[b]{2}{*}{ Locality } & \multirow[b]{2}{*}{ Samples } & \multirow[b]{2}{*}{$\begin{array}{l}\text { Lat. } \\
{\left[{ }^{\circ} \text { North] }\right.}\end{array}$} & \multirow[b]{2}{*}{$\begin{array}{l}\text { Long. } \\
\text { [ }^{\circ} \text { East] }\end{array}$} & \multicolumn{5}{|c|}{ Sample-average FHe data } & \multicolumn{3}{|c|}{ Locality-average FHe data } \\
\hline & & & & $\begin{array}{c}\text { number } \\
\text { of ages }\end{array}$ & $\begin{array}{c}\text { median } \\
{[\mathrm{Ma}]}\end{array}$ & $\begin{array}{c}\mathrm{Cl} \\
{[\mathrm{Ma}]}\end{array}$ & $\begin{array}{c}\text { REE+Y } \\
\text { [ppm] }\end{array}$ & colour & $\begin{array}{c}\text { number } \\
\text { of ages }\end{array}$ & $\begin{array}{c}\text { median } \\
{[\mathrm{Ma}]}\end{array}$ & $\begin{array}{c}\mathrm{Cl} \\
{[\mathrm{Ma}]}\end{array}$ \\
\hline \multirow[t]{6}{*}{ Annaberg Dörfel } & RW-2-12 & 50.5765 & 12.9525 & 9 & 99.2 & 21.7 & 563 & yellow & 42 & 104.5 & 7.4 \\
\hline & RW-2-15a & & & 8 & 179.4 & 34.4 & 276 & colorless & & & \\
\hline & $R W-2-15 b$ & & & 11 & 123.9 & 13.8 & 227 & green & & & \\
\hline & RW-2-15c & & & 5 & 69.3 & 19.1 & 259 & pink & & & \\
\hline & $R W-2-15 d$ & & & 9 & 84.0 & 8.1 & 398 & pink & & & \\
\hline & DF15 & & & -- & -- & -- & 62 & colorless & & & \\
\hline \multirow{6}{*}{ Annaberg Frohnau } & FRO-1 & 50.5765 & 12.9525 & 11 & 98.9 & 10.7 & 614 & colorless & 30 & 80.6 & 9.2 \\
\hline & RW-2-23a & & & 3 & 60.0 & -- & 337 & colorless & & & \\
\hline & $\mathrm{RW}-2-23 \mathrm{~b}$ & & & 2 & 48.0 & -- & 221 & black & & & \\
\hline & RW-5-25a & & & 5 & 75.3 & 8.8 & 440 & honey & & & \\
\hline & $R W-5-25 b$ & & & 4 & 42.3 & 76.1 & 168 & pink & & & \\
\hline & RW-9-8a & & & 5 & 93.0 & 19.0 & 156 & yellow & & & \\
\hline \multirow[t]{7}{*}{ Ehrenfriedersdorf } & ED268 & 50.6418 & 12.9789 & 4 & 122.1 & 24.6 & 273 & rosa & 54 & 109.7 & 4.5 \\
\hline & ED506 & & & 1 & 101.9 & -- & -- & pink & & & \\
\hline & RW-2-20 & & & 15 & 118.2 & 8.9 & 424 & yellow & & & \\
\hline & RW-2-21 & & & 8 & 119.9 & 15.0 & 401 & honey & & & \\
\hline & RW-2-22a & & & 9 & 110.4 & 4.8 & 370 & pink & & & \\
\hline & $R W-2-22 b$ & & & 13 & 95.4 & 10.7 & 325 & pink & & & \\
\hline & RW-9-5 & & & 4 & 89.2 & 31.0 & 343 & yellow & & & \\
\hline \multirow[t]{3}{*}{ Freiberg } & RW-9-1 & 50.9598 & 13.0023 & -- & -- & -- & 436 & honey & -- & -- & --- \\
\hline & RW-9-12b & & & -- & -- & -- & 535 & yellow & & & \\
\hline & RW-9-13 & & & -- & -- & -- & 72 & colorless & & & \\
\hline \multirow[t]{4}{*}{ Horni Krupka } & RW-5-7 & 50.7165 & 13.8550 & 1 & 36.5 & -- & 125 & colorless & 19 & 79.0 & 10.4 \\
\hline & RW-5-8 & & & 8 & 79.0 & 6.6 & 126 & colorless & & & \\
\hline & RW-5-9 & & & 6 & 101.7 & 7.0 & 1353 & honey & & & \\
\hline & RW-5-10 & & & 4 & 22.5 & 4.2 & 224 & colorless & & & \\
\hline \multirow[t]{4}{*}{ Lauta } & RW-2-8a & 50.6634 & 13.1543 & 11 & 74.7 & 7.4 & 510 & honey & 35 & 111.7 & 10.3 \\
\hline & RW-2-8b & & & 6 & 113.5 & 32.4 & 329 & pink & & & \\
\hline & RW-2-8c & & & 9 & 133.9 & 21.7 & 388 & pink & & & \\
\hline & RW-2-8d & & & 9 & 164.5 & 42.5 & 251 & black & & & \\
\hline \multirow[t]{4}{*}{ Sadisdorf } & SD41 & 50.8251 & 13.6463 & 3 & 215.7 & -- & 2514 & colorless & 20 & 234.4 & 15.9 \\
\hline & SD1001 & & & 9 & 228.3 & 19.2 & 502 & brown & & & \\
\hline & SD1004b & & & 4 & 293.3 & 19.7 & 883 & brown & & & \\
\hline & UK86 & & & 4 & 210.9 & 31.2 & 222 & colorless & & & \\
\hline \multirow[t]{4}{*}{ Zinnwald } & RW-5-11 & 50.7294 & 13.7675 & 10 & 76.3 & 18.6 & 116 & black & 33 & 109.7 & 10.1 \\
\hline & ZW1005 & & & 4 & 71.0 & 23.9 & 1382 & green & & & \\
\hline & ZW315/2g & & & 17 & 130.7 & 10.6 & 1854 & green & & & \\
\hline & ZW322 & & & 2 & 86.4 & -- & 46 & pink & & & \\
\hline
\end{tabular}

Tab. 5.1: Summary of the obtained fluorite (U-Th-Sm)/He ages, sample locations, and REE+Y content of the studied fluorite samples from the Erzgebirge. The confidence interval $(\mathrm{Cl})$ of the median is calculated according to Bonett and Price (2002).

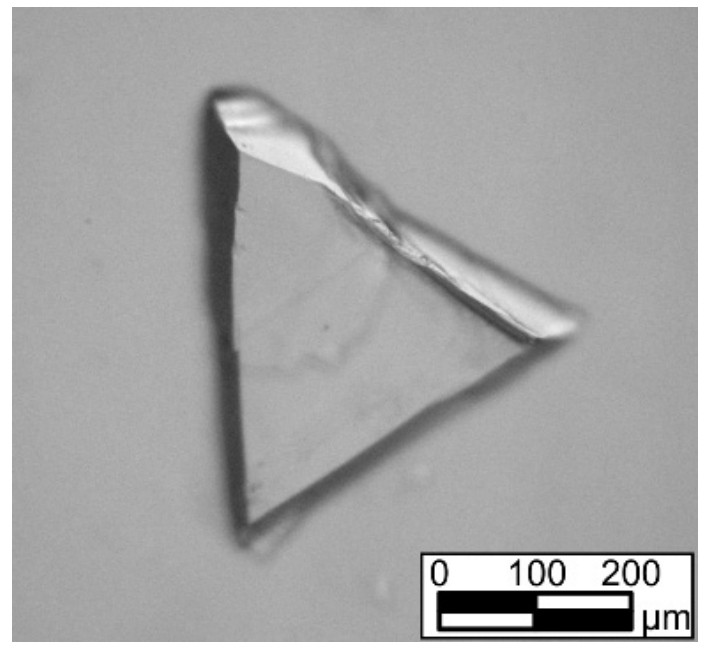

Fig. 5.3: Image of a typical single fluorite fragment analyzed (inclusion-free, photographed in ethyl alcohol).

Fluorite samples from Horni Krupka, Ehrenfriedersdorf, Dörfl, Frohnau and Lauta were studied by cathodoluminescence $(\mathrm{CL})$ imaging and spectroscopy to check their defect structure, homogeneity and 
5. The age of the latest thermal overprint of tin and polymetallic deposits in the Erzgebirge, Germany: constraints from fluorite (U-Th-Sm)/He thermochronology

internal textures (cf. Kempe and Götze, 2002) if not previously investigated (Kempe et al., 2002). For $\mathrm{CL}$ imaging, a JEOL scanning electron microscope (SEM) JSM 7001F with a thermal field emission electron gun equipped with a GATAN MiniCL detector was used. For picture photographs, the SEM was operated at $20 \mathrm{kV}$ and $0.6 \mathrm{nA}$. CL spectra were obtained by means of a system consisting of a GATAN MonoCL 4 mirror, an optical fiber guide and a Princeton Instruments monochromator Acton SP 2300 equipped with a PIXIS 256 CCD which was attached to the same microscope. The SEM was operated at $20 \mathrm{kV}$ and $1 \mathrm{nA}$ with a defocused beam when taking the spectra.

Fluorite (U-Th-Sm)/He thermochronology was performed on 233 aliquots of 38 samples (between 1 and 17 aliquots per sample; Tab. 5.1) from 8 localities (see details in EA5.1). In the samples from the Freiberg mining district and from the Sn-bearing veins at Dörfel, the measured He content was too low to obtain meaningful results. Thus, these samples are not considered for age interpretations. For sample preparation, the outer surface of the euhedral crystals was stained by a marker pen and afterwards carefully crushed. Only intact shards derived from the interior of the crystals with no or only very tiny inclusions were selected to avoid implantation of helium from U-Th-Sm rich phases and alpha-ejection as well as excess $\mathrm{He}$ and tiny mineral phases of extreme actinide content (cf. Pi et al., 2005; Fig. 5.3). Typically, an average fragment size of $c a$. 100 to $400 \mu \mathrm{m}$ edge length was used. The alpha-ejection correction (Farley et al., 1996) was not necessary in this case because fragments from the outer surface of the crystals were excluded. Only single-fragment aliquots were dated. The rationale behind this analytical concept was to study the reliability of the method when the dated volumes are very small in size and might be influenced by primary or secondary zoning that is common in fluorite crystals (e.g. Kempe et al., 2002; Schwinn and Markl, 2005). Furthermore, such heterogeneity may also be related to a possible age distribution within the samples, which would be overlooked if larger sample sizes are used for analysis as discussed below. Furthermore, the accumulation of helium may be spatially decoupled from the volumes where the alpha-emitting elements are concentrated which could have remarkable effects in zoned crystals due to the travel range of alpha particles, which is ca. 13 to $14 \mu \mathrm{m}$ for ${ }^{238} \mathrm{U}$ and ${ }^{232} \mathrm{Th}$ in fluorite (calculated by the SRIM method, see Ziegler et al., 2010). Multi-fragment aliquots may yield more consistent ages as in this way the randomly biased fragments average the influence of alpha-ejection and other factors (see discussion below).

The single-fragment aliquots were wrapped in ca. $1 \times 1 \mathrm{~mm}$-sized platinum capsules and degassed in high vacuum by heating with an infrared diode laser. The extracted gas was purified using a SAES Ti-Zr getter at $450{ }^{\circ} \mathrm{C}$. The chemically inert noble gases and a minor amount of other rest gases were then expanded into a Hiden triple-filter quadrupole mass spectrometer equipped with a positive ion counting detector. Crystals were checked for complete degassing of helium by sequential reheating and helium measurement. Following degassing, samples were retrieved from the gas extraction line, unpacked and spiked with calibrated ${ }^{230} \mathrm{Th}$ and ${ }^{233} \mathrm{U}$ solutions. The fluorites were then dissolved in Savillex Teflon ${ }^{\circledast}$ vials using ultrapure $30 \% \mathrm{HCl}$ at $75{ }^{\circ} \mathrm{C}$ and held for 24 hours at this temperature until total drying. The digestion was controlled by a stereo microscope and the last step was repeated until total dissolution. The sample solutions were analyzed in $4 \% \mathrm{HCl}$ matrix using a Perkin Elmer Elan DRC II ICP-MS equipped with an APEX micro-flow nebulizer. The actinide concentrations were determined by isotope dilution method and the $\mathrm{Sm}$ and the other rare earth elements by external calibration method. The level of detections (LOD) was between 1 and 2 pg, slightly varying for the different ICPMS sessions. FHe ages were calculated using Taylor series that can be summarized by

$$
{ }^{4} \mathrm{He}_{\mathrm{t}}={ }^{4} \mathrm{He}_{\mathrm{i}}+8^{* 238} \mathrm{U}\left(\exp ^{(\lambda 238 \mathrm{t})}-1\right)+7^{* 235} \mathrm{U}\left(\exp ^{(\lambda 235 \mathrm{t})}-1\right)+6^{* 232} \mathrm{Th}\left(\exp ^{(\lambda 232 \mathrm{t})}-1\right)+{ }^{147} \mathrm{Sm}\left(\exp ^{(\lambda 147 \mathrm{t})}-1\right)
$$

where ${ }^{4} \mathrm{He}_{\mathrm{t}}$ and ${ }^{4} \mathrm{He}_{\mathrm{i}}$ are the total and initial helium content, respectively (McDougall and Harrison, 1988). The uncertainties of $\mathrm{FHe}$ ages were calculated as a square root of sum of squares of uncertainty 
of He and He-production-weighted uncertainties of $U$, Th and Sm measurements. The sample and locality averages are expressed - to a first approximation - as medians because the single-fragment ages are mostly not Gaussian distributed and thus the arithmetic mean and the standard deviation are not statistically robust (see discussion below). For the same reason we cannot apply any standard deviation based outlier rejection procedure like suggested by Fitzgerald et al. (2006) for apatite (UTh)/He data. Remarkably, the analytical uncertainties of He and actinide data do not provide hints for rejection of individual ages that are considerably older than the dominant proportion of age data.

The concentrations of REEs and some other elements were determined on the dissolved crystal fragments that were used for (U-Th-Sm)/He geochronology. Fluorites with a REE+Y content exceeding $3000 \mathrm{ppm}$ have been excluded from this study to avoid extreme chemical compositions which may change significantly the diffusion mechanisms and thus influence the closure temperature $\left(T_{c}\right)$ of fluorite.

\section{Results}

\subsection{Cathodoluminescence (CL)}

$\mathrm{CL}$ imaging and spectroscopy demonstrate a significant heterogeneity in the defect structure of fluorite crystals and aggregates from Mesozoic "fba" veins in accordance with earlier results obtained for the samples from late Variscan Sn-W mineralisation (Kempe et al., 2002). This heterogeneity is only partly paralleled by visible variations in color. The imaged textures may be related to primary growth zoning (oscillatory zoning, sector zoning, etc.) and secondary alteration, respectively. This is illustrated by the "fba" sample RW 2-22a from Ehrenfriedersdorf in Fig. 5.4a, b. This sample is mainly transparent and exhibits a yellow to honey-brown color with some cloudy patchy violet inner and normally zoned violet outer rim zones and a few small, nearly colorless crystal overgrowths (Fig. 5.4a). The cloudy patchy violet zones are clearly related to secondary alteration. In CL images, the yellow to honey-brown crystal parts appear dark or weakly luminescent with normal oscillatory and sector growth zoning. The weak luminescence is mainly related to the emission lines from $\mathrm{REE}^{3+/ 2+}$ centers and a broad-band feature peaking at about $575 \mathrm{~nm}$ (Fig. 5.4b). The luminescence of cubic Dy ${ }^{3+}$ at 671 and $759 \mathrm{~nm}$ prevails over non-cubic Dy ${ }^{3+}$ (482 and $584 \mathrm{~nm}$ ) in accordance with the dilute character of the incorporation of the REE. In contrast, the cloudy violet patches exhibit strong luminescence (Fig. 5.4a) dominated by two broad band features peaking at 305 and $565 \mathrm{~nm}$, respectively (Fig. 5.4b). Luminescence signals from $\mathrm{REE}\left(\mathrm{Eu}^{2+}\right.$ and non-cubic $\left.\mathrm{Dy}^{3+}\right)$ are only of very minor importance in these spectra. The band shape of the main luminescence features and comparison with the spectra of the yellow crystal parts indicate that the bands at 305 and $575 \mathrm{~nm}$ consist of more than one signal. The nature of these bands is unclear. Investigation on pure, artificially grown optical fluorite indicates that they are related to the concentration of interstitial defects occurring in variable amounts depending on growth conditions (Kempe et al., unpublished). In contrast, violet zones in oscillatory growth zoning are characterized by very low luminescence intensity (Fig. 5.4a). 
5. The age of the latest thermal overprint of tin and polymetallic deposits in the Erzgebirge, Germany: constraints from fluorite (U-Th-Sm)/He thermochronology
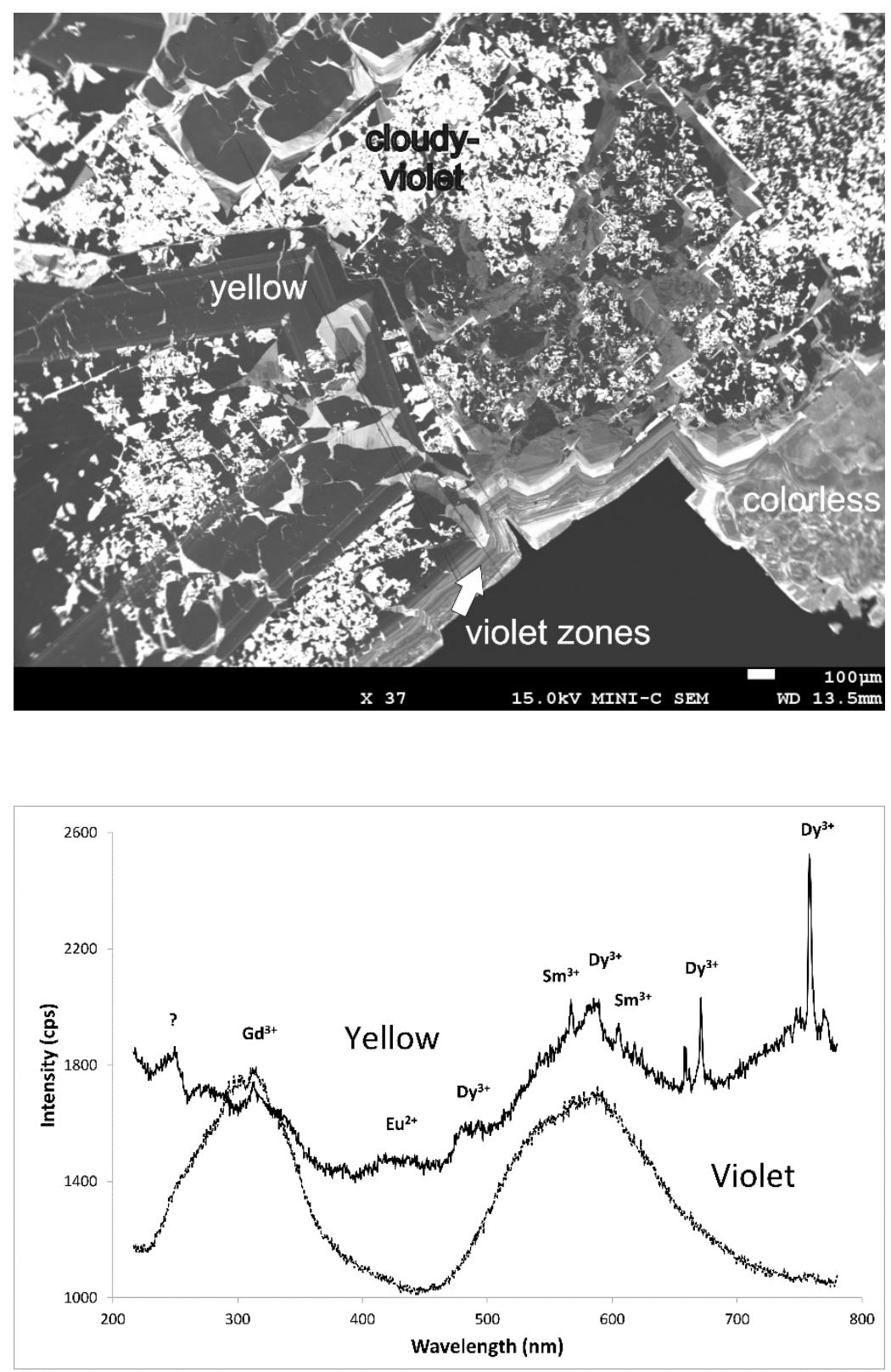

(Continued on next page) 


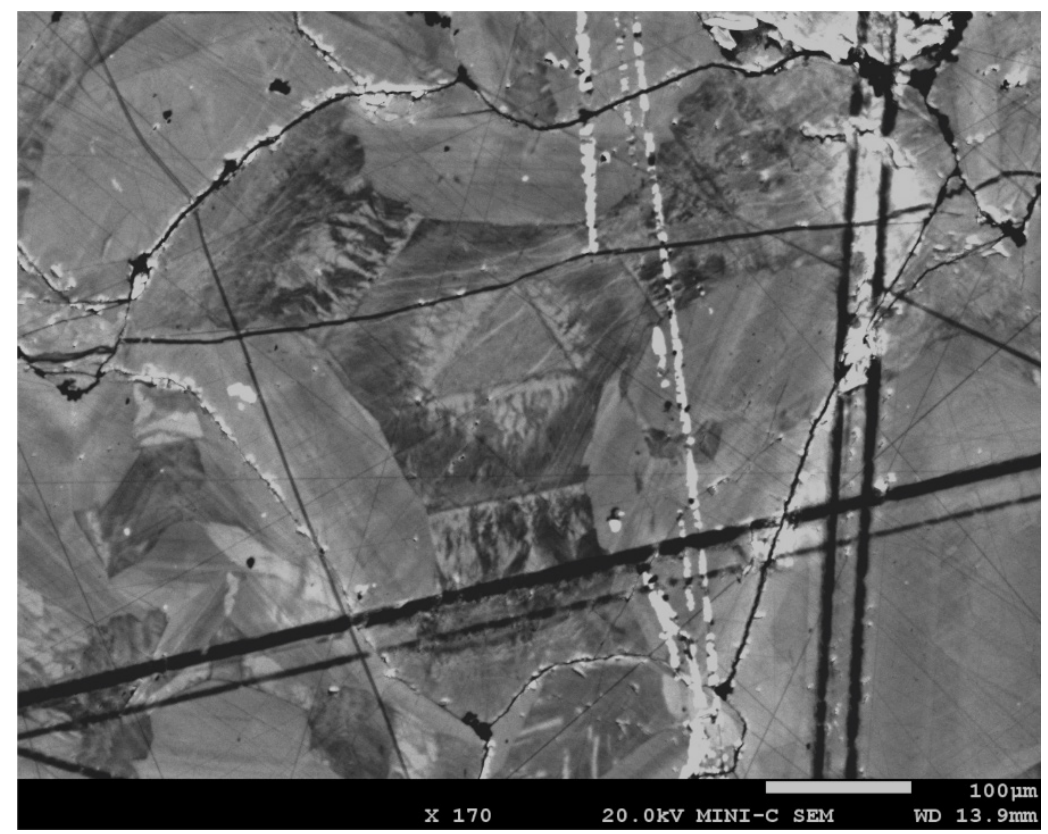

Fig. 5.4: SEM-CL images and spectra of fluorite from Mesozoic ("fba") mineralisation: (a) CL image of fluorite sample RW-2-22a (Ehrenfriedersdorf) with yellow to honey-brown central crystal parts infiltrated by violet patchy zones of secondary alteration. An almost colorless overgrowth is visible in the lower right part of the image. Note that outer crystal rims also contain some violet zones (arrow). (b) Typical CL spectra from (a) of a weak luminescent yellow and strongly luminescent patchy violet crystal part. The spectra are stacked for clarity. See text for further explanations. (c) CL image of fluorite sample RW-2-8c (Lauta) with primary oscillatory and sector zoning. Note the fibrous internal texture of the violet colored crystal sectors.

We assume that such zones formed during circulation of U-rich fluids (Kempe et al., 2002) but the zones are often not enriched in U. A characteristic feature of them is a fibrous internal texture illustrated here by $\mathrm{CL}$ imaging of a sample from Lauta (RW2-8c; Fig. 5.4c). All described types of defect structures enhancing, modifying, or quenching $\mathrm{CL}$ emission may also influence the He diffusion behavior in fluorite and thus the ability of the structure to retain $\mathrm{He}$. It is not possible to separate the various fluorite types from each other by handpicking without $\mathrm{CL}$ imaging.

\subsection{Rare earth element contents}

The average $R E E+Y$ content of the 233 dated fluorite aliquots is $479 \mathrm{ppm}$ (details in Electronic Appendix EA5.1). The results of the REE measurements are presented in REE patterns obtained by chondrite normalization using the values by Sun and McDonough (1989). The patterns can be subdivided into two major groups according to the two mineralisation types they are belonging to (Fig. 5.5). The samples from Lauta, Frohnau, and Freiberg show mainly hump-shaped patterns (i.e. mid-REE enrichment) with minor Eu anomalies, which is typical for the Mesozoic "fba" deposits. In contrast, samples from Zinnwald, Horni Krupka, and Sadisdorf display pronounced Eu anomalies, enrichment of heavy REE and, sometimes, also the tetrad effect in their REE distribution patterns (Monecke et al., 2002), which is characteristic for the late Variscan Sn-W deposits. Samples from Dörfel and Ehrenfriedersdorf show both patterns (Fig. 5.5). Using linear discriminant analysis the samples can be classified by their relative content of light, medium, and heavy REE (La, Gd, and Er; Fig. 5.6). This discrimination procedure yields high match for the polymetallic and Sn-W fluorites (89\% and $97 \%$, respectively). Consequently, the observed REE patterns of the selected samples correspond well to the two main mineralisation periods. 
5. The age of the latest thermal overprint of tin and polymetallic deposits in the Erzgebirge, Germany: constraints from fluorite (U-Th-Sm)/He thermochronology

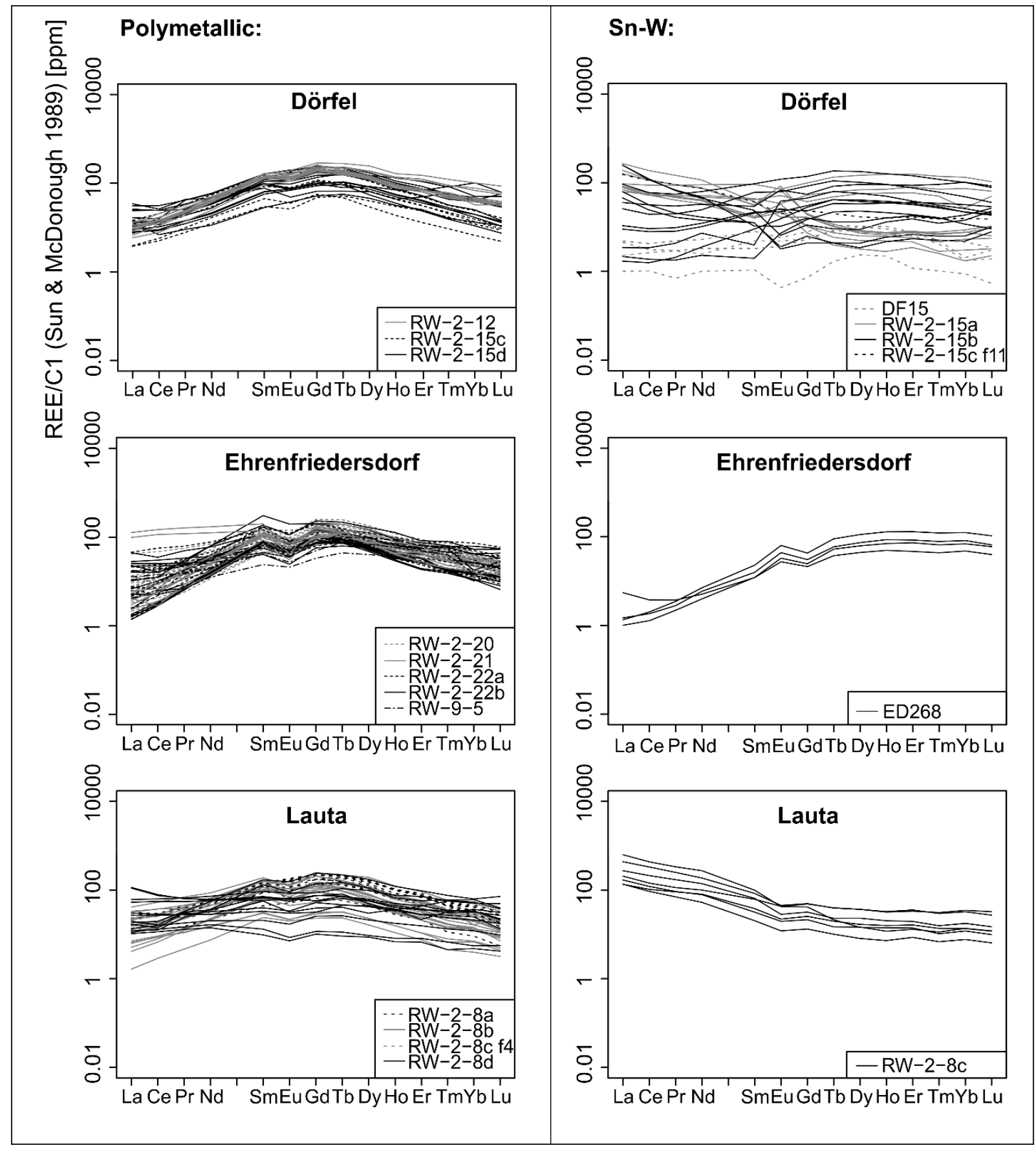

(Continued on next page) 


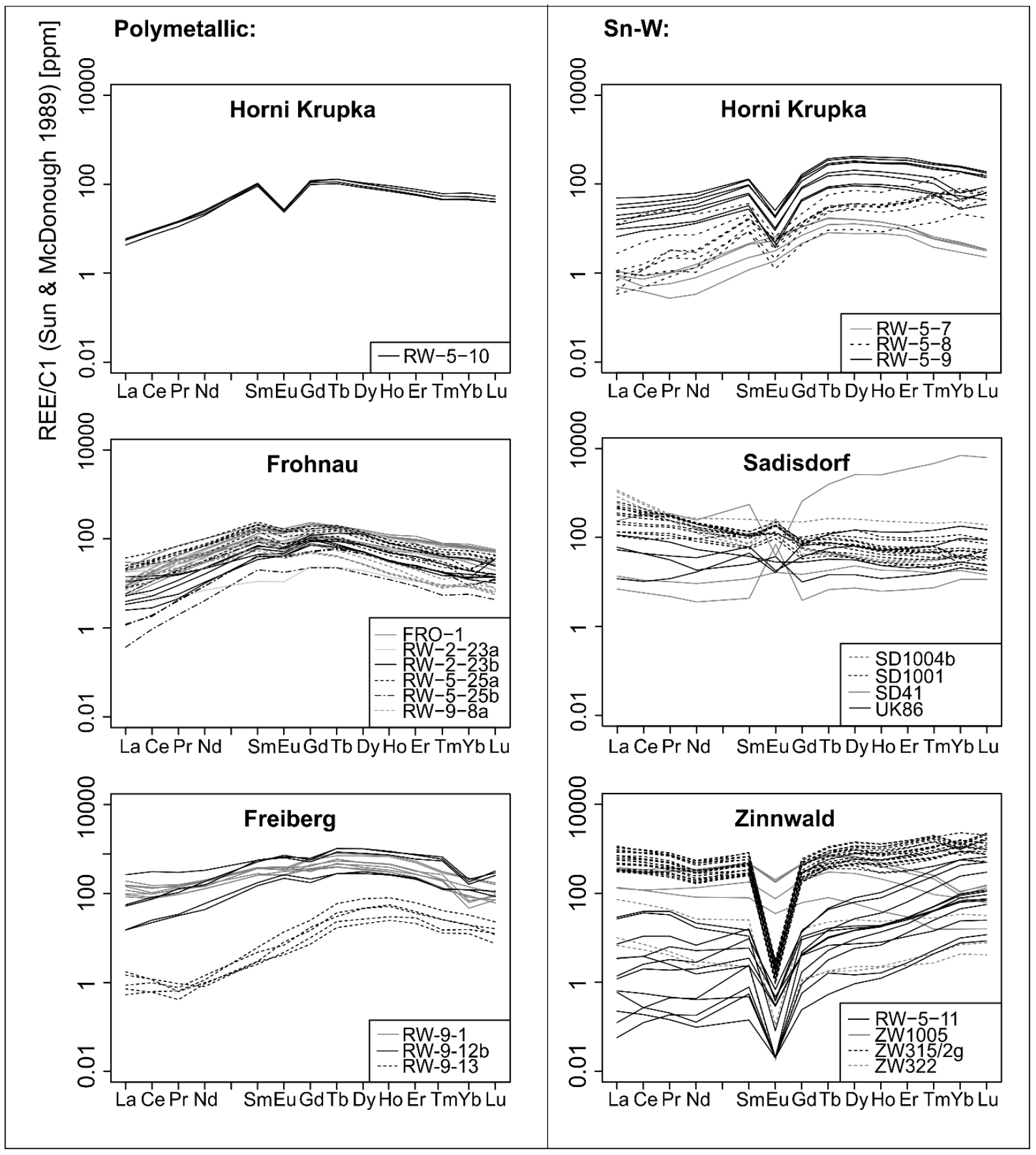

Fig. 5.5: REE distribution patterns of single crystal fragment fluorite samples (chondrite normalized after Sun and McDonough, 1989). The REE patterns illustrate the variability of chemical composition of fluorite studied. Fluorite from the Mesozoic polymetallic mineralisation (left side, hump-shaped patterns) and the late Variscan Sn-W deposits (right side, Eu anomalies, heavy REE enrichment, and tetrad effect) can be distinguished clearly. 
5. The age of the latest thermal overprint of tin and polymetallic deposits in the Erzgebirge, Germany: constraints from fluorite (U-Th-Sm)/He thermochronology

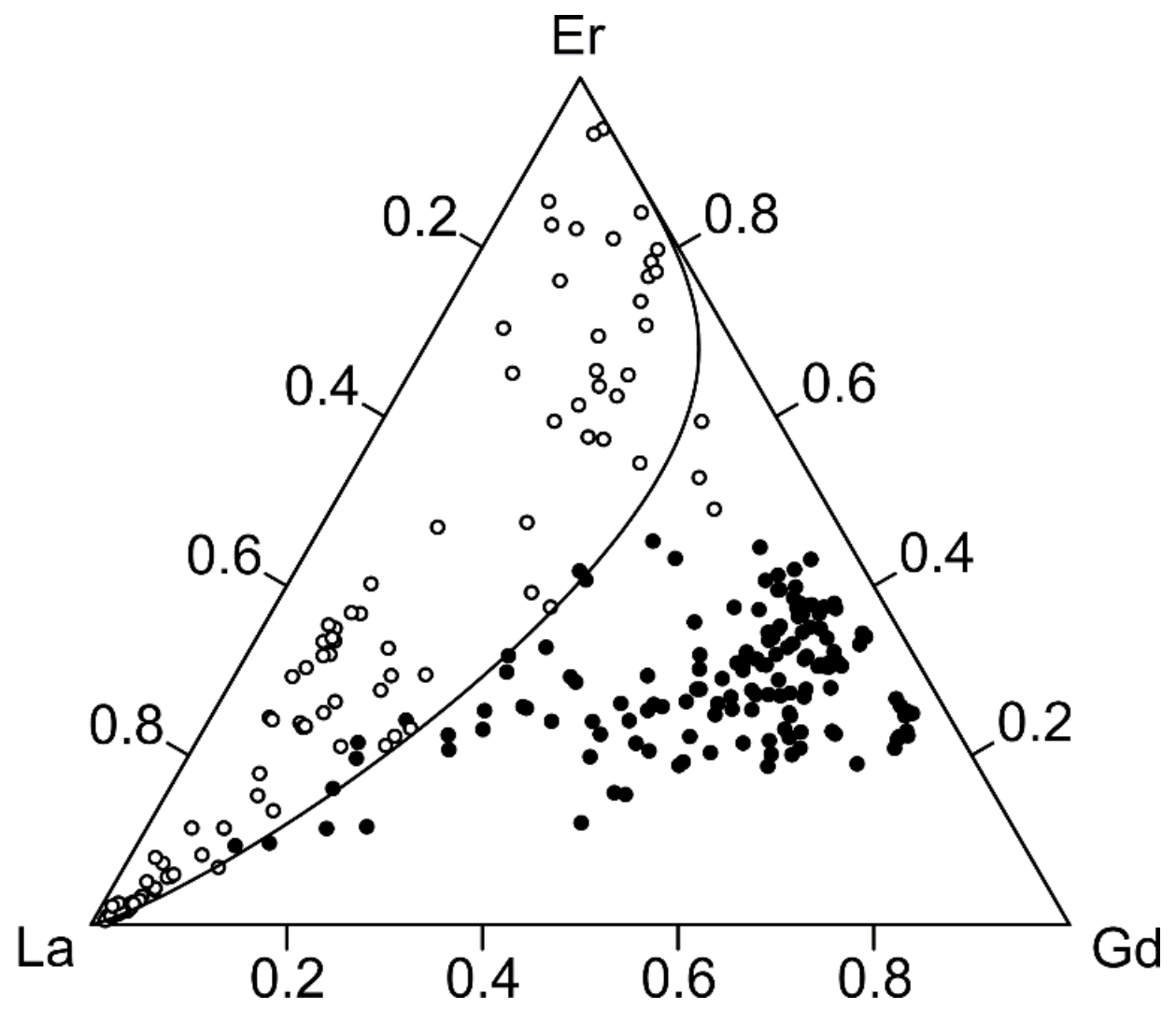

Fig. 5.6: Linear discrimination of polymetallic (black) and Sn-W (white) fluorite in ternary diagram using REE elements $L a, G d$, and Er.

\section{3. $(U-T h-S m) / H e$ ages}

The summary of fluorite helium ages and the principal statistical data obtained on fluorites of the studied mining districts are compiled in Tab. 5.1, while the detailed raw data are listed in the Electronic Appendix EA5.2. The individual single fragment ages are plotted in Fig. 5.7. Median FHe ages for the individual localities range from $79 \mathrm{Ma}$ to $234 \mathrm{Ma}$. Six out of seven localities yield Cretaceous median FHe ages between 79 and $112 \mathrm{Ma}$, only the Sadisdorf fluorite from the eastern Erzgebirge yields a Triassic median FHe age (Fig. 5.8). Except for this "oldest" sample the single-fragment aliquots yielded a reasonable confidence interval of the median (calculated by the method of Bonett and Price, 2002) below $11 \mathrm{Ma}$ (Tab. 5.1). 

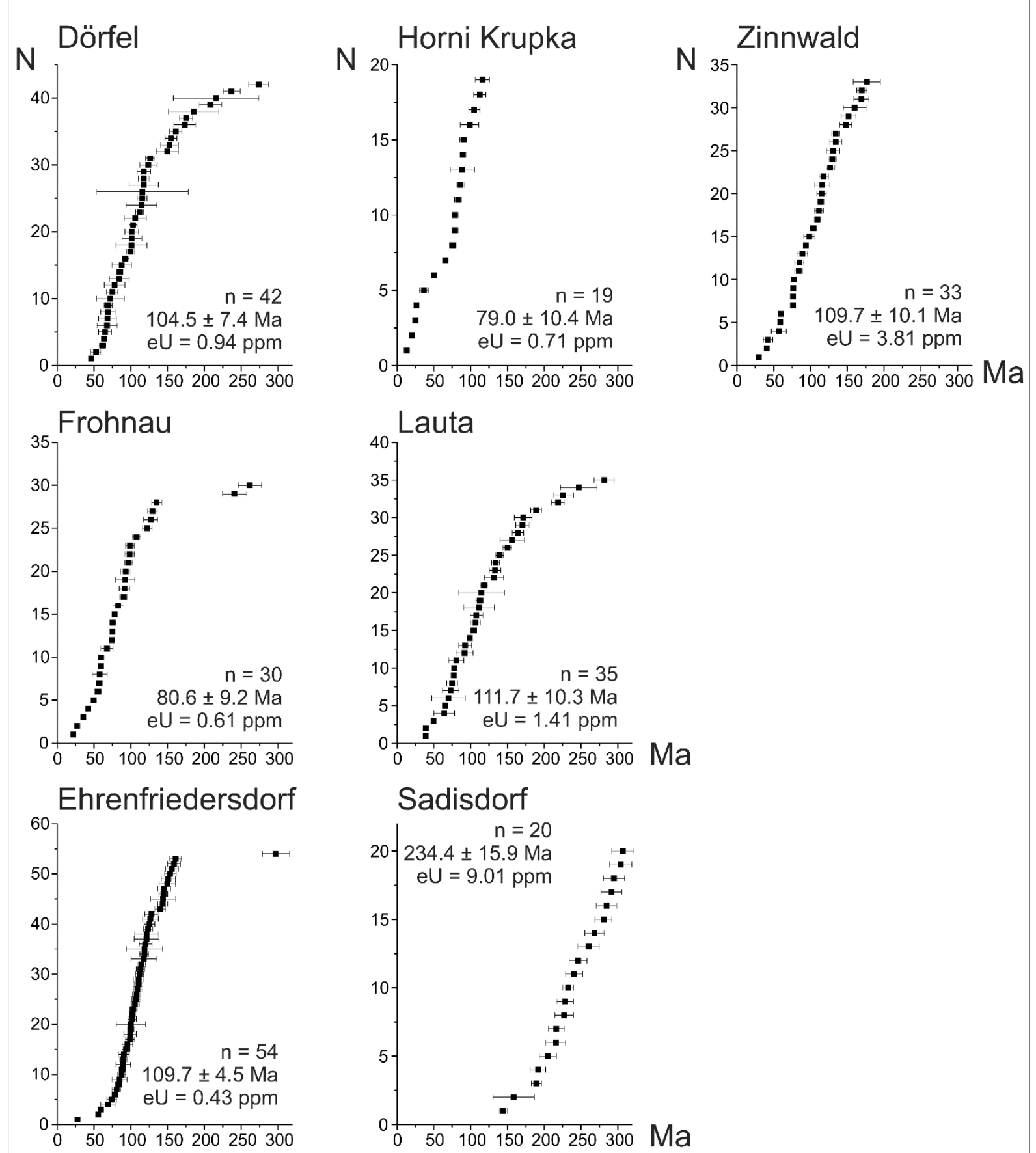

Fig. 5.7: Increasing scatter plot of the single-fragment fluorite (U-Th-Sm)/He ages. eU values (effective uranium concentration, a parameter that weights the decay of the two parents for their alpha productivity, computed as $[\mathrm{U}] \mathrm{ppm}+0.235^{*}[\mathrm{Th}] \mathrm{ppm}$ ) vary between $0.43 \mathrm{ppm}$ and $9.01 \mathrm{ppm}$. The ages refer to the median and its respective confidence interval for each locality (Tab. 5.1). 
5. The age of the latest thermal overprint of tin and polymetallic deposits in the Erzgebirge, Germany: constraints from fluorite (U-Th-Sm)/He thermochronology

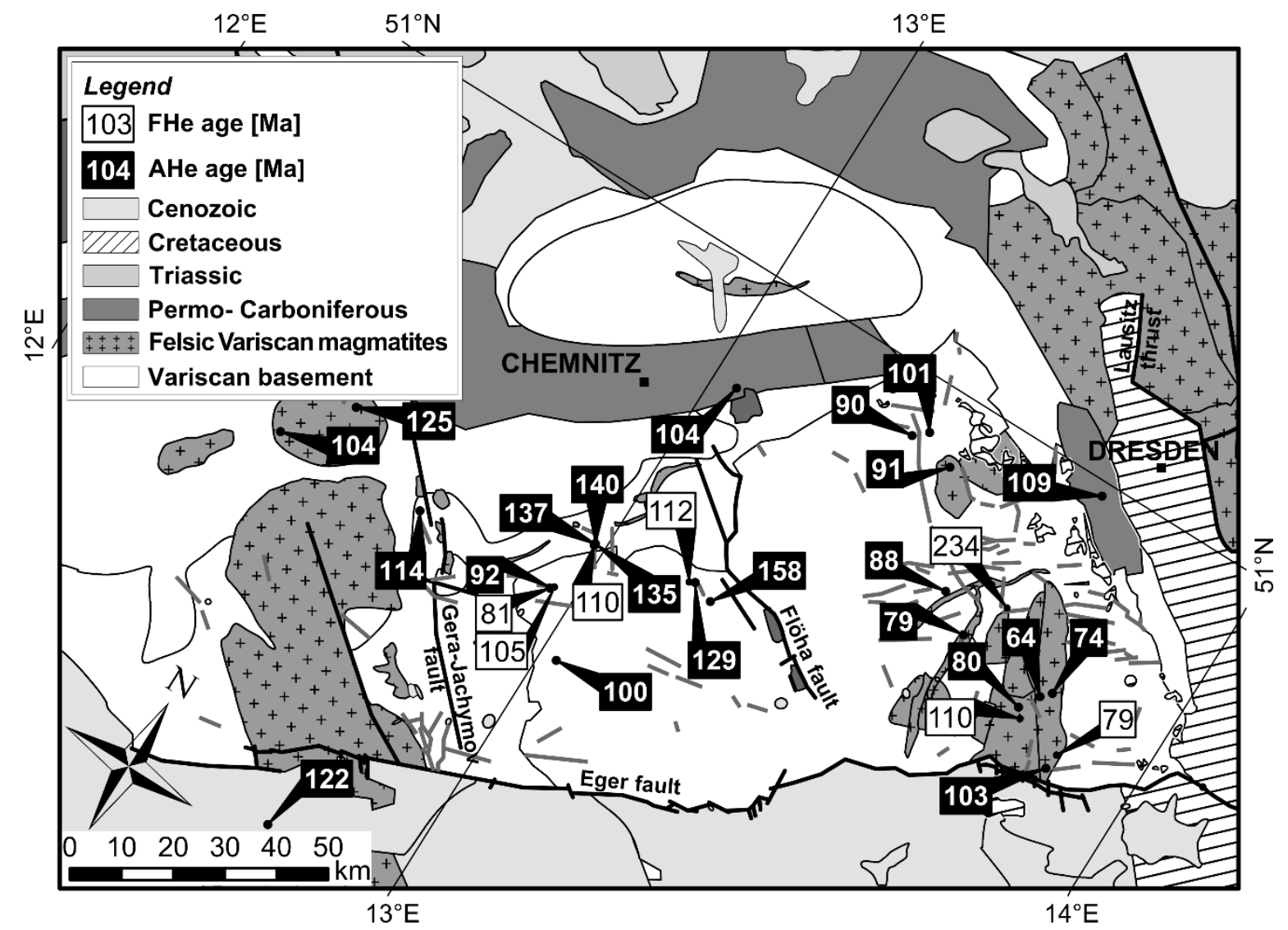

Fig. 5.8: Simplified geological map of the Erzgebirge with median fluorite (U-Th-Sm)/He ages (black numbers; this study) and apatite (U-Th-Sm)/He ages (white numbers; Wolff et al., 2015b). The ages are given in Ma, uncertainties and further analytical details are listed in the Electronic Appendix EA 5.1.

\subsection{Source of radiogenic helium}

The ratio of the alpha-emitting, radioactive elements carry genetic information on fluorite formation and can be used as an index for the homogeneity of the studied fluorites. The $U$, Th and Sm concentrations in the 233 dated single-fragment fluorite aliquots range between the level of detection and $35 \mathrm{ppm}, 305 \mathrm{ppm}$, and $105 \mathrm{ppm}$, respectively. The average concentrations are ca. $0.8 \mathrm{ppm} \mathrm{U}, 12.5$ $\mathrm{ppm}$ Th, and $12.3 \mathrm{ppm} \mathrm{Sm}$. The contributions of the three alpha-emitting elements to the total radiogenic helium are highly variable (Fig. 5.9). It is possible to distinguish two types of localities. In case of the Zinnwald, Ehrenfriedersdorf and Lauta samples, the sources of helium (from U, Th or Sm) show characteristic proportions that define distinct compositional fields with only minor overlap (Fig. 5.9a). For instance, the He is derived mainly from Th in fluorites from Ehrenfriedersdorf, while in Lauta the Th-contribution is subordinate. U-generated He is dominant in most Lauta samples while it is a minor component for Zinnwald and Ehrenfriedersdorf sample. In some fluorites Sm-generated He is dominating, its contribution can be as high as $75 \%$ as, e.g. in some Zinnwald samples. These relatively well-defined distributions indicate relative homogeneity of the fluorite crystals from these locations. In the other localities (Fig. 5.9b), the proportion of $\mathrm{U}-$, Th- and Sm-generated helium is not characteristic and the single-fragment aliquots show much wider scatter. These U-Th-Sm characteristics do not correlate to a late Variscan or Mesozoic formation age of the deposit. Thus, we assume that these features are principally controlled by the wave-length and amplitude of the intracrystal zonation patterns and additional heterogeneities (as revealed by $\mathrm{CL}$ imaging) that are characteristic for a given sample and its formation history. 


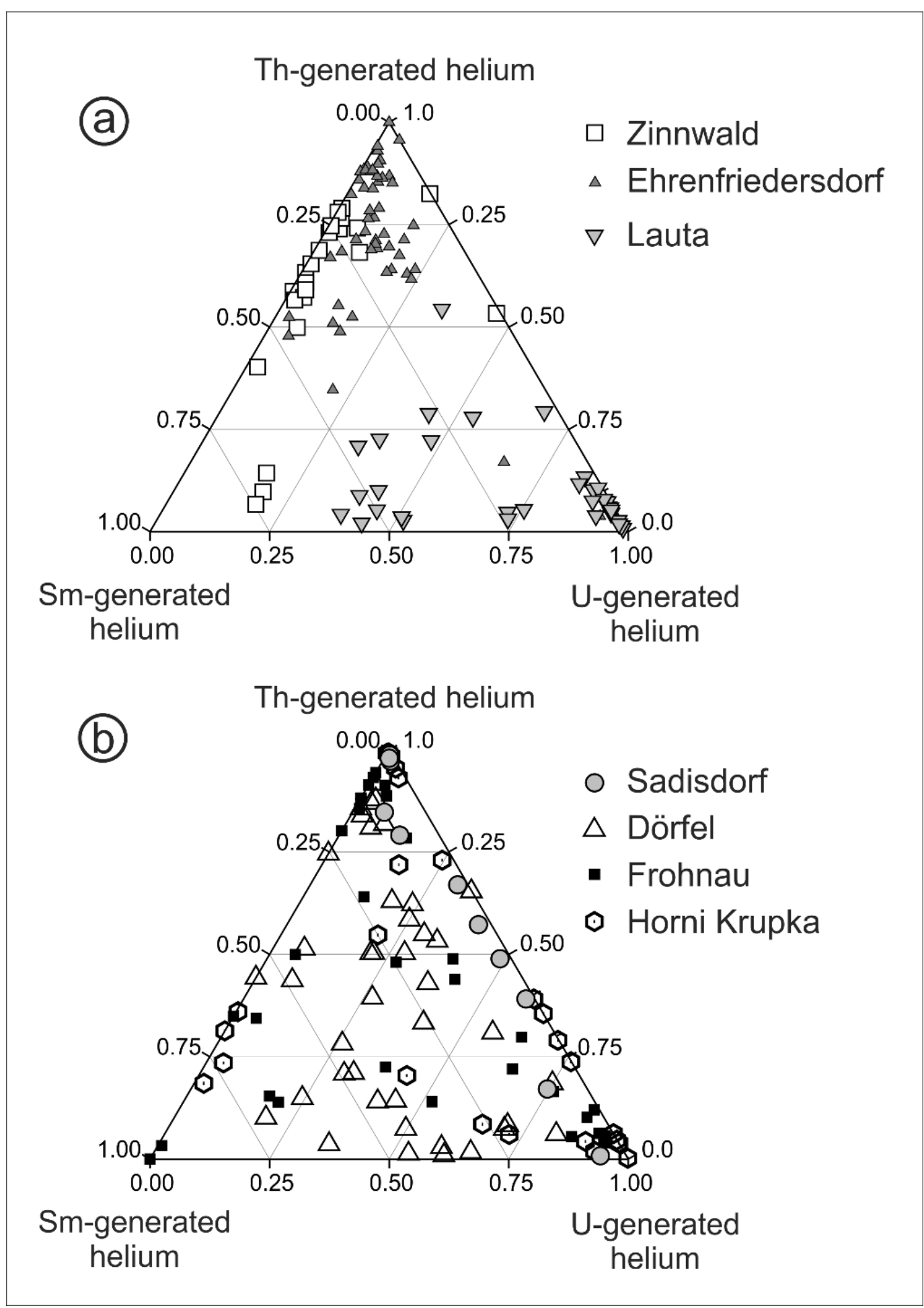

Fig. 5.9: The contributions of the three alpha-emitting elements to the total radiogenic helium budget of the dated fluorite samples. In three samples, the radioactive element ratios are roughly diagnostic (a), while in the other four samples the ratios are highly variable and do not discriminate the samples (b).

\section{Discussion}

7.1.Chemical heterogeneity and structural properties of the studied fluorites Variations in chemical composition (e.g. REE distribution patterns, $\mathrm{Y}, \mathrm{U}$ and Th concentrations) reflect the formation conditions of hydrothermal fluorite influenced by external supply of trace elements, 
5. The age of the latest thermal overprint of tin and polymetallic deposits in the Erzgebirge, Germany: constraints from fluorite (U-Th-Sm)/He thermochronology

remobilization of elements from the host rocks, fractionation of them in the hydrothermal environment and during fluorite precipitation (Bau, 1991; Monecke et al., 2002, 2011; Schwinn and Markl, 2005). In this respect, there is a clear distinction between fluorites from Sn-W mineralisation and samples from the Mesozoic polymetallic veins. Our data underline the contrasting chemical and structural characteristics of fluorite from the two mineralisation types. For the Erzgebirge these differences are also constrained by chemical studies on fluid inclusions (Klemm, 1994) and Sr and Nd isotope investigations (Höhndorf et al., 1994).

There is not only a clear distinction between samples from the two mineralisation types but also a variability in chemical composition and structure (expressed in color and in CL characteristics) within each mineralisation group and at each locality (Fig. 5.5, Fig. 5.9, EA5.2; cf. Kempe et al., 2002). For example, the high Th contents in the brownish fluorite sample (SD1001) from Sadisdorf and in the rose fluorite from an early cassiterite-bearing tourmaline veinlet at Ehrenfriedersdorf (ED 268) reflect the high Th activity at the early stages of evolution in tin-bearing hydrothermal systems (Morozov et al., 1996). The REE distribution pattern of the latter sample with depletion of light REE (including Sm), enrichment of heavy REE, and a small positive or no Eu anomaly is also typical of early fluorites from such deposits (Gavrilenko et al., 1997). Similarly, the high U content in fluorite from Lauta (Fig. 5.9) may be related to remobilization of $U$ during vein formation, which is also mirrored by the occurrence of pitchblende in the paragenesis. Finally, there is an intra-sample variability in composition and defect structure as demonstrated by $\mathrm{CL}$ imaging and spectroscopy (Fig. 5.4) but also by variations in chemical composition of single fragments derived from one individual crystal (Fig. 5.9). Structural variability and heterogeneity may influence FHe dating as will be discussed in more detail below.

\subsection{Intra-sample FHe age distributions}

The number of aliquots analyzed from the mining localities ranges between 19 and 54, but typically exceeds 30 (Tab. 5.1), thus these data sets allow one statistical treatment. Only some samples pass the chi-square normality test, while in case of the Lauta and Dörfel data the fitting to lognormal distribution is fair. In some other sample sets (e.g. Frohnau and Ehrenfriedersdorf) even a bimodal character with extremely old single-fragment aliquot ages from 250 to $300 \mathrm{Ma}$ is possible (Fig. 5.7). Rejection of the few ages older than $200 \mathrm{Ma}$ for Frohnau and Ehrenfriedersdorf let the remaining data sets pass the normality test.

The possible biasing factors that contribute to the considerable spread of single-fragment FHe ages are the following:

\section{(i) Initial (non-radiogenic) helium}

During the formation of the fluorite crystals the ore-bearing fluids may carry high amount of radiogenic noble gases ( $\mathrm{Ar}$ and $\mathrm{He}$ ). This gas may be trapped in fluid inclusions as "parentless" or "excess" helium (e.g. Fitzgerald et al., 2006). The only way to reduce their possible contribution is the careful selection of fluid inclusion free aliquots. Working in alcohol immersion the achievable optical resolution is around $1 \mu \mathrm{m}$. As the selected crystal fragments did not contain any visible fluid inclusions further the SEM investigations did not show sub-micrometer sized inclusions. Thus we assume that the contribution of "parentless" He from fluids is negligible.

\section{(ii) Actinide- and Sm-rich refractory inclusions}

If refractory mineral inclusions carry alpha-emitting elements and these minerals are not dissolved by the routine fluorite digestion techniques then we have deficit of mother elements and the calculated ages became biased towards older ages. We observed rarely tiny inclusions close to optical resolution of the research microscope, but their high actinide content could not be approved by in-situ analytical tests (SEM, EMPA and LA-ICP-MS). The majority of the aliquots did not contain any visible inclusion 38 
and did not yield increased amounts of helium at the sequential reheating. Consequently, although unlikely, this source of bias cannot be excluded completely.

\section{(iii) Zonation, heterogeneity}

The alpha-particle, ejected during radioactive decay, has a stopping distance of 13 to $14 \mu \mathrm{m}$ in the fluorite lattice. This implies, that the concentration of alpha-emitting elements and the accumulation of helium are not necessarily consistent at micro-scale. The $\mathrm{CL}$-mappings indicate that fragments with a typical size of 100 to $400 \mu \mathrm{m}$ that we used for dating may contain He or actinide anomalies. Therefore, the zoned character of the crystals definitely contributes to the scatter in the singlefragment ages. This is supported by the fact that the FHe ages of the samples having definite U-Th-Sm ratios (Fig. 5.9a) yield lower relative standard deviations of the single-fragment age distributions than the samples with highly variable U-Th-Sm ratios (Fig. 5.9b): $38 \%$ and $50 \%$, respectively.

\section{(iv) Variation in He diffusivity}

From former studies (Evans et al., 2005; Pi et al., 2005) and own preliminary laboratory experiments it appears that the closure temperature of fluorite is highly variable. We assume that the observed variability in chemical composition and defect structures and densities causes significant intra-crystal variation of diffusivity. If so, different domains in a given fluorite crystal may have different closure temperatures and single-fragment ages are thus influenced by variable helium loss resulting in the large age scatter observed in the data. This point is of principle importance for FHe thermochronology and will be discussed in more detail in a forthcoming paper.

\section{(v) Analytical uncertainty}

The precision of $\mathrm{He}, \mathrm{U}$, Th and Sm measurements can be estimated by repeated measurement of certified reference materials. In case of our fluorite fragments, the amounts of actinides and $\mathrm{Sm}$ are considerably less compared to the routinely dated apatite and zircon crystals. The masses of these elements were typically below $1 \mathrm{ng}$, often close to the detection limit as mirrored by the high relative standard error values (see Table EA5.2). This is a consequence of the single-fragment approach. By increasing the dated mass of fluorites by multi-fragment technique, the analytical uncertainty would be probably reduced.

From the biasing factors listed above, only the analytical uncertainty can be estimated numerically. A quantitative estimation of the contributions from the other four factors is not feasible. Due to the typically asymmetric character of the single-aliquot FHe age distributions we prefer to express the averages by using locality-medians as detailed in the following discussion. The right-hand asymmetry of the distributions has no diagnostic meaning in this approach. The He and radioactive element measurements have assumable Gaussian error distributions; their division (alike the age equation) results in a lognormal-like distribution with the long tail towards older ages. The other biasing factors (i) to (iv) are usually also positively skewed and they are superimposed on the analytical uncertainty resulting in the total errors.

\subsection{Geological meaning of fluorite (U-Th-Sm)/He ages}

In general, low-temperature thermochronology like fission track and (U-Th-Sm)/He methods yield ages that can be classified into three categories following the approach of Wagner (1972):

(i) If the mineral experienced rapid cooling immediately after its formation, then the undisturbed thermochronometer accumulates the products of radioactive decay and the measured age expresses a formation age. This scenario is typical for volcanic rocks. However, low-T thermochronology of 
5. The age of the latest thermal overprint of tin and polymetallic deposits in the Erzgebirge, Germany: constraints from fluorite (U-Th-Sm)/He thermochronology

hydrothermal mineralisation may also yield formation ages when the ore body experienced rapid cooling and was not influenced by a later thermal overprint.

(ii) If the mineral experienced long-lasting cooling after formation (or after a high-T event that caused complete reset), then the radioactive decay products disappear from the mineral until the system finally cools below the closure temperature of the given thermochronometer. Such cooling ages are typical for metamorphic units and the age provides a datum, when the sample passed the temperature range of the so-called partial annealing zone (nuclear tracks) or partial retention zone (Hethermochronology).

(iii) Complex thermal histories result in mixed ages when one or more thermal events cause only partial loss of decay products. This is characteristic for slightly (re-)heated formations, for instance, shallow burial in sedimentary basins or host bodies of hydrothermal deposits, when the temperature and the effective heating time of the hydrothermal activity were not sufficient for total reset. In this case, measured ages are younger than the formation age, but they do not express the age of any particular distinct cooling event.

Despite the high variability in mineral paragenesis, chemical composition, real structure, internal textures and formation age of the fluorite samples, there is an overall consistence in the single fragment age distributions for six of the seven studied localities. The first step in the evaluation of our FHe ages is the comparison of the low-T age constraints to the known formation ages. In case of fluorites from Sn-W mineralisations, the formation ages are certainly late Variscan, ca. $325 \mathrm{Ma}$ or 300 Ma, according to Romer et al. (2007; 2010a) or Kempe et al. (2004), respectively. The locality medians of the FHe ages, however, are mainly Cretaceous (112 to $79 \mathrm{Ma}$ ). Only the Sadisdorf site yields an older, Triassic age (234 Ma), but this age is also significantly younger than Variscan. Therefore, an interpretation of the FHe ages from the late Variscan Sn-W deposits as formation ages must be rejected.

In case of fluorites from the younger, polymetallic mineralisations the situation is less clear because there are no paragenetic or textural evidences on their formation ages. Furthermore, the isotope geochronometers used in former studies indicate a wide spread of - frequently mixed - ages (see Fig. 5.2a). Thus, the formation age of the veins is hardly known. The fluid inclusion data indicate that the minimum formation temperature of fluorite in Mesozoic mineralisations of the central Erzgebirge including Lauta and Ehrenfriedersdorf was in the range between 200 and $320^{\circ} \mathrm{C}$ (Jung and Meyer, 1991; Seifert et al., 1994; Klemm, 1994). This temperature range can perform nearly complete He reset in probably already existing fluorite crystals when the duration of effective heating time of the hydrothermal activity exceeds ca. 500 years (estimated according to Arehart et al., 2003). This is a conservative estimate for the time span of the activity of a fluid mobilization system (e.g. Goldfarb et al., 1991; Yardley and Cleverley, 2013). This implies that the FHe ages determined on "fba" deposits should be interpreted as cooling ages.

The interpretation of the median FHe ages from six localities as Cretaceous cooling ages is further supported by some recent literature data from the region. Siebel et al. (2010) studied the thermal history in the intracontinental Danube fault zone near Regensburg, Germany, located to the SW of the Erzgebirge, by a multi-chronology approach. Few FHe ages obtained from fluorite samples of the Kittenrain fluorite vein deposit spread around 130 to $110 \mathrm{Ma}$ and were interpreted as result of partial reset of the isotope system during reactivation of the Danubian Fault during the Cretaceous while the fluorite mineralisation is interpreted to be late Variscan in accordance with the late Variscan age of the primary pitchblende formation in the region. We note here the analogy to the late Variscan age and remobilization of $U$ mineralisation in the Erzgebirge region. 
$\mathrm{CL}$ imaging reveals alteration textures in the fluorite crystals, which points to secondary processes at elevated temperatures. If the latest, fluorite-generating hydrothermal phase is close to the time of the thermal climax of the main mineralisation period then the FHe age practically reflects the age of the ore forming process. Recently, Ostendorf et al. (2014) performed direct age determination on the Mesozoic polymetallic, "fba" mineralisation at Freiberg, Germany using the Rb-Sr isochron method on sphalerite. The reported age of $113 \pm 4 \mathrm{Ma}$ is in accordance with or slightly predates our Cretaceous FHe ages on the Mesozoic mineralisations elsewhere in the Erzgebirge region (Tab. 5.1). Thus, the interpretation of Cretaceous FHe ages as formation ages cannot be rejected completely. Moreover, the FHe ages suggest that the Mesozoic thermal event terminated before latest Cretaceous, i.e. at around $80 \mathrm{Ma}$. Whether this thermal event is caused by hydrothermal activity has to remain unsettled in this case. A later Tertiary overprint is not recognized by the FHe method. This result is consistent with observations from apatite (U-Th)/He data (Wolff et al., 2015b).

The four Sadisdorf fluorite samples gave consistent and considerably older (U-Th-Sm)/He ages than those from the other mining districts (Tab. 5.1). The Triassic FHe age can be interpreted in two ways. The first option is that this deposit experienced shallow post-Variscan burial and was only weakly affected by the Mesozoic thermal events. Thus it experienced minor rejuvenation from the original late Variscan age due to the weaker Mesozoic overprint. Alternatively, we can assume that the overprint is uniform in the region, but this fluorite has anomalous helium diffusivity behavior with higher closure temperature resulting in only minor helium loss during the Mesozoic thermal event. In any case, as we cannot assign a well-defined Triassic tectono-thermal event to this site, this age is interpreted as a mixed age.

The oldest single-fragment ages of the likely bimodal data sets from Frohnau and Ehrenfriedersdorf (three fragments with FHe ages between 241 and 297 Ma; see Fig. 5.8 and Electronic Appendix) raise the question whether the fluorites of the tin and polymetallic ore deposits have kept some memory of their formation in late Variscan times. This would be possible when low He diffusivity in some crystal domains have kept the old age information despite some Mesozoic thermal overprint. These old FHe ages are in accordance with the formation age of the $\mathrm{Sn}-\mathrm{W}$ mineralisation in the western Erzgebirge constrained earlier by the zircon U-Pb method (Kempe et al., 2004). Such interpretation of the few older ages would also support a formation of at least a part of the polymetallic ore mineralisation already in late Variscan times, probably shortly after the Sn-W deposits.

\subsection{Relations to other, well-established thermochronometers}

The range of the defined median FHe ages corresponds well to the apatite (U-Th-Sm)/He (AHe) ages from the same ore districts (Fig. 5.2b, c and Fig. 5.8; Wolff et al., 2015b). In the central block of the Erzgebirge, between the Gera-Jachymov fault and the Flöha fault, as well as in the Zinnwald district, the apparent FHe ages and the apparent AHe ages are largely similar. Only the FHe ages from Sadisdorf samples are significantly older than the corresponding AHe ages (see discussion above). However, the AHe ages show a heterogeneous distribution in the study area (Fig. 5.8; Wolff et al., 2015b). The data has been interpreted to reflect three major tectonic blocks with different thermal histories. Following the exhumation to near-surface position after the Variscan orogeny the Erzgebirge basement suffered a Permo-Mesozoic burial temperature reaching ca. 80 to $100^{\circ} \mathrm{C}$ while the sedimentary cover thins out towards north. The tectonic blocks are locally superposed by hydrothermal activity along well defined pathways corresponding to the known vein deposits (Wolff et al., 2015b). This pattern suggests a localized character of thermal anomalies that preferentially culminates in the ore districts. The resulting time-temperature conditions have caused a total reset of large parts of fluorite in most of the fluorite-bearing ore districts but possibly only a partial reset of the fluorite sample from the Sadisdorf deposit. Likely, the Erzgebirge did not suffer a single overall penetrative heating event. 
5. The age of the latest thermal overprint of tin and polymetallic deposits in the Erzgebirge, Germany: constraints from fluorite (U-Th-Sm)/He thermochronology

The closure temperature of the FHe system was estimated at $200^{\circ} \mathrm{C}$ and $60^{\circ} \mathrm{C}$ (Evans et al., 2005; Pi et al., 2005). Ongoing experiments point to the lower end of this closure temperature range for the fluorites analyzed herein. Even though these closure temperatures are still to be verified, it is noticeable that our new FHe age data not only overlap with the previously published AHe ages (Fig. $5.2 \mathrm{c}$ and Fig. 5.8) but also with the youngest hydrothermally reset zircon He ages in the Erzgebirge (ca. 134 to $112 \mathrm{Ma}$; Wolff et al., 2015b). This as well suggests a closure temperature for the fluorite system just within the range reported, below the zircon He system (ca. $180{ }^{\circ} \mathrm{C}$ to $160^{\circ} \mathrm{C}$, Reiners et al., 2002) and similar to or slightly higher than the apatite system (ca. $80^{\circ} \mathrm{C}$ to $60^{\circ} \mathrm{C}$ Farley, 2000).

\subsection{Modelling of the thermal history by FHe age data}

A measured FHe age, like any (U-Th-Sm)/He age is the result of a thermal evolution path, where the radiogenic helium production and the temperature driven diffusional loss of helium (e.g. McDougall and Harrison, 1988). The concept of closure temperature (Dodson, 1973) describes the accumulation of daughter isotopes and the evolution of the age when the geological formation is cooling monotonously. However, the description of complex thermal histories requires a more dynamic evaluation procedure that considers the known constraints of the regional thermal evolution and also the kinetic parameters of the dated mineral-method pair. Typically, apatite and zircon FT and (U-Th$\mathrm{Sm}) / \mathrm{He}$ thermochronological data supply the major input for the modelling of the low-T thermal history. In our study, the modelling is based -for the first time- on fluorite He-ages and diffusion parameters.

For modelling of the thermal history, the HeFTy software (Ketcham, 2005) was used. Data from two characteristic mining sites from the central and eastern Erzgebirge were selected for this evaluation (Ehrenfriedersdorf and Zinnwald, respectively). Beyond FHe data, apatite fission track ages and track length distributions were available for Ehrenfriedersdorf, while for Zinnwald a wider temperature range was covered by zircon and apatite (U-Th-Sm)/He and apatite fission track data (samples A6 and D4, respectively; see Wolff et al., 2015b). The helium diffusion parameters for fluorite have been estimated to be $E_{a}=33 \mathrm{kcal} / \mathrm{mol}$ and $\log D_{0} / \mathrm{a}^{2}=4.0 \mathrm{~s}^{-1}$ according to our preliminary measurements. These values are in accordance with the published values of $E_{a}=30.5 \mathrm{kcal} / \mathrm{mol}$ and $\log D_{0} / \mathrm{a}^{2}=4.9 \mathrm{~s}^{-1}$ (Evans et al., 2005). The resulting time-temperature paths are covered by envelopes and presented in Fig. 5.10. 


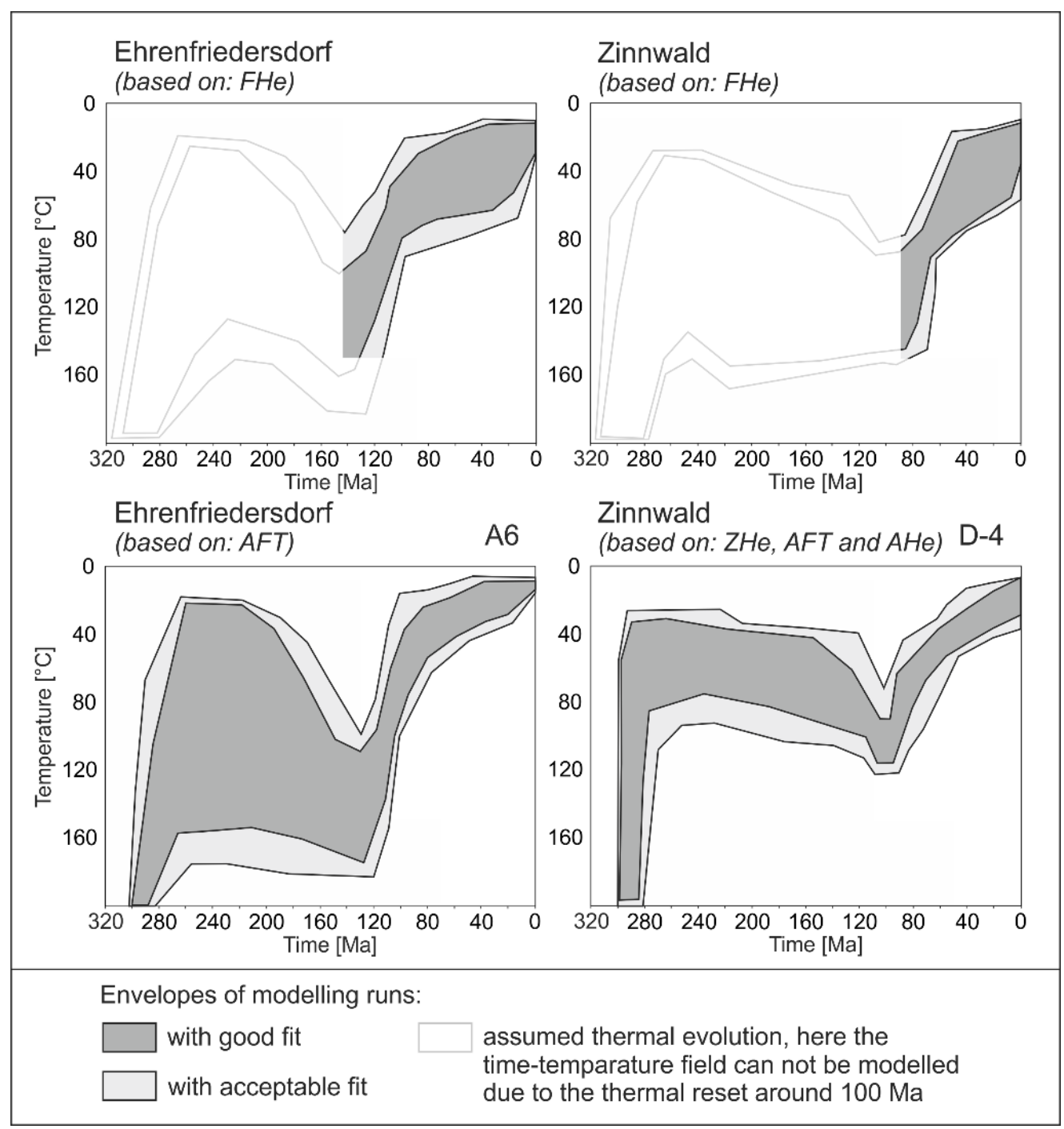

Fig. 5.10: Comparison of modeled thermal history based on the classical, widely used low-T thermochronometers (lower panels; Wolff et al., 2015b) and the new, fluorite (U-Th-Sm)/He -based modelling results (upper panels). For modelling, the HeFTy software (Ketcham, 2005) was used; the applied diffusion parameters are explained in the text. The constraints of the modelling were identical for apatite and zircon and for the fluorite-based modelling runs. Envelopes of the acceptable time-temperature paths (corresponding to 'goodness of fit' >0.05) shown by light grey fields and the envelopes of the 'good fits' (GOF >0.5) by dark grey fields. The pre-Cretaceous thermal history cannot be properly constrained by FHe chronometer.

Results indicate that the thermal histories calculated from the fluorite (U-Th-Sm)/He data (Fig. 5.10, top) are pretty similar to those calculated using well-established apatite (+ zircon) data (Fig. 5.10, bottom). The apatite and zircon-based modelling yields a slightly narrower range of acceptable timetemperature envelopes compared to solely FHe-based modelling. This is to be expected and relates to the fact that the AFT data are associated with track length measurements that supply more parameters to constrain the thermochronological modelling. We conclude that thermal modelling of the fluorite (U-Th-Sm)/He data using HeFTy software and diffusion parameters determined on the dated fluorite crystals reveals geologically meaningful thermal histories that are largely similar to those derived by other thermochronological data. 
5. The age of the latest thermal overprint of tin and polymetallic deposits in the Erzgebirge, Germany: constraints from fluorite (U-Th-Sm)/He thermochronology

\subsection{Methodological Outlook}

In order to evaluate the applicability of the FHe method, a conservative approach has been chosen by analyzing single-fragment aliquots. In this way, we aimed to detect the limits of the applicability of the method. Our approach allows one an evaluation of the effects of zonation and sample heterogeneity. A more steady and pragmatic approach for further studies would be the analysis of multi-fragment aliquots. This has been simulated by an $\mathrm{n}$-fold validation, randomly creating multi-fragment aliquots from the single-fragment data. Using 5-fragment aliquots the standard errors calculated for the localities are reduced significantly from the range of 16 to $5 \mathrm{Ma}$ to a range between 2.9 and $0.8 \mathrm{Ma}$ (see comparison in Tab. 5.2). These much narrower confidence intervals are largely similar to the typical error range of other low-T geochronological methods, and the multi-fragment technique would make fluorite (U-Th-Sm)/He thermochronology suitable for routine applications. On the other hand, the chemical variability as an indicator of the heterogeneity and zonation of the dated minerals gained by the single-fragments analyses is lost using the multi-fragment aliquot technique.

\begin{tabular}{|c|c|c|c|c|c|c|c|c|c|c|c|c|c|c|}
\hline & A. Dörfl & s.d. & A. Frohnau & s.d. & Efd. & s.d. & Horni Krupka & s.d. & Lauta & s.d. & Zinnwald & s.d. & Sadisdorf & s.d. \\
\hline & {$[\mathrm{Ma}]$} & {$[\mathrm{Ma}]$} & {$[\mathrm{Ma}]$} & {$[\mathrm{Ma}]$} & {$[\mathrm{Ma}]$} & {$[\mathrm{Ma}]$} & {$[\mathrm{Ma}]$} & {$[\mathrm{Ma}]$} & {$[\mathrm{Ma}]$} & {$[\mathrm{Ma}]$} & {$[\mathrm{Ma}]$} & {$[\mathrm{Ma}]$} & {$[\mathrm{Ma}]$} & {$[\mathrm{Ma}]$} \\
\hline 1st random selection & 114 & 1.2 & 78 & 1.3 & 105 & 1.2 & 68 & 1.7 & 127 & 1.2 & 107 & 1.3 & 241 & 1.1 \\
\hline 2 nd repetition & 115 & 1.2 & 89 & 1.2 & 111 & 1.1 & 79 & 1.4 & 126 & 1.3 & 112 & 1.2 & 241 & 1.1 \\
\hline 3rd repetition & 117 & 1.3 & 86 & 1.4 & 112 & 1.2 & 73 & 1.2 & 111 & 1.3 & 100 & 1.1 & 248 & 1.1 \\
\hline 4th repetition & 117 & 1.2 & 80 & 1.3 & 106 & 1.3 & 76 & 1.3 & 127 & 1.3 & 103 & 1.1 & 239 & 1.0 \\
\hline 5th repetition & 117 & 1.2 & 81 & 1.4 & 106 & 1.2 & 73 & 1.2 & 127 & 1.2 & 103 & 1.2 & 232 & 1.2 \\
\hline 6th repetition & 112 & 1.3 & 96 & 1.3 & 108 & 1.1 & 70 & 1.1 & 115 & 1.2 & 107 & 1.2 & 249 & 1.1 \\
\hline \multicolumn{15}{|c|}{ Descriptive statistics of multi-fragment aliquot ages } \\
\hline mean & 115.3 & & 85.0 & & 108.0 & & 73.2 & & 122.2 & & 105.3 & & 241.7 & \\
\hline s.d. & 2.1 & & 6.8 & & 2.9 & & 4.0 & & 7.2 & & 4.2 & & 6.3 & \\
\hline s.e. & 0.8 & & 2.8 & & 1.2 & & 1.6 & & 2.9 & & 1.7 & & 2.6 & \\
\hline \multicolumn{15}{|c|}{ Descriptive statistics of single-fragment aliquot ages } \\
\hline mean & 116.6 & & 90.2 & & 113.1 & & 70.5 & & 122.3 & & 104.9 & & 239.4 & \\
\hline s.e. & 8.1 & & 9.6 & & 5.1 & & 7.4 & & 9.9 & & 6.8 & & 10.6 & \\
\hline
\end{tabular}

Tab. 5.2: Table of simulated $n$-fold validation, randomly creating multi-fragment aliquots from the singlefragment data.

\section{Conclusions}

1) The fluorite (U-Th-Sm)/He method is well-suited for ore deposits and hydrothermally altered regions where the well-established apatite-based low-T thermochronometers cannot be applied due to the high solubility of apatite in acid environments.

2) Modelling of FHe thermochronological data using diffusion parameters determined on the dated fluorite samples yields geologically meaningful thermal histories similar to results based on other wellestablished thermochronological methods.

3) The closure temperature range (or partial retention zone) of the FHe thermochronometer of chemically non-extreme fluorite (i.e. REE $+Y<3000 \mathrm{ppm}$ ) appears to be similar or somewhat higher compared to the He closure temperature in apatite and lower than the (U-Th-Sm)/He closure temperature in zircon. However, further studies on the diffusion behavior of He in fluorite are needed.

4) FHe data from six mining districts of the Erzgebirge indicate that the thermal activity in the studied area terminated before latest Cretaceous. A later, Tertiary thermal overprint is not recognized.

5) The Cretaceous thermal event was not able to reset the FHe thermochronometer all over the entire Erzgebirge as indicated by mixed ages for the Sadisdorf tin deposit.

6) The oldest FHe ages measured in few aliquots might indicate that some polymetallic vein deposits in the Erzgebirge were generated already in late Variscan time. 


\section{Electronic Appendix}

EA5.1: Details of the trace element analyses obtained on fluorite single-fragments by solution ICP-MS technique using external calibration (REE+Y chondrite normalized after Sun and McDonough, 1989).

EA5.2: Details of the (U-Th-Sm)/He analyses sorted by locations. Rad. d.: radiation density. Amount of helium is given in nano-cubic-cm in standard temperature and pressure. Amount of radioactive elements are given in nanograms. Uncertainties of helium and the radioactive element contents are given as 1 sigma, in relative error $\%$. Uncertainty of the sample average age is 1 standard error, as $(S D) /(n) 1 / 2 ;$ where $S D=$ standard deviation of the age replicates and $n=$ number of age determinations.

\section{Acknowledgments}

This study was funded by the German Research Foundation (DFG grant DU373/6). We gratefully acknowledge the donation of mineral species by the mineral collection of the Technical University Bergakadamie Freiberg and the Mining Museum of Altenberg. We are indebted to Irina Ottenbacher and Judit Dunkl-Nagy for the careful mineral separation and for the He measurements, and to the Central Metal Workshop of the Geoscience Center Göttingen for maintenance of the GÖochronology Laboratory. We further thank Raimon Tolosana-Delgado for his valuable support in discrimination analysis and R. Romer for critical comments on an earlier version of the manuscript. The reviewers Wolfgang Siebel and Feri Molnar greatly helped to improve the paper. 


\section{Variable helium diffusion characteristics in fluorite}

The following article contains the results of the major part of the laboratory diffusion experiments. It yields the core of my thesis by combining the diffusion analysis with the empirical case study. It is published 2016 in Geochimica et Cosmochimica Acta, 188, 21-34, Doi: 10.1016/j.gca.2016.05.029

License Number for reuse permission: 3883560041032

Wolff, R. ${ }^{1,2}$, Dunkl, I. ${ }^{1}$, Kempe, U. ${ }^{3}$, Stockli, D. ${ }^{4}$, Wiedenbeck, M. ${ }^{5}$, and von Eynatten, H. ${ }^{1}$

${ }^{1}$ University of Göttingen, Geoscience Center, Sedimentology and Environmental Geology, Goldschmidtstr. 3, 37077 Göttingen, Germany

${ }^{2}$ Current Adress: University of Münster, Geology and Palaentology, Corrensstr. 24, 48149 Münster, Germany

${ }^{3} \mathrm{TU}$ Bergakademie Freiberg, Institut für Mineralogie, Freiberg, Germany

${ }^{4}$ The University of Texas at Austin, Department of Geological Sciences, Austin, USA

${ }^{5}$ Helmholtz-Zentrum Potsdam Deutsches GeoForschungsZentrum, Potsdam, Germany

Corresponding author: Reinhard Wolff, rwolff@uni-muenster.de, +491795022260

Keywords: fluorite, helium, diffusion, thermochronology 


\section{Abstract}

Precise analysis of the diffusion characteristics of helium in fluorite is crucial for establishing the new fluorite (U-Th-Sm)/He thermochronometer ( $\mathrm{FHe}$ ), which potentially provides a powerful tool for dating ore deposits unsuitable for the application of conventional geochronometers. Incremental helium outgassing experiments performed on fluorites derived from a spectrum of geological environments suggest a thermally activated volume diffusion mechanism. The diffusion behaviour is highly variable and the parameters range between $\log D_{0} / a^{2}=0.30 \pm 0.27$ to $7.27 \pm 0.46 \mathrm{~s}^{-1}$ and $E_{a}=96 \pm 3.5$ to $182 \pm$ $3.8 \mathrm{~kJ} / \mathrm{mol}$. Despite the fact that the $\mathrm{CaF}_{2}$ content of natural fluorites in most cases exceeds 99 weight percent, the closure temperature $\left(T_{c}\right)$ of the fluorite $(\mathrm{U}-\mathrm{Th}-\mathrm{Sm}) / \mathrm{He}$ thermochronometer as calculated from these diffusion parameters varies between $46 \pm 14{ }^{\circ} \mathrm{C}$ and $169 \pm 9{ }^{\circ} \mathrm{C}$, considering a $125 \mu \mathrm{m}$ fragment size. Here we establish that minor substitutions of calcium by rare earth elements and yttrium (REE $+\mathrm{Y}$ ) and related charge compensation by sodium, fluorine, oxygen and/or vacancies in the fluorite crystal lattice have a significant impact on the diffusivity of helium in the mineral. With increasing REE $+Y$ concentrations $F$ vacancies are reduced and key diffusion pathways are narrowed. Consequently, a higher closure temperature is to be expected. An empirical case study confirms this variability: two fluorite samples from the same deposit (Horni Krupka, Czech Republic) with $c a .170{ }^{\circ} \mathrm{C}$ and $c a .43{ }^{\circ} \mathrm{C} \mathrm{T}_{c}$ yield highly different (U-Th-Sm)/He ages of $290 \pm 10 \mathrm{Ma}$ and $79 \pm 10 \mathrm{Ma}$, respectively. Accordingly, the fluorite sample with the high $\mathrm{T}_{c}$ could have quantitatively retained helium since the formation of the fluorite-bearing ores in the Permian, despite subsequent Mesozoic burial and associated regional hydrothermal heating. In contrast, the fluorite with the low $T_{c}$ yields a Late Cretaceous age close to the apatite fission track (AFT) and apatite (U-Th)/He ages (AHe) from the same locality. Remarkably, thermal modelling of FHe yields comparable results to the well-established modelling based on AFT and AHe.

\section{Introduction}

(U-Th-Sm)/He thermochronology of accessory minerals like apatite and zircon can provide excellent constraints on low-temperature thermal histories. However, the use of this method is limited to rocks that contain these minerals. Especially in some ore deposits (e.g. greisens) apatite is often rare or lacking due to the typically low $\mathrm{pH}$ of the ore-bearing fluids. In contrast, fluorite is a common constituent in high- to low-temperature hydrothermal veins, in granites, pegmatites, carbonatites and alkaline intrusives, in stratabound deposits and in the cement of some clastic sediment. In particular, hydrothermal veins occur in a wide variety of geological settings, but such veins are often not well suited for apatite and zircon-based geochronology. The need to date the formation age of such ore deposits led to the development of isotopic techniques for fluorite geochronology using $\mathrm{Sm} / \mathrm{Nd}$ (Chesley, Halliday and Scrivener, 1991; Chesley et al., 1994; Gigoux et al., 2015), and U-Th-Pb (Hofstra et al., 2000). Fluorite (U-Th-Sm)/He (FHe) thermochronology was introduced by Evans et al. (2005) and applied by Pi et al. (2005) and Siebel et al. (2009). A comprehensive dataset of FHe ages measured on samples from several ore deposits of the Erzgebirge (Germany/Czech Republic) along with FHe-based thermal modelling yielded constraints on the thermal history compatible with results from wellestablished thermochronometers such as apatite fission track and apatite (U-Th)/He (Wolff et al., 2015a ; Wolff et al., 2015b).

The parameters controlling helium diffusion in fluorite, and thus the closure temperatures $\left(T_{c}\right)$, are still under debate. Evans et al. (2005) published helium diffusion data on 200 - $350 \mu \mathrm{m}$ diameter fragments of colourless fluorite. These measurements were accomplished by stepwise degassing between $215^{\circ} \mathrm{C}$ and $335{ }^{\circ} \mathrm{C}$. These authors suggested that volume diffusion is the dominant mechanism by which helium is released from fluorite. The observed deviation in the Arrhenius plot from linearity at higher 
temperatures was attributed to grain size effects, shape variability and/or defect/radiation damage density. The linear segment of their data yields an $E_{a}=127.6 \mathrm{~kJ} / \mathrm{mol}$ and $\log D_{0} / \mathrm{a}^{2}=4.9 \pm 0.6 \mathrm{~s}^{-1}$ (at linearity of $\left.R^{2}=0.9984\right)$. These results correspond to a $T_{c}$ of $60^{\circ} \mathrm{C} \pm 5{ }^{\circ} \mathrm{C}$. In contrast, Peter W. Reiners' diffusion experiments (published in Pi et al., 2005) indicated a fluorite $T_{c}$ of $200{ }^{\circ} \mathrm{C}$. According to the empirical case study of Wolff et al. (2015a) the fluorite helium $T_{c}$ is in the range of the thermal sensitivities of $\mathrm{ZHe}$ and $\mathrm{AHe}$ thermochronometers.

All of the above listed diffusion experiments are based on only very few data sets and the chemical composition of the studied specimens or other crystallographic characteristics were not reported. Yet, fluorite is famous for its broad variety in colour which results mainly from radioactive irradiation and the degree of substitution of calcium and fluorine in the crystal lattice, leading Evans et al. (2005) to suggest that variations in mineral colours may correlate with the diffusion characteristics of fluorite. However, the relation between colour and real structure (i.e. substitution of formula elements, vacancies, etc.) remains ambiguous (e.g. Dill and Weber, 2010). In order to shed light on this situation, we performed a detailed study on helium diffusion in fluorite using highly diverse samples derived from a variety of geological settings with variable genesis, precipitation temperatures, colours, habits and REE distribution patterns. The associated differences in $T_{c}$ were constrained in a case study where distinct $\mathrm{FHe}$ ages from natural fluorites from one deposit with differing $\mathrm{T}_{\mathrm{c}}$ could be compared.

\section{Sample selection}

Using the (U-Th-Sm)/He method, we have dated over 660 fluorite crystal aliquots from 112 samples originating from 58 localities (Wolff et al., 2015a). Sample selection for diffusion experiments was based on this data set because proper test material needs to be homogeneous, free of inclusions, and should contain sufficient helium to allow multi-step degassing experiments. Decrepitation experiments were performed on 7 samples, whereas diffusion experiments were performed on 34 aliquots from 14 samples (Tab. 6.1). Beyond 'near stoichiometric' fluorites, we performed diffusion experiments on samples with unusual compositions including Y-rich fluorite (sample K2), brownish, thorium-rich fluorite (SD1001), "black" (dark pink), stink-fluorite (RW-5-11), and sodium-and REE-rich green fluorite (HK13). Most of the samples were characterized in detail in earlier studies, e.g. fluorites from tin and polymetallic deposits in the Erzgebirge (Zinnwald, Horni Krupka, Sadisdorf, and Lauta; see Kempe et al., (2002); Wolff et al. (2015a)), from Usakos, Namibia (Bühn et al., 2002; 2003), from the giant Bedeposit Ermakovka, Transbaikalia (Kempe and Götze, 2002), and from the W-deposit of Kyzyltau, Mongolian Altai (Kempe and Belyatsky, 2000). Samples from inaccessible mining sites in the Erzgebirge could be obtained from the mineral collection of the Technische Universität Berkakademie Freiberg. 


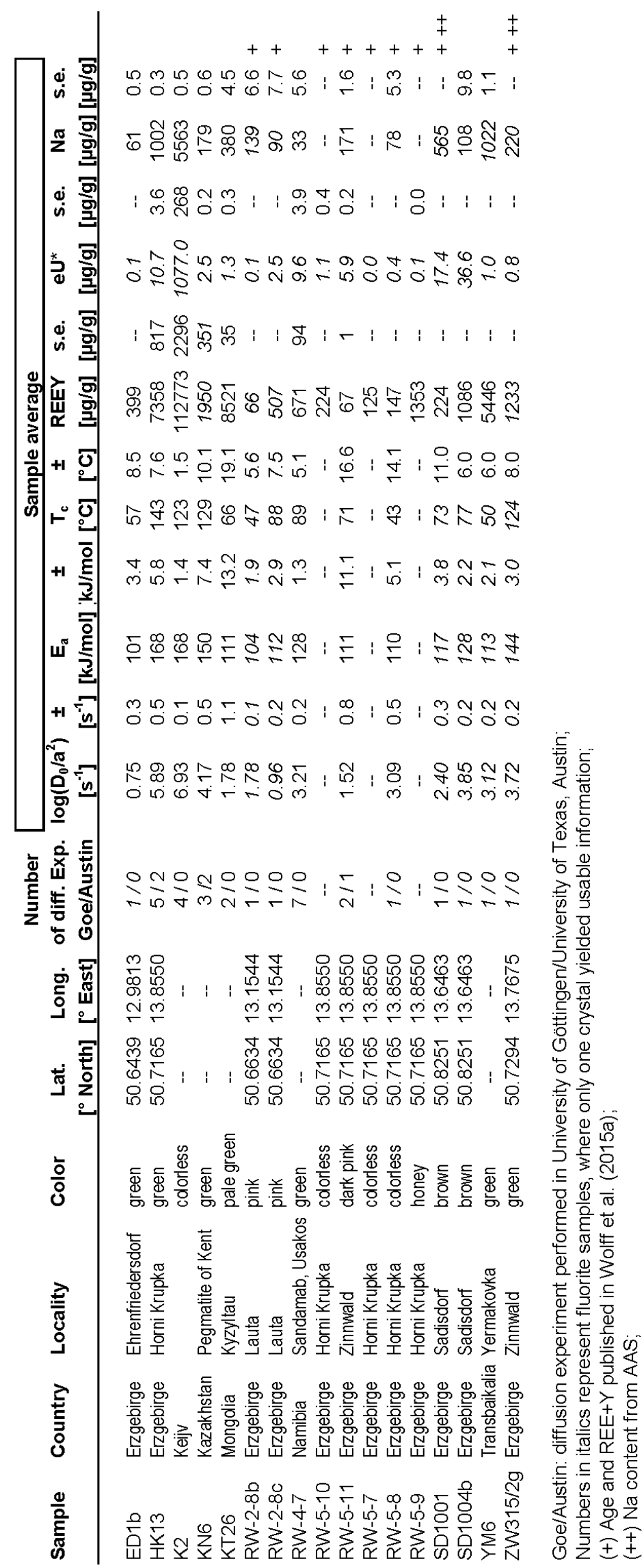

Tab. 6.1: Synopsis of locality, colour, number of analysed crystals, diffusivities, activation energies, closure temperatures, $R E E+Y$ content, effective $U$ content (e $U^{*}$, see text for explanation), and sodium content of the studied fluorite samples. 


\section{Methods}

\subsection{Mineral chemistry}

The concentrations of 27 cations were determined on same aliquots previously used for diffusion experiments and age dating. The dissolved fluorite aliquots were analysed using externally calibrated solution ICP-MS analyses (see data in Electronic Appendix EA6.1). The chemical composition was determined on inclusion free crystal fragments of $c a .13$ to $338 \mu \mathrm{g}$ (average $72 \mu \mathrm{g}$ ). The sensitivity and resolution of this technique is between classical wet chemical analyses performed on powdered samples consisting of several hundred $\mathrm{mg}$ and the laser ablation technique that consumes less volume, but has considerably higher uncertainty. Additionally, the laser ablation method is typically not viable for fluorite because of the low adsorption of UV light in the mineral, frequent fragmentation and small explosions that occur during ablation.

We also investigated whether variations in trace levels of anions might influence He diffusion rates in fluorite. The CAMECA 1280-HR instrument at the Helmholtz-Zentrum Potsdam was used to establish variations in the $\mathrm{C}, \mathrm{O}, \mathrm{P}, \mathrm{S}$ and $\mathrm{Cl}$ contents of six samples with variable $\mathrm{REE}, \mathrm{Y}$, and $\mathrm{Na}$ composition. Due to the lack of a suitable fluorite reference material, it was only possible to determine the relative abundances of these anionic species between the samples and the inter- and intra-crystalline variability of their concentrations within a single sample. By normalizing to the observed ${ }^{19} \mathrm{~F}^{-}$count rate, our method was able to establish the relative concentrations of these trace elements over a range exceeding $10^{5}$. The spot size diameter for a single analysis was roughly $10 \mu \mathrm{m}$ with a total sampling mass in the low nano-gram range (for analytical parameters see EA6.2).

\subsection{Cathodoluminescence spectra}

A JEOL JSM 7001F scanning electron microscope (SEM) with a thermal field emission electron gun equipped with a GATAN MiniCL detector was used for $C L$ imaging. The SEM was operated at $20 \mathrm{kV}$ and $0.6 \mathrm{nA}$. CL spectra were obtained by means of a system consisting of a GATAN MonoCL 4 mirror, an optical fibre guide and a Princeton Instruments Acton SP 2300 monochromator equipped with a PIXIS $256 \mathrm{CCD}$. The SEM was operated at $20 \mathrm{kV}$ and $1 \mathrm{nA}$ with a defocused beam when taking spectra.

\subsection{Helium diffusion experiments}

The outer surface of euhedral crystals or crystal fragments was stained, and the samples were carefully crushed. Only intact, inclusion-free shards derived from the interior of the crystals were selected. The maximum stopping distance of alpha particles is estimated as $14.2 \mu \mathrm{m}$ by NUDAT $2.6(7 / 14 / 2014)$ data base and ranges calculated by the software programs ASTAR and SRIM (Ziegler et al., 2010; see EA6.3). Both size and shape parameters of the crystal fragments were determined by multiple microphotographs. The average fragment size used for diffusion experiments was between 100 and $400 \mu \mathrm{m}$ and the radius value used for calculation of diffusion parameters refers to the maximum insphere dimension that can be constructed based on such photographs.

The step heating experiments were performed in two laboratories (University of Göttingen/Germany and Jackson School of Geoscience, University of Texas in Austin/USA) using slightly different instruments and degassing schedules. In both laboratories the helium diffusion experiments were based on the stepwise degassing apparatus of Farley et al. (1999). The single- and multi-fragment aliquots were placed in $c a .1 \times 1 \mathrm{~mm}$-sized platinum capsules prior to stepwise degassing under high vacuum.

In the Göttingen laboratory, the heating was performed by PID-controlled low voltage gold covered halogen lamps. The steps were chosen for the samples individually considering the former dating experiments in order to provide convenient amounts of He through the entire degassing procedure. 
The samples were held at the respective heating temperature reached between the single steps to avoid thermal stress of the crystals and reduce the thermal hysteresis. The temperature was raised from 280 to $520^{\circ} \mathrm{C}$ in $20^{\circ} \mathrm{C}$ steps for most samples (EA6.4). Beforehand, seven samples were studied in decrepitation experiments (for experimental details see EA6.5 and Burlinson, 1991) in order to assign the temperature range where diffusion experiments can be performed without significant fragmentation and subsequent change of the diffusion domain size of the fluorite crystals. As intense decrepitation initiates at $c a .300{ }^{\circ} \mathrm{C}$ (EA6.5), the starting temperature for diffusion experiments was chosen to be as low as 150 to $280^{\circ} \mathrm{C}$. Accordingly, the first diffusion steps should be unaffected by decrepitation that might change the size of the diffusion domain. However, at higher temperatures it possibly overlaps with diffusion experiments. Interestingly, at temperatures where the decrepitation events reach a maximum, in some cases (e.g. sample K2) the diffusion experiments showed minor deviations from linear behaviour. Even though there are uncertainties, e.g. the shorter temperature holding time and not using high vacuum, the experiments emphasize the importance of careful selection of inclusion-free fluorite fragments and of checking the integrity of the crystals after the diffusion experiments to minimize the possible influence of helium liberated from fluid inclusions.

Temperature cycling experiments had been used to investigate whether complex heating schedules yield comparable results to the method using monotonic increasing temperature steps. Therefore, a decrease and increase in $40{ }^{\circ} \mathrm{C}$ steps for two hours after the first sequence was chosen (for detailed heating schedule see EA6.4). The extracted gas was purified and analysed as described in Section 4.5, below (see also Wolff et al., 2015a). Following the stepwise degassing, the Pt capsules were totally degassed by reheating with an infrared diode laser. Subsequent dissolution, spiking and actinide measurements were identical to the procedure applied for the (U-Th-Sm)/He dated crystals (Wolff et al., 2015a; see below).

In the Austin laboratory, total cooling was applied between the heating steps while the extracted gas was purified in a cryo-trap (see also Stockli and Farley, 2004). At least two heating cycles between 150 ${ }^{\circ} \mathrm{C}$ and $550^{\circ} \mathrm{C}$ in $10^{\circ} \mathrm{C}$ steps were performed at all samples. The purified gas was analysed by a Pfeiffer mass spectrometer. The actinide and $\mathrm{Sm}$ contents of the dissolved $\left(\mathrm{HCl}\right.$ and $\left.\mathrm{HNO}_{3}\right)$ and spiked solution were measured with an Element 2 mass spectrometer.

Diffusion parameters $E_{a}$ and $D_{0} / a 2$ were calculated using the equations $5 a-c$ of Fechtig and Kalbitzer (1966). If this diffusion process is exponentially activated by temperature the overall temperature dependence can be described by a linear Arrhenius relationship:

$$
D=D_{0} \exp \left(-\frac{E_{a}}{R T}\right)
$$

Hereby, $T$ is the temperature, $E_{a}$ the activation energy in the sense of Arrhenius, and $D_{0}$ the diffusivity at infinite high temperatures (frequency factor) (Eq. 6.1). The $T_{c}$ has been calculated after Dodson (1973) with the assumption of a spherical geometry and $10^{\circ} \mathrm{C} / \mathrm{Ma}$ cooling rate. For regression and uncertainties Monte Carlo inversion has been applied using the Matlab code of Goldsmith and Stockli (version 2, available on request at DS, for further details see EA6.6).

\subsection{Fluorite (U-Th-Sm)/He thermochronology}

The fluorite $(\mathrm{U}-\mathrm{Th}-\mathrm{Sm}) / \mathrm{He}$ method is based on the He accumulation from the radioactive decay of ${ }^{147} \mathrm{Sm}$ as well as that which accumulates from the ${ }^{238} \mathrm{U},{ }^{235} \mathrm{U}$ and ${ }^{232} \mathrm{Th}$ decay chains. The alpha-ejection correction (Farley, Wolf and Silver, 1996) was not applied, because fragments from the outer surface of the crystals had been excluded from the analyses. We dated only single-fragment aliquots; the crystal fragments were wrapped in ca. 1×1 mm-sized platinum capsules and totally degassed in high vacuum by heating with an infrared diode laser. The extracted gas was spiked with ${ }^{3} \mathrm{He}$ and purified 
using a SAES Ti-Zr getter at $450^{\circ} \mathrm{C}$. The chemically inert noble gases and a minor amount of other trace gases were then expanded into a Hiden triple-filter quadrupole mass spectrometer equipped with an ion counting detector. Crystals were checked for degassing of helium by sequential reheating and helium measurement. We assume that the loss of the actinide elements during the thermal treatment was negligible. Due to their high atomic masses the diffusion of $U$ and Th is even slower than it was determined for REEs by Cherniak et al. (2001). Following degassing, samples were retrieved from the gas extraction line, the crystals were removed from Pt capsules and spiked with calibrated ${ }^{230} \mathrm{Th}$ and ${ }^{233} \mathrm{U}$ solutions. The fluorites were then dissolved in open Savillex Teflon ${ }^{\circledR}$ vials using ultrapure $30 \% \mathrm{HCl}$ at $75^{\circ} \mathrm{C}$ for 24 hours (until totally dry). The dissolution process was monitored by a stereo microscope and the last step was repeated until total digestion was achieved. The digested samples were taken up in $4 \% \mathrm{HCl}$ and the solutions were analysed using a Perkin Elmer Elan DRC II ICP-MS equipped with an APEX micro-flow nebulizer. The actinide concentrations were determined by isotope dilution and the $\mathrm{Sm}$ and other elements by external calibration. The typical uncertainties of the actinide measurements range between 1.4 and $2.3 \%$ and for the externally calibrated elements between 4 and $5 \%$. The level of detection (LoD) was between 1 and $2 \mathrm{pg}$, slightly variable in the different ICP-MS sessions.

\section{Results}

A synopsis of the results of the experiments is given in Tab. 6.1. The details of the diffusion experiments and calculations, the fluorite (U-Th-Sm)/He data, and the cation and anion concentrations are presented in the Electronic Appendices 6.1-6.7.

\subsection{Chemical composition of the fluorite samples}

\subsubsection{Cations}

The most abundant cations in fluorite have been monitored in our study (details in EA6.1). The sum of rare earth elements and yttrium ( $R E E+Y)$ contents of the 34 fluorite aliquots commonly range between $66 \pm 1$ and 8,782 $\pm 73 \mu \mathrm{g} / \mathrm{g}$ (RW-2-8b, HK13). However, one extreme Y-rich fluorite sample with an average of $112,773 \pm 2297 \mu \mathrm{g} / \mathrm{g} \mathrm{REE}+\mathrm{Y}$ has also been analysed (K2). This sample has the least internal variation in chemical composition. Sodium contents range from $33 \pm 6$ to $5563 \pm 0.5 \mu \mathrm{g} / \mathrm{g}$ for samples RW-4-7 and K2, respectively.

\subsubsection{Anions}

The relative concentrations of the anions C, O, F, P, S and Cl were analysed in seven samples (EA6.2) by SIMS (results are listed in EA6.7). By normalizing the observed count rates to that of ${ }^{19} \mathrm{~F}^{-}$(from $3.0^{*} 10^{8}$ to $5.7^{*} 10^{8}$ counts per second), the variations of the other anions could be established. The ${ }^{16} \mathrm{O}$ $/{ }^{19} \mathrm{~F}^{-}$ratio is at least two orders of magnitude higher than the other anion/F- ratios. The ${ }^{35} \mathrm{Cl}^{-} /{ }^{19} \mathrm{~F}^{-}$vs. ${ }^{16} \mathrm{O}^{-} /{ }^{19} \mathrm{~F}^{-}$ratios from the seven fluorite samples show distinct clusters (Fig. 6.1). 


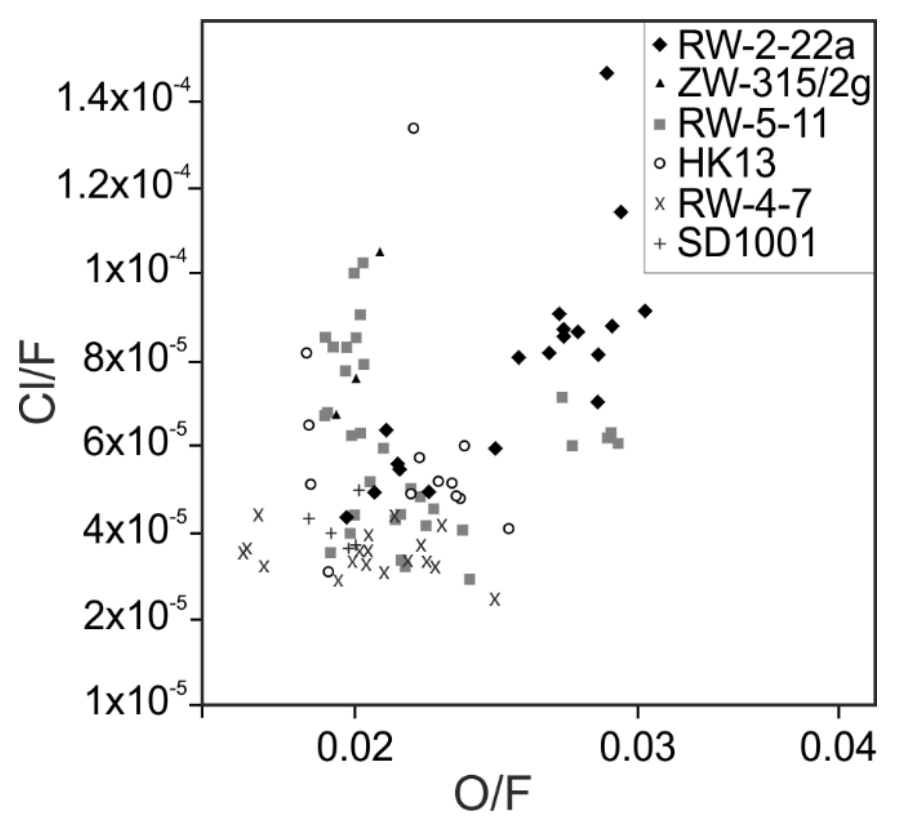

Fig. 6.1: Ratio of O/F versus CI/F (ion counting ratios not corrected for variation in ion yields) indicate cluster of internally more homogeneous fluorite samples (e.g. SD-1001, RW-4-7) and heterogeneous samples, measured by SIMS.

\subsection{The alpha-emitting elements in fluorites}

The 34 analysed fluorite aliquots contain between 0.007 and $57 \mu \mathrm{g} / \mathrm{g} \mathrm{U}, 0.05$ and $5563 \mu \mathrm{g} / \mathrm{g}$ Th, and 0.3 and $1101 \mu \mathrm{g} / \mathrm{g} \mathrm{Sm}$. The averages are $8 \mu \mathrm{g} / \mathrm{g} \mathrm{U}, 745 \mu \mathrm{g} / \mathrm{g}$ Th and $221 \mu \mathrm{g} / \mathrm{g} \mathrm{Sm}$. It was suggested earlier that, because $U$ cannot be easily incorporated in the fluorite structure, only $\mathrm{Th}^{4+}$ and $\mathrm{Sm}^{2+} / \mathrm{Sm}^{3+}$ readily substitute for $\mathrm{Ca}^{2+}$ (Kempe et al., 1994). Accordingly, Th and Sm are the main contributors to the total radiogenic He production in most cases (Fig. 6.2). In this study, we use a parameter $\mathrm{eU}^{*}$ instead of the commonly used effective $\mathrm{U}$ content $(\mathrm{eU}=\mathrm{U} \mu \mathrm{g} / \mathrm{g}+0.253 * \mathrm{Th} \mu \mathrm{g} / \mathrm{g})$. The new parameter also takes into account the contribution from Sm $\left(\mathrm{eU}^{*}=\mathrm{U} \mu \mathrm{g} / \mathrm{g}+0.253 * \mathrm{Th} \mu \mathrm{g} / \mathrm{g}+0.005 * \mathrm{Sm} \mu \mathrm{g} / \mathrm{g}\right)$. In the samples used for diffusion experiments, the eU* ranged between 1 and $1367 \mu \mathrm{g} / \mathrm{g}$. Remarkably, samples K2, KN6 and RW-4-7 show very homogeneous internal distributions of the radioactive elements. In samples RW-5-11, RW-2-8b, $c$ and YM6, $U$ contributes significantly to the total radiogenic $\mathrm{He} . \mathrm{Sm}$ is the main source of the radiogenic He only in samples KT26 and YM6. 

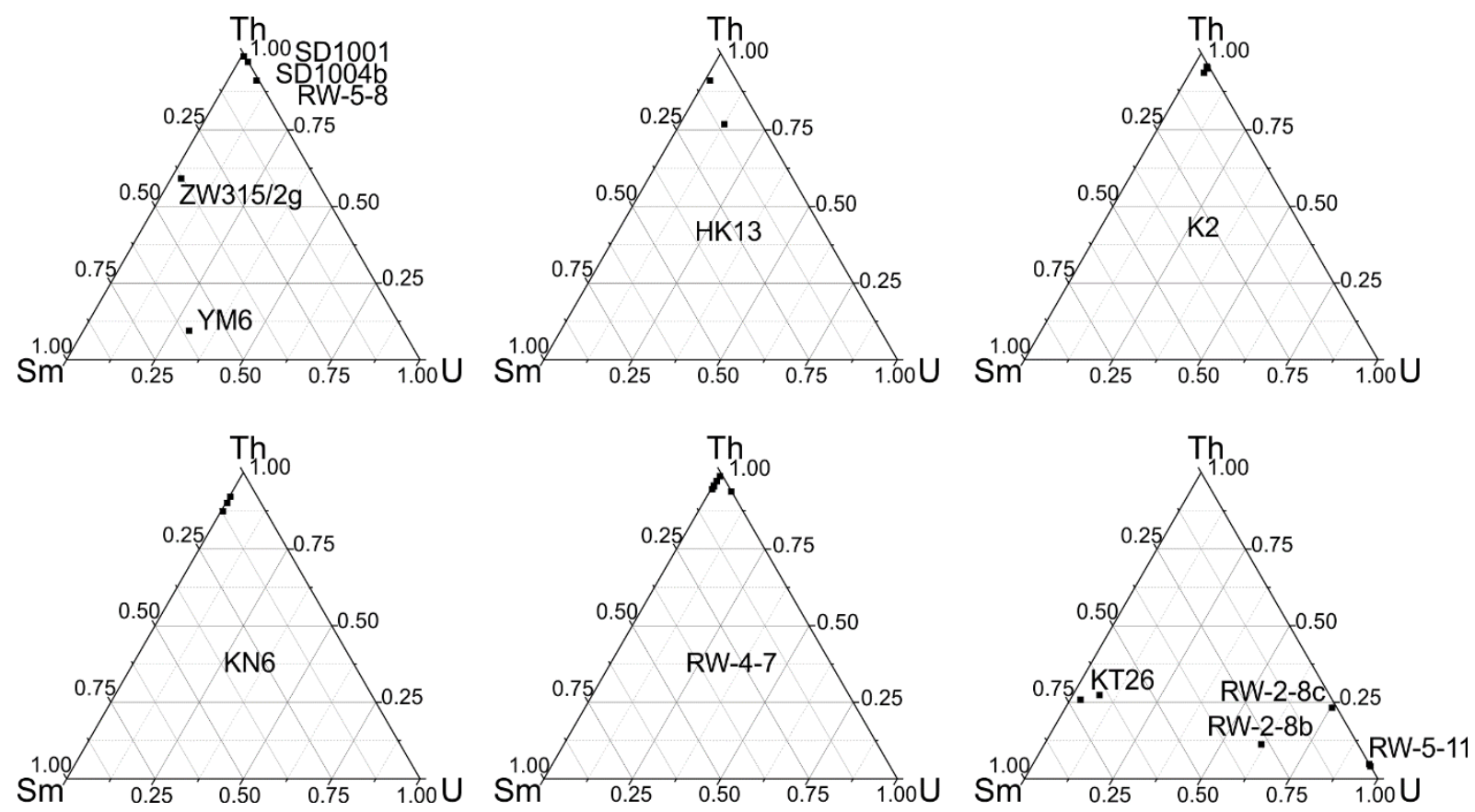

Fig. 6.2: The contributions of the three alpha-emitting elements to the total radiogenic helium budget of the analysed fluorites reveal those samples with dominant Th contribution. The homogeneous actinide content of the samples can be well identified.

\subsubsection{Cathodoluminescence}

Two fluorite samples RW-5-11 and RW-4-7 were additionally analysed by cathodoluminescence (CL) imaging and spectroscopy (Fig. 6.3) to establish their internal textures and characteristics of the related defect structures (Kempe and Götze, 2002). Most other samples used in this study have been previously characterized by the same methods (Kempe et al., 2002; Wolff et al., 2015a) including RW2-22c, RW-2-8c, RW-5-11, HK13, ED1b, K2, KN6, KT26, SD1001, SD1004b, YM6, and ZW315/2g. Here we highlight results from key samples that are relevant to the discussion of diffusion characteristics. Kempe et al. (2002) described patchy secondary alteration replacing primary growth zoning for green fluorite in sample ZW315/2g. This fluorite sometimes included brownish fluorite and is rimed by pink Fluorite ZW315/2g. Sample SD1001 represents rare Th-rich, brownish fluorite. CL imaging revealed the occurrence of a microbreccia, interpreted to be related to the formation of a breccia pipe within the Sadisdorf tin deposit. The sample RW-5-11 shows complex textures with broken crystals in the interior, growth zoning in the outer regions and fibrous textures in pink zones (Fig. 6.3). RW-4-7 is more homogeneous and shows frequent pinkish zoning. 


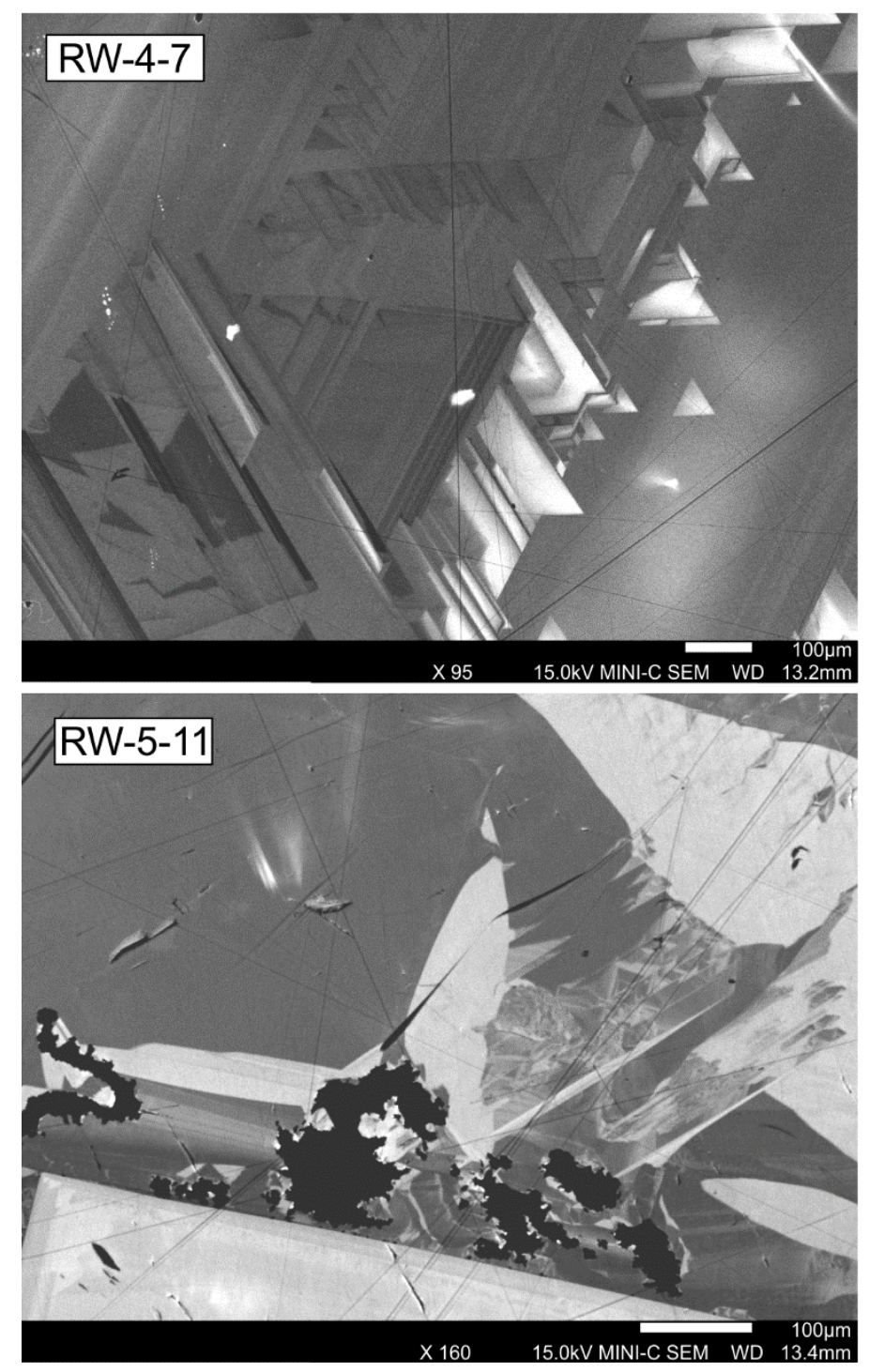

Fig. 6.3: SEM-CL images of fluorite: (upper) CL image of fluorite sample RW-4-7 (Namibia) with homogeneous patterns and skeletal zonation (lower) CL image of fluorite sample RW-5-11 (Zinnwald, Erzgebirge) with complex textures with broken crystals and primary zoning.

\subsection{Diffusion behaviour}

The results of the 34 diffusion experiments are presented as Arrhenius plots in Figures 6.4-6.7 (for details see EA6.6) and as calculated diffusion parameters in Tab. 6.1. For diffusion experiments mainly green fluorites were chosen because such fluorites are usually richer in Th and Sm than samples having other colours, and consequently sufficient helium for the multi-step degassing. However, pink, colourless, brown and dark pinkish-black fluorite samples were also studied by diffusion experiments (Tab. 6.1). The analysed aliquots contained from 0.8 to $5102 \mathrm{ncc}$ [nano-cubic centimetres, equivalent to $10^{3} \mathrm{\mu m}^{3}$ ] helium; in the diffusion experiments between 11.8 and 99.8 vol\% of the total helium was released, in most cases more than $75 \%$ (EA6.4). In order to calculate diffusion parameters, a linear segment on the Arrhenius plot needs to be identified (e.g. McDougall and Harrison, 1988). The first isothermal steps were, in most cases, disregarded as they released unreasonably high amounts of helium. Such inconsistent results during the first fractional release steps (typically less than $2.5 \%$ of the total released $\mathrm{He}$ ) is probably related to surface roughness and irregularities as described by Farley (2000). Subsequent heating steps of the first monotonic heating sequence (bold in EA6.4) revealed a 
strong linear relationship between $\ln \mathrm{D}_{0} / \mathrm{a}^{2}$ and inverse temperature with an $\mathrm{R}^{2}$ between 0.947 and 0.999 on 34 to 2 degrees of freedom with an average of 8 (Figs. 6.4-6.7). The higher temperature steps were only rejected when they clearly deviated from the linear segment, resulting in a decreasing in the coefficient of determination $\left(R^{2}\right)$ by 0.004 (regular in EA6.4). The calculated helium diffusion parameters of fluorites from the linear segments yielded a range of log $D_{0} / a^{2}=0.30 \pm 0.27$ to $7.27 \pm$ $0.46 \mathrm{~s}^{-1}$. The corresponding activation energy ranges between $E_{a}=96 \pm 3.5$ to $182 \pm 3.8 \mathrm{~kJ} / \mathrm{mol}$ (EA6.6). This corresponds to a range in $\mathrm{T}_{\mathrm{c}}$ from $43 \pm 14{ }^{\circ} \mathrm{C}$ to $170 \pm 9{ }^{\circ} \mathrm{C}$ (assuming a $10^{\circ} \mathrm{C} / \mathrm{Ma}$ cooling rate and sphere geometry). The second and, if performed, the third heating cycles yielded linear segments that commonly overlapped in the Arrhenius plot with the first.

Samples HK13 and K2 yielded the highest average log $D_{0} / \mathrm{a}^{2}$ with $6.6 \pm 0.35$ and $7.1 \pm 0.37 \mathrm{~s}^{-1}$, respectively. The lowest log $D_{0} / a^{2}$ values were $0.30 \pm 0.27$ and $0.97 \pm 0.22 \mathrm{~s}^{-1}$ for samples $R W-5-11$ and RW-2-8c, respectively. Sample HK13 also has the highest average activation energy of $169 \pm 13 \mathrm{~kJ} / \mathrm{mol}$, whereas the lowest recorded average value was $104 \pm 1.90 \mathrm{~kJ} / \mathrm{mol}$ for sample RW-2-8b. There is no indication for a simple correlation between diffusion characteristics and sample colouration despite a tendency to low activation energies in pink samples. The coloration was held widely constant for a single sample by carful separation in cases when there is visible variation in the original specimen.

\section{4. (U-Th-Sm)/He dating of a selected, complex locality}

To verify the variations in $T_{c}$, an empirical case study was performed on fluorite samples from the Krupka tin deposit, Krušne Horí, Czech Republic. Thirteen aliquots of sample HK13 yielded a mean age of $290 \mathrm{Ma} \pm 10 \mathrm{Ma}$ (EA6.7). The Th/U ratio of this sample varied between 23 and 34 and the average measured REE+Y content is $5277 \pm 516 \mu \mathrm{g} / \mathrm{g}$. The maximum eU* is $19 \mu \mathrm{g} / \mathrm{g}$. From the same locality another sample was also studied that has a significantly lower REE+Y content of $c a .130 \pm 28 \mu \mathrm{g} / \mathrm{g}$. Nineteen fluorite aliquots of this fluorite yielded a mean (U-Th-Sm)/He age of $79 \mathrm{Ma} \pm 10 \mathrm{Ma}$ (Wolff et al., 2015a).

\section{Discussion}

First we will discuss both the Arrhenius plots of our data in general and the diffusion mechanism governing the loss of helium. Thereafter, we will address the reproducibility of the diffusion measurements and compare the results measured independently in two laboratories. After verifying the robustness of these results we will address the intrinsic factors affecting helium diffusion in fluorite, including diffusion domain size, radiation damage, and the chemical composition of the crystals.

\subsection{Evaluation of laboratory diffusion data}

\subsubsection{Linearity in Arrhenius plots supports isotropic volume diffusion}

In the simplest and isotropic case - which should be expected in a first approximation for fluorite due to its cubic crystal lattice symmetry - helium would move through a crystal only by volume diffusion governed by a single, thermally activated process. Under such conditions, the temperature dependence of diffusivity can be characterized by a single activation energy and a single diffusivity value for an infinitely high temperature. If these conditions apply then bulk diffusion experiments over a given temperature range will yield a straight line on an Arrhenius plot. However, in more complicated cases such as anisotropy, multiple diffusion domains or fast diffusion pathways, the Arrhenius relation will not result in a straight line but instead in more complex patterns (e.g. changes in slope or curves; 
Reiners et al., 2002). The most important feature of our data is the obvious linear Arrhenius behaviour of all fluorites in the analysed temperature range from 150 to $550^{\circ} \mathrm{C}$ (Figs. 6.4-6.7). Only one sample, $\mathrm{K} 2$, shows a very minor change in slope towards higher temperatures (Fig. 6.4).

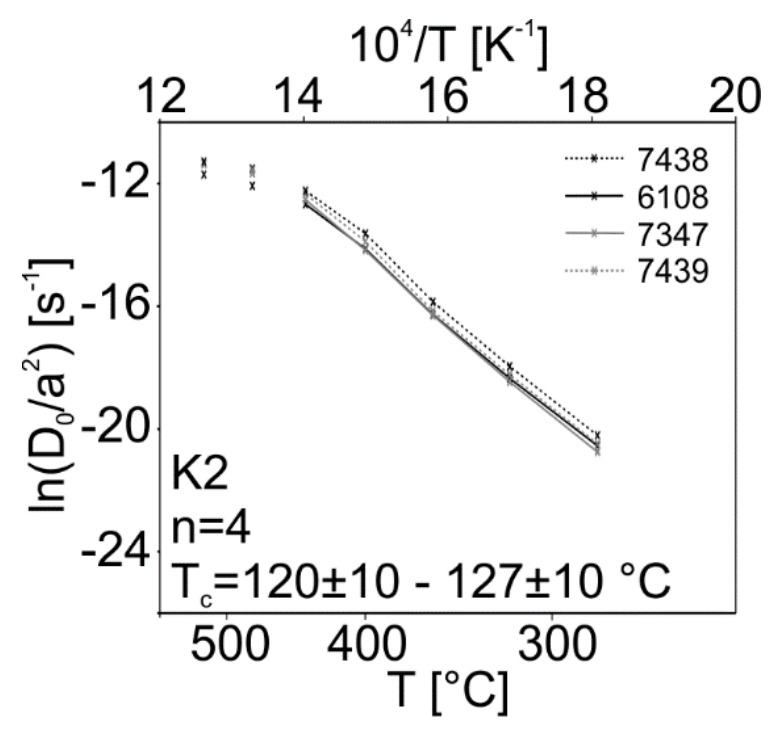

Fig. 6.4: Arrhenius plot of step-heating experiment of $K 2$ fluorite sample (two high temperature steps are rejected due to their deviation from linear trend, for details see discussion). The consistency of the diffusion results from differing aliquots of this sample demonstrates both the homogeneity of the material and the robustness of the experimental setup.

Such a change in slope at higher temperatures has been observed by Evans et al. (2005) in the case of fluorite, too, and might be indicative of insufficient mineral integrity, e.g. grain size effect, shape variability, and annealing effects of irradiation damage. We conclude that annealing might be the case here because $\mathrm{K} 2$ has received the highest radioactive dose (ca. $8.6^{*} 10^{18}$ alpha decay event/gram; see discussion below). In the interpretation of the diffusion data from sample $\mathrm{K} 2$ the two corresponding values showing this change in slope have been disregarded (Fig. 6.4). As the behaviour of all other samples supports the single activation energy assumption, yielding excellent correlations $\left(R^{2}>0.947\right)$, there is very strong evidence that only a single, isotropic diffusion mechanism may be regarded responsible for the diffusional loss of $\mathrm{He}$ in fluorite, namely thermally activated volume diffusion. Besides, because of the cubic crystal symmetry it is unlikely assuming anisotropic diffusion.

\subsubsection{Complex heating schedules confirm the robustness of results}

For 17 samples (marked in the last column in EA6.6 and details in EA6.4), after the initial stepwise degassing using a monotonic heating sequence, we performed one or more additional heating cycles by repeatedly reducing and increasing temperatures (Farley, 2000). The prograde heating steps of these extended temperature cycling experiments yielded indistinguishable diffusion parameters from the monotonic heating experiments (e.g. Figs. 6.5-6.7, EA6.4). The retrograde steps resulted in slightly more scatter, but we did not observe systematic deviation from the prograde steps. This observation form the prograde steps confirms that He diffusivity is independent of the cumulative fraction of gas released and the chosen heating schedules. Furthermore, it indicates that there was no phase transformation or fragmentation of the crystals during the initial degassing experiments. These findings, together with the observed strongly linear behaviour $\left(R^{2}>0.947\right)$, excludes a multi-diffusion domain (MDD) model (Lovera et al., 1989), which explains the deviation from a linear Arrhenius trend by a non-homogeneous population of diffusion domain sizes. The remaining 17 samples of our set were only step-heated to a temperature of $550^{\circ} \mathrm{C}$ once, because by then the fluorite samples lost most 
of their He. Hence, a subsequent cooling and temperature cycling was not possible for these samples, which may have introduced a certain bias in our dataset. However, this bias in the dataset cannot be significant, as samples degassed by single and multiple heating cycles allow to draw the same conclusion. Applying more heating cycles by using proton induced ${ }^{3} \mathrm{He}$ would offer the means of improving such diffusion experiments in the future (e.g. Shuster and Farley, 2003; Tripathy-Lang et al., 2015).

\subsubsection{Repeated measurements and the reliability of diffusion experiments}

In order to obtain information about analytical reproducibility, from five samples between 2 and 7 aliquots were measured in the Göttingen laboratory. Four aliquots of sample K2 yielded the least variation: $E_{a}=164 \pm 4.3$ to $170 \pm 4.4 \mathrm{~kJ} / \mathrm{mol}$ and $\log D_{0} / \mathrm{a}^{2} 6.6 \pm 0.35$ to $7.1 \pm 0.37 \mathrm{~s}^{-1}$ corresponding to a $T_{c}$ of $120 \pm 10$ to $127 \pm 10{ }^{\circ} \mathrm{C}$ (Tab. 2; Fig. 6.4). We interpret these consistent results as the consequence of the chemical and defect homogeneity of the $\mathrm{K} 2$ sample as revealed by our cation analyses (EA6.1) and CL studies. The broader spread in parameters observed between aliquots from the other samples is governed mostly by chemical-crystallographical heterogeneities. Thus, we can estimate the reproducibility of the laboratory diffusion experiments from the spread of the results yielded by the most homogeneous sample. Following this approach the method reproducibility would be approximately $\pm 6 \mathrm{~kJ} / \mathrm{mol}$ for $E_{a}, \pm 0.5 \mathrm{~s}^{-1}$ for $\log D_{0} / a^{2}$, and $\pm 7^{\circ} \mathrm{C}$ for $T_{c}$.

\begin{tabular}{lc}
\multicolumn{1}{c}{ Sample K2 } & $\mathrm{n}=4$ \\
\hline & \\
$\log \mathrm{D}_{0} / \mathrm{a}^{2}\left[\mathrm{~s}^{-1}\right]$ & $6.6 \pm 0.35-7.1 \pm 0.37$ \\
$\mathrm{E}_{\mathrm{a}}[\mathrm{kJ} / \mathrm{mol}]$ & $164 \pm 4.3-170 \pm 4.4$ \\
$\mathrm{~T}_{\mathrm{c}}\left[{ }^{\circ} \mathrm{C}\right]$ & $120 \pm 10-127 \pm 10$ \\
$\mathrm{REE}+\mathrm{Y}[\mu \mathrm{g} / \mathrm{g}]$ & $109,193 \pm 917-119,515 \pm 1382$
\end{tabular}

Tab. 6.2: The major results of the diffusion experiments and the REE+Y content of sample K2 (the Arrhenius plot is presented in Fig. 6.4).

\subsubsection{Inter-laboratory comparison: accuracy of diffusion experiments}

Samples HK13, KN6 and RW-5-11 were analysed in two laboratories in order to constrain the role of laboratory bias (Fig. 6.6). The diffusion arrays overlap in the Arrhenius plot for sample RW-5-11 and KN6 (Fig. 6.6b, c), however, even though the aliquot sizes are comparable (Austin: $117 \mu \mathrm{m}, 138 \mu \mathrm{m}$ and Göttingen: $119.5 \mu \mathrm{m}, 126 \mu \mathrm{m}$, and $153 \mu \mathrm{m}$ ), the array of the Austin analysis plot systematically below the Göttingen results for sample HK13 (Fig. 6.6a). Comparing the calculated diffusivities and activation energies, both laboratories show wide spreads (Tab. 6.3). In the case of HK13, the $E_{a}$ parameters are in agreement but the diffusivities in the Göttingen laboratory are slightly higher. The $E_{a}$ value determined in the Austin laboratory was lower for RW-5-11 and higher for KN6, relative to those determined in Göttingen. Such variability may be due to the differences in heating schedule protocols. In Göttingen, the sample was held at temperature during the He measurement whereas in Austin, the sample was allowed to cool down between steps. We assume that the latter heating schedule, implying higher temperature variations, generates more thermal expansion and submicroscopic fractures in the crystal. The induced fast paths along with a decrease in diffusion domain size could have increased the overall diffusivity. These different heating strategies might additionally contribute to the observed difference in HK13. However, inter-aliquot heterogeneity, different extraction cell volumes or dissimilar temperature measurement methods cannot be ruled out as possible explanations. The resulting variation between the different laboratories seems to be minor compared to the influence of the heterogeneity of fluorite itself (see next section). We conclude that 
the observed differences in the results are not reliable evidence for inherent systematic biases between the two laboratory set-ups.

\begin{tabular}{lcc}
\multicolumn{1}{c}{ Sample } & Göttingen & Austin \\
\hline HK13: & $\mathbf{n = 3}$ & $\mathbf{n}=\mathbf{2}$ \\
$\log \mathrm{D}_{\mathrm{o}} / \mathrm{a}^{2}\left[\mathrm{~s}^{-1}\right]$ & $5.5 \pm 2.3-7.3 \pm 0.46$ & $4.1 \pm 0.15-6.2 \pm 0.32$ \\
$\mathrm{E}_{\mathrm{a}}[\mathrm{kJ} / \mathrm{mol}]$ & $162 \pm 3.1-181 \pm 6.2$ & $151 \pm 1.9-182 \pm 3.8$ \\
$\mathrm{~T}_{\mathrm{c}}\left[{ }^{\circ} \mathrm{C}\right]$ & $128 \pm 6-148 \pm 14$ & $136 \pm 5-170 \pm 9$ \\
\hline $\mathbf{R W}-\mathbf{5}-\mathbf{1 1}:$ & $\mathbf{n}=\mathbf{2}$ & $\mathbf{n}=\mathbf{1}$ \\
$\log \mathrm{D}_{0} / \mathrm{a}^{2}\left[\mathrm{~s}^{-1}\right]$ & $1.1 \pm 0.19-3.2 \pm 0.26$ & $0.30 \pm 0.27$ \\
$\mathrm{E}_{\mathrm{a}}\left[\mathrm{kJ} / \mathrm{mol}^{\circ}\right.$ & $105 \pm 2.7-133 \pm 3.5$ & $96 \pm 3.5$ \\
$\mathrm{~T}_{\mathrm{c}}\left[{ }^{\circ} \mathrm{C}\right]$ & $62 \pm 7-104 \pm 10$ & $48 \pm 6$ \\
\hline $\mathbf{K N} 6$ & $\mathbf{n}=\mathbf{3}$ & $\mathbf{n}=\mathbf{2}$ \\
$\log \mathrm{D}_{0} / \mathrm{a}^{2}\left[\mathrm{~s}^{-1}\right]$ & $3.09 \pm 0.26-$ & $3.95 \pm 0.54-$ \\
$\mathrm{E}_{\mathrm{a}}[\mathrm{kJ} / \mathrm{mol}]$ & $4.48 \pm 0.31$ & $6.01 \pm 0.63$ \\
$\mathrm{~T}_{\mathrm{c}}\left[{ }^{\circ} \mathrm{C}\right]$ & $930 \pm 2.5-154 \pm 4.2$ & $151 \pm 6.4-173 \pm 7.3$ \\
& $93 \pm 7-136 \pm 11$ & $138 \pm 17-153 \pm 18$
\end{tabular}

Tab. 6.3: The major results of the diffusion experiments of three fluorite samples analysed in two different laboratories (see Arrhenius plots presented in Fig. 6.6).

\subsubsection{Variations of the diffusion parameters in the different fluorite samples}

The total range between the analysed fluorite aliquots is $E_{a}=86 \mathrm{~kJ} / \mathrm{mol}$ and $\log D_{0} / a^{2} 6.13 \mathrm{~s}^{-1}$ corresponding to a $\mathrm{T}_{\mathrm{c}}$ range from 169 to $46{ }^{\circ} \mathrm{C}$ (considering a $125 \mu \mathrm{m}$ fragment size of all studied fluorite, for details see Tab. 6.4). The two samples with the lowest $T_{c}, Y M 6$ and RW-2-8b, show low $E_{a}$ values (113 \pm 2.1 to $104 \pm 1.9 \mathrm{~kJ} / \mathrm{mol}$, Fig. $6.7 \mathrm{~b}$ ). Sample $K T 26$ with a slightly higher $T_{c}$ has also a low $E_{a}$ of $111 \pm 13.2 \mathrm{~kJ} / \mathrm{mol}$ (Fig. 6.7a). The samples with an intermediate $T_{c}$ between 90 and $125^{\circ} \mathrm{C}$ have considerably higher $E_{a}(130$ to $145 \mathrm{~kJ} / \mathrm{mol})$ and also high diffusivities $\left(\log D_{0} / a^{2} 3.27\right.$ to $4.03 \mathrm{~s}^{-1}$, Fig. 6.7c). Samples HK13 and K2 possess the highest diffusivities ( $\log D_{0} / a^{2} 5.59$ to $5.87 \mathrm{~s}^{-1}$ ), and these also yielded the highest $T_{c}$. Such variations in both activation energy and diffusivity between the samples is much larger than the reproducibility of the diffusion measurements conducted on K2 (Fig. 6.4) and the inter-laboratory differences discussed above.

\begin{tabular}{cc} 
& $\mathrm{n}=34$ \\
\hline & \\
$\log \mathrm{D}_{0} / \mathrm{a}^{2}\left[\mathrm{~s}^{-1}\right]$ & $0.30 \pm 0.27-7.27 \pm 0.46$ \\
$E_{\mathrm{a}}[\mathrm{kJ} / \mathrm{mol}]$ & $96 \pm 3.5-182 \pm 3.8$ \\
$\mathrm{~T}_{\mathrm{c}}\left[{ }^{\circ} \mathrm{C}\right]$ & $43 \pm 14-170 \pm 9$ \\
$\mathrm{REE}+\mathrm{Y}[\mu \mathrm{g} / \mathrm{g}]$ & $66 \pm 1.5-$ \\
& $119,514 \pm 1382.4$
\end{tabular}

Tab. 6.4: Summary of the results from the diffusion experiments on the various fluorite samples.

We conclude that our results are robust and that differences in diffusion parameters between different fluorite varieties really exist, and that such differences greatly exceed the uncertainty of our analytical methods. Moreover, the data agree with the previously published range in $T_{c}$ (Evans et al., 2005, Pi et al., 2005). Obviously, helium diffusion in fluorite is variable just as in the case for the well-studied 
phases apatite (e.g. Farley, 2000; Shuster et al., 2006a; Shuster and Farley, 2009) and zircon (e.g. Reiners et al., 2002; Flowers et al., 2009; Gautheron et al., 2009).

\subsection{Possible factors influencing He diffusion}

\subsubsection{Influence of diffusion domain size}

If the diffusion domain (DD) is equal to the physical size of the crystal, then the diffusivity array in the Arrhenius plot shifts down with increasing crystal radius. If the effective DD is much smaller than the crystal, then diffusivity is independent of the dimensions of the crystal (e.g. Farley, 2000). This model can be tested by diffusion experiments performed on aliquots of different fragment sizes taken from the same crystal. If aliquots of different grain sizes plot on the same line in the Arrhenius plot, then the DD is smaller than the physical dimensions of the analysed crystal fragments whereas if they yield different $y$-axis intercepts then the DD is larger than the size of the biggest analysed aliquot. Diffusion parameters were determined on seven multi-fragment aliquots made from sample RW-4-7 with different radii (10-125 $\mu \mathrm{m}$ ). This particular is ideal for such an experiment due to its homogeneity (see $\mathrm{REE}+\mathrm{Y}$ and $\mathrm{CL}$ imaging, Fig. 6.3, upper panel). The results are presented in Fig. 6.5 and show that with increasing crystal radii, diffusivity decreases. The difference in diffusivity for the aliquots is $c a .4 .5 \mathrm{In}$ units in total (Fig. 6.5). This agrees well with the expected difference, which is predicted by $D_{0} / a^{2}$ of $(125 / 10)^{2}=156$. Hence, the diffusion domain is definitely larger than $125 \mu \mathrm{m}$, and it would be reasonable to assume the whole crystal acts as a single domain. Therefore, the $T_{c}$ given in this publication is valid for the analysed fragment sizes and has to be corrected if applied to bigger crystals. For example, the measured $T_{c}$ on a $125 \mu \mathrm{m}$ fragment increases by ca. $60^{\circ} \mathrm{C}$ in the case of a $0.5 \mathrm{~mm}$ mono-crystal, composed of a single diffusion domain.

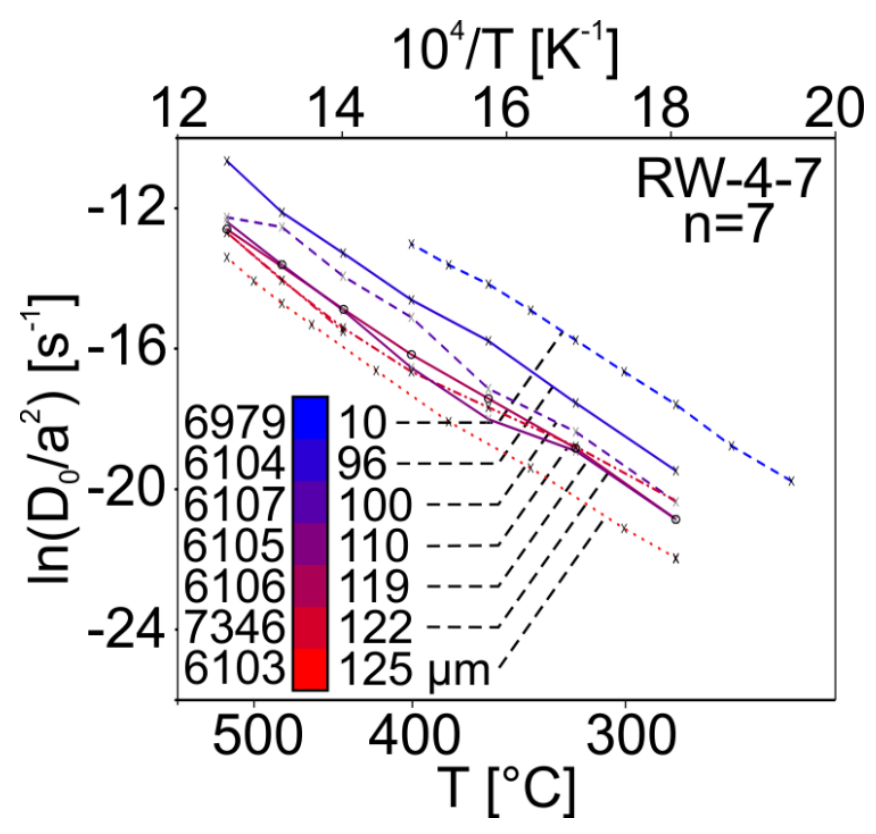

Fig. 6.5: Arrhenius plot of seven aliquots from sample RW-4-7 covering roughly one order of magnitude in grain size (colour scale from small to big, blue to red, respectively). With decreasing crystal size the diffusivity array shifts upwards. This is consistent with a relationship of the diffusion domain size and the grain size. 

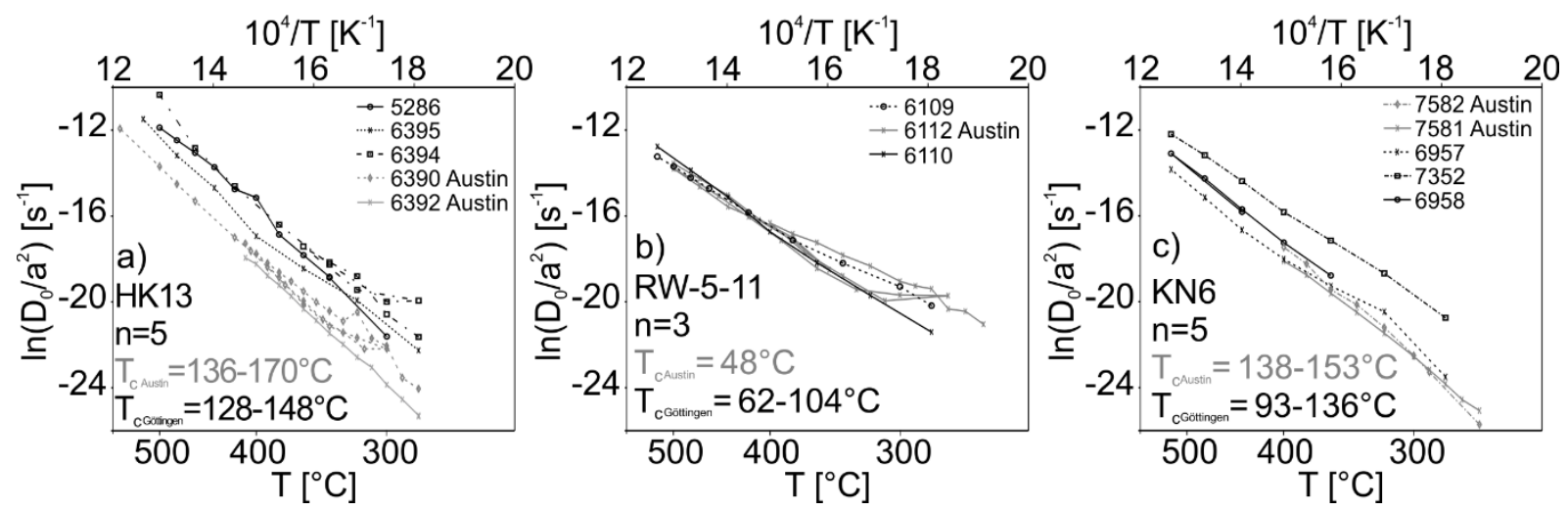

Fig. 6.6: Comparison of the experiments generated in the Austin (grey) and Göttingen (black) laboratories: Arrhenius plots of step-heating He diffusion experiments on three different fluorite specimens ( $a$ : HK13, b: RW5-11, and c: KN6) and calculated Tc (grey: Austin, black: Göttingen). Although the grain sizes are comparable the diffusion arrays of Austin are lower for the sample HK13, whereas they overlap well for the other two samples.

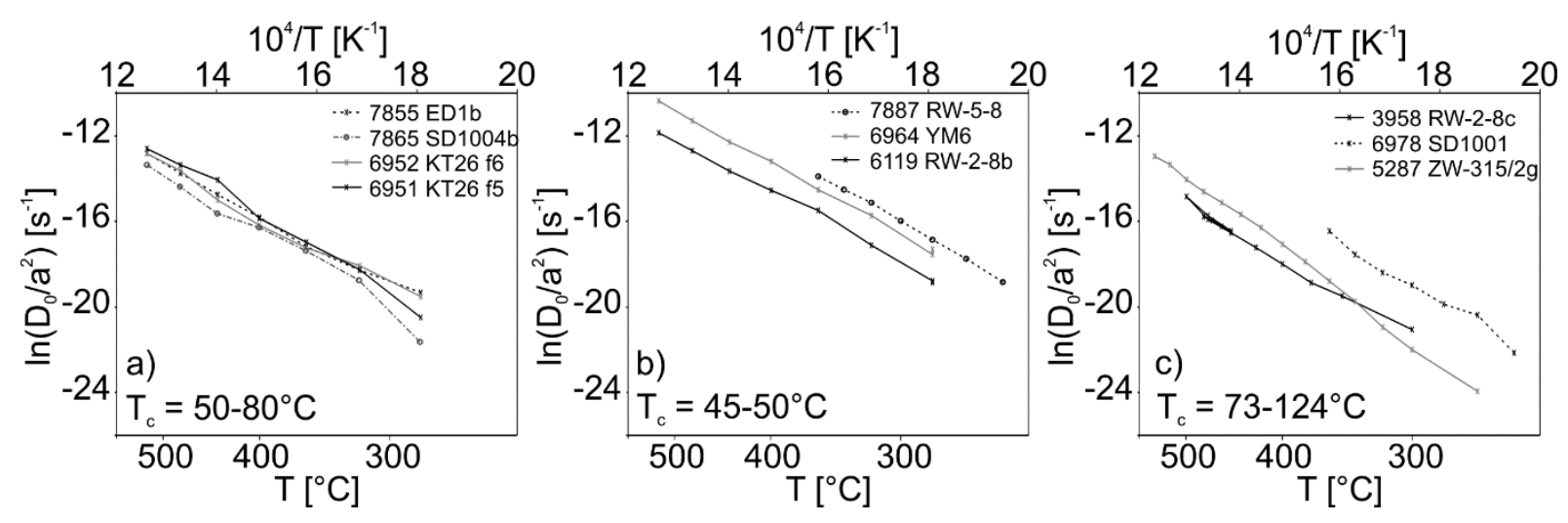

Fig. 6.7: a) Samples ED1b, KT26, SD1004b with intermediate $T_{c .}$ b) Samples YM6, RW-2-8b, RW-5-8 with low $T_{c}$. c) Samples SD1001, ZW315/2g, RW-2-8c with high $T_{c}$.

\subsubsection{The possible influence of radiation damage density}

A possible explanation for variability in diffusion parameters is the accumulation of radiation damage (e.g. Nasdala et al., 1995). In the case of the commonly used apatite and zircon helium thermochronometers, the role of damage density is well studied (e.g. Shuster et al., 2006a, b; Shuster and Farley, 2009; Flowers et al., 2009; Gautheron et al., 2009). Alpha particle recoil damage is the most important factor in these cases and can be quantified by the effective $U$ concentration (Flowers et al., 2009). The accumulation of radiation-induced metamictization in zircon generates defects that are easily detected by the full width at half maximum of Raman peaks (Nasdala et al., 1995; Presser and Glotzbach, 2009). A finite amount of radiation induced damage produces isolated defects into which helium can be trapped, effectively retarding further diffusive migration. At some higher level of damage, amorphization will occur, effectively creating a network of fast diffusion pathways. Once such a network of interconnected pathways is established, diffusivity rapidly increases (Shuster and Farley, 2009). With increasing accumulated radiation damage zircon first increases its $T_{c}$, but, once above a given damage threshold, $T_{c}$ decreases dramatically (Guenthner et al., 2013). In zircon this threshold where the radiation damage density strongly enhances He diffusivity is $\sim 2 * 10^{18}$ alpha decay events/gram (Guenthner et al., 2013). Modelling shows a threshold of $1.6^{*} 10^{16}$ alpha decay events/gram for interconnection of the damage zones in zircon (Nasdala et al., 2004; Ketcham et al., 2013). In our fluorite samples the average radiation dosage received is $c a .1 * 10^{15}$ alpha decay 
events/gram. This value is several orders of magnitude below the threshold mentioned for enhanced He diffusivity in zircon and apatite. The only exception is the fluorite sample K2 with an extremely high dosage of $8.6^{*} 10^{18}$ alpha decay events/gram. We used this sample to test the role of radiation on helium diffusion in fluorite. The change in slope at higher temperatures $\left(c a .440{ }^{\circ} \mathrm{C}\right.$ ) in the Arrhenius plot might indicate the onset of annealing of radiation damage in fluorite. But within the broad range of radiation damage analysed, we did not detect any systematic influence of radiation damage on the $T_{c}$. This strongly suggests that accumulated radiation damage is not the dominant control responsible for the variable $T_{c}$ observed between the various fluorite samples.

\subsubsection{The possible influence of the replacement of Ca by tri-valent REE cations}

A plausible explanation for the observed variability in $T_{c}$ is suggested by the correlation of the REE+Y content with the $T_{c}$ (Fig. 6.8). $\mathrm{REE}+\mathrm{Y}$ readily substitute for $\mathrm{Ca}^{2+}$ because they have almost identical ionic radii, but subsequently the different charges need to be compensated. In samples with non-extreme compositions (excluding the Y-rich fluorite $\mathrm{K} 2$ and the samples KT26, YM6), our data suggest a trend towards higher $T_{c}$ with increasing $R E E+Y$ content. For the outlier sample $K 2$, effects of clustering of $R E E+Y$ that occur with increasing $R E E+Y$ content might be responsible. Moore and Wright (1981) first described clusters of REE+Y in fluorite and Kazanskii et al. (2005) suggested that such clusters had a hexamer structure. Samples KT26 and YM6 are from Be and W ore deposits with highly unusual geochemical settings. They are the only fluorite samples that we analysed where $\mathrm{Sm}$ is the main contributor to the total radiogenic helium budget (Fig. 6.2). Nevertheless, a decreasing degree of $\mathrm{Ca}^{2+}$ substitution by $R E E+Y$ is apparently sufficient to decrease $T_{c}$ and increase He diffusivity. Similar effects on diffusivities by lattice deformation have been postulated for other minerals e.g. by Bengtson et al. (2012) and Farley (2007).

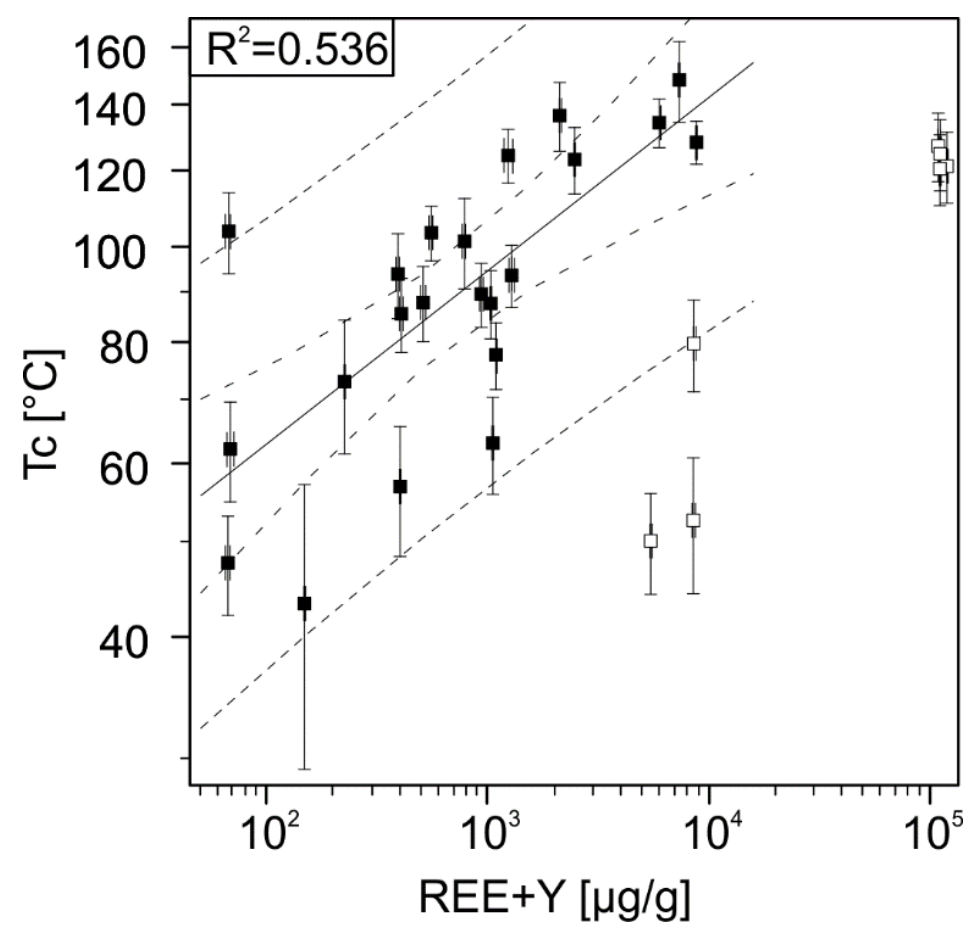

Fig. 6.8: Most prominent cations (REE+Y $[\mu \mathrm{g} / \mathrm{g}]$ ) substituting for Ca plotted against the closure temperature. With increasing $R E E+Y$ content a higher $T_{c}$ can be expected. Samples represented by empty boxes are excluded from the calculation of the confidence interval - due to their extreme composition/genesis (KT26, YM6, and the

$Y$-rich fluorite K2). Broken and dashed lines are the 95\% confidence and prediction interval of the linear interpolation, respectively. 
Our observations point to a chemical/crystallographic control on He diffusivity in fluorite. In particular, their potential to trigger charge compensation mechanisms should be considered. Möller et al. (1998) outlined four major anionic charge compensation mechanisms for the substitution of $\operatorname{REE}^{3+}$ and $\mathrm{Y}^{3+}$ for $\mathrm{Ca}^{2+}$.

(i) $2 \mathrm{Ca}^{2+}=2 \mathrm{REE}^{3+}+\mathrm{O}^{2-}$ replacing adjacent $\mathrm{F}-$

(ii) $3 \mathrm{Ca}^{2+}=2 \mathrm{REE}^{3+}+\mathrm{Ca}$-vacancy

(iii) $2 \mathrm{Ca}^{2+}=\mathrm{REE}^{3+}+\mathrm{Na}^{1+}$ replacing neighboring $\mathrm{Ca}_{2}+$

(iv) $\mathrm{Ca}^{2+}=\mathrm{REE}^{3+}+\mathrm{F}^{1-} \mathrm{F}^{1}$, body-centred position

Below we discuss the potential impact of these mechanisms on He diffusivity.

(i) For oxygen (as well as $\mathrm{P}, \mathrm{Cl}, \mathrm{C}$ and $\mathrm{S}$ ) our SIMS data reveal no correlation between anion contents and the determined $T_{c}$. Noteworthy, the fluorite samples showed clusters, homogeneous internal distribution of the anion proportions based on $\mathrm{O}$ and $\mathrm{Cl}$ ratios (Fig. 6.1). Only sample RW-5-11 does not show distinct clusters, which is consistent with the heterogeneity observed by $\mathrm{CL}$ imaging (Fig. 6.3, lower panel).

(ii) Lattice vacancies, which might be expressed as ionic porosity (Dahl, 1997), and their distribution can either enhance diffusion by increasing mobility or act as energy wells trapping He and retard its mobility. Besides their "ambivalent" role, their quantification is not possible from our results.

(iii) The substitution of Ca by Na could result in a minor lattice deformation due to the slightly different ionic radii and, if this substitution is not compensated by $R E E+Y$, it can create $F$ vacancies. However, there is no obvious correlation between the $\mathrm{Na} /(\mathrm{REE}+\mathrm{Y})$ ratio and the $\mathrm{T}_{c}$ (Tab. 6.1).

(iv) When tri-valent cation substitution is compensated by fluorine ions then the F1 body-centred positions of the lattice becomes occupied and the anion lattice became a mixture between $\mathrm{CaF}_{2}$ and $\mathrm{YF}_{3}$ (Nowacki, 1938). These additional $\mathrm{F}^{-}$ions contribute to a retardation of diffusion along the pathways for helium and will have a direct influence on its diffusivity through the fluorite crystal lattice.

Although, the role of lattice vacancies is ambivalent, our data suggests two mechanisms explaining the significant variability of He diffusion in fluorite. (1) The expected position for the He released by radioactive decay in the fluorite lattice is the interstitial one in the empty F-coordinated hexahedrons of the structure. Diffusion may occur through the neighbouring interstitials (eight for every interstitial position, all equally likely) through two neighbouring fluorine ions (Nekrasov and Kupryashkin, 2001). Since the substitution of Ca by REE $+Y$ is typically less than 1 weight percent, it is difficult to expect that this minor substitution compensated by (i), (iii), or (iv) may significantly affect the interstitial diffusion pathway of $\mathrm{He}$. Situation changes when there is substitution of $\mathrm{F}^{-}$by $\mathrm{O}^{2-}$ or $\mathrm{Ca}^{2+}$ by $\mathrm{Na}^{+}$not compensated by trivalent REE+Y. In these cases (detected in pink fluorite), we assume that resulting $\mathrm{F}$ vacancies may significantly enhance diffusion paths and lower the $T_{c}$ as observed for several low-REE+Y samples in our study. Likewise, a quantitative excess of (neutral) fluorine $F^{0}$ occupying interstitial positions in the fluorite structure should reduce the diffusivity. Unfortunately, we have no hints for the second mechanism in or samples. (2) We assume that the $\mathrm{Ca}^{2+}$ vacancies formed by compensation mechanism (ii), in conjunction with the already existing empty F-coordinated hexahedrons, might act as energy wells trapping the helium atoms. In this case even $<1$ weight percent presence of vacancies is several orders of magnitude higher than the He concentration in the lattice. So, it can have easily a determinant negative effect on the mobility of He by trapping the gas atoms in the more abundant vacancies. 
The available data suggest that the mechanism responsible for the variation in $T_{c}$ is most probably related to the vacancy density in fluorite. Either, substitution not compensated by REE+Y increase the number of $\mathrm{F}$ vacancies enhancing $\mathrm{He}$ diffusion, or substitution generated $\mathrm{Ca}^{2+}$ vacancies trap $\mathrm{He}$ and excess $\mathrm{F}$ ions induce a narrowing of the available diffusion pathways. Hence, the $\mathrm{REE}+\mathrm{Y}$ content can be used as proxy for the $T_{c}$.

\section{Testing variable closure temperature in an empirical case study}

The fluorite sample HK13 from Horny Krupka, Erzgebirge (Czech Republic), yielded an average FHe age and standard error of $290 \mathrm{Ma} \pm 10 \mathrm{Ma}$ (Fig. 6.9). This is in close agreement with the mica Ar/Ar ages of between $314 \pm 2 \mathrm{Ma}$ and $312 \pm 2 \mathrm{Ma}$ for the Zinnwald and Horni Krupka Li-F granitoids (Seifert et al., 2011) and subsequent Permian rhyolitic volcanism (Romer et al., 2010a). The analysed fluorite has greenish colour and high average $R E E+Y$ concentration of $5277 \pm 516 \mu \mathrm{g} / \mathrm{g}$. However, 19 aliquots from four fluorite samples from the same locality having lower amounts of REE+Y (ca. $130 \pm 28 \mu \mathrm{g} / \mathrm{g}$ ) gave FHe ages of $79 \mathrm{Ma} \pm 10 \mathrm{Ma}$ (Fig. 6.9; Wolff et al., 2015a). Remarkably, both their REE pattern and their paragenesis point to the same genesis coupled to the granite intrusion in late Variscan times (Wolff et al., 2015a). The younger FHe ages are comparable to apatite fission track and (U-Th-Sm)/He ages of 98 and $103 \mathrm{Ma}$, respectively, from the same locality and thermal modelling of FHe yields comparable results (Wolff et al., 2015b). These ages reflect the timing of overall Cretaceous cooling for the entire Erzgebirge basement (Wolff et al., 2015b).

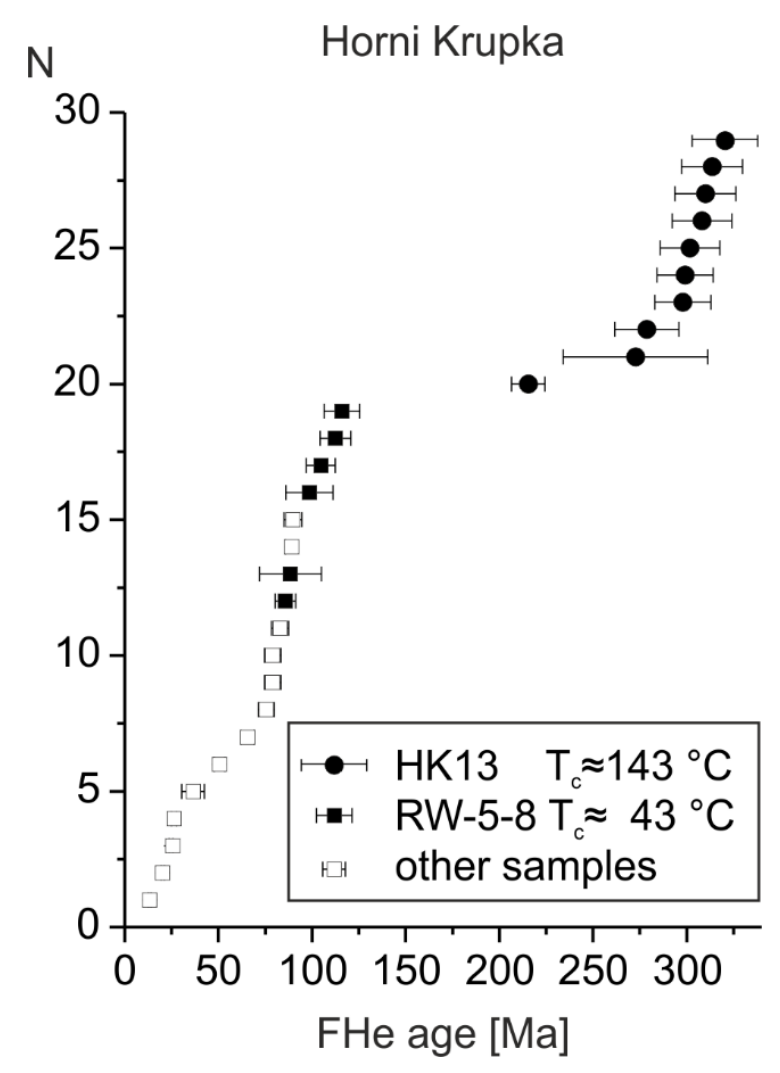

Fig. 6.9: Fluorite (U-Th-Sm)/He ages plotted in increasing order; the dated single-fragment aliquots derive from different samples of the Horni Krupka mining district. The bimodal age distribution corresponds well with the measured closure temperatures. The old ages actually resemble post-emplacement cooling, while the young age group reflects the age of the Cretaceous regional hydrothermal heating event. 
The calculated closure temperature for HK13 is the highest identified in our study ( 130 to $170{ }^{\circ} \mathrm{C}$ ) while the younger sample (RW-5-8) yielded a considerably lower $\mathrm{T}_{\mathrm{c}}$ of $c a .43^{\circ} \mathrm{C}$ (Fig. 6.7 and Fig. 6.8). Due to their close proximity and the lack of evidence for any local perturbation of isotherms, it is concluded that these samples must have experienced the same thermal history. Moreover, FHe ages of the different samples yielded the age of the two most characteristic periods of thermal evolution of the region, namely post-Variscan cooling and Late Cretaceous exhumation and termination of hydrothermal activity (Voigt, 2009; Wolff et al., 2015b). After the Permian, the deposit was heated during burial above the low-REE fluorite's closure temperature (and even above the apatite He closure temperature), but the maximum temperature remained below the closure temperature of the highREE fluorite.

The dependence of the He diffusivity on the chemical composition as predicted from the laboratory diffusion experiments is thus confirmed by the Horny Krupka case study.

\section{Conclusions}

Diffusion of helium in fluorite was measured by stepwise degassing in two laboratories on a large number of aliquots.

- The results are robust, although minor differences were detected between the laboratories using different analytical designs. This underlines the need for further cross-calibrations of different laboratory techniques.

- The linearity of the Arrhenius plots indicate a thermally activated volume diffusion. However, diffusivity of helium in different fluorite samples is highly variable and the determined closure temperatures range from 169 to $46^{\circ} \mathrm{C}$, considering a $125 \mu \mathrm{m}$ fragment size of all studied fluorite.

- Fluorite formed in differing environments and with differing parageneses has variable degree of $\mathrm{Ca}$ $>$ REE $+Y$ substitution, but typically less than 1 weight percent. Further, the detected closure temperatures show a general correlation with the REE $+Y$ contents. Therefore, the $R E E+Y$ content can be used as a proxy for the closure temperature.

- Our data allow us to draw the conclusion that most likely the decrease in closure temperature brought about by substitution not charge compensated by $R E E+Y$ results in increasing $F$ vacancies probably enhancing the diffusion within the fluorite lattice. Additionally, the increasing proportion of the third fluorine ion is blocking the helium diffusion pathways due to its body centred position in the cubic $\mathrm{YF}_{3^{-}}$ type crystal lattice. Further, we assume that substitution generated vacancies can have the effect of trapping $\mathrm{He}$ in the fluorite lattice.

- Laboratory-determined closure temperatures have been verified by an empirical case study: from one deposit two fluorites with different compositions and closure temperatures yielded different $\mathrm{FHe}$ ages. The $290 \mathrm{Ma}$ and the $79 \mathrm{Ma}$ data coincide with the Permian and Cretaceous cooling periods, which have been well-established for the region. 


\section{Acknowledgments}

This study was funded by the German Research Foundation (DFG grant DU373/6). We are greatful to Harald Dill (Hannover), the mineral collection at University of Freiberg and the Bergbaumuseum at Altenberg for the donation of mineral species. We are indebted to the Central Metal Workshop at Geoscience Center Göttingen for the maintenance of the GÖochron Laboratories and to Kingsley Burlinson for the decrepitation experiments (Burlinson Geochemical Services, Darwin, Australia). Frédéric Couffingal gave expert help during SIMS data collection. Special thanks to Adam Goldsmith for the diffusion experiments in Austin, Igor Villa (Milano, Bern), Noreen Evans (Curtin), and István Dódony (Budapest) for enlightening discussions. Thoughtful suggestions and comments by Stephen Cox and an unknown reviewer as well as careful editorial handling by David Shuster helped to improve the manuscript.

\section{Electronic Appendix}

EA 6.1: Average REE+Y content on fluorite single-fragments by solution ICP-MS technique.

*: The trace element concentrations were determined by external calibration using multi-element standard solutions analysed during the analytical sequence, applying a standard to sample ratio of 1:8. The drift of the ICP-MS was corrected by the lolite and Pepita software. The uncertainty of the trace element ratios is around $2 \%$, while the absolute concentrations $(\mathrm{m} / \mathrm{m})$ of elements have ca. $6 \%$ uncertainty due the propagated error of the ICP-MS Ca analyses (that was used as matrix element for concentration calculations).

EA 6.2: Details of the anion analyses by SIMS using the CAMECA 1280-HR instrument (details on instrumental settings in the header) at the Helmholtz-Zentrum Potsdam to quantify variations in the $\mathrm{C}, \mathrm{O}, \mathrm{P}, \mathrm{S}$ and $\mathrm{Cl}$ contents of the fluorite samples.

EA 6.3: Stopping distances and vacancies created per ion for the actinides in fluorite derived from NUDAT $2.6(7 / 14 / 2014)$ data base and ranges calculated by the software programs ASTAR and SRIM (Ziegler, Ziegler and Biersack, 2010).

EA 6.4: Details of the stepwise degassing experiments. Amount of helium is given in nano-cubic-cm in standard temperature and pressure with $2 \mathrm{sd}$ error, temperature in ${ }^{\circ} \mathrm{C}$ and time in seconds, the parameters used for linear interpolation are bold (for details on analysis see methods chapter).

EA 6.5: Decrepitation results of some fluorite samples from the Erzgebirge (Germany). The experiments were performed by Burlinson Geochemical Services, Darwin, Australia.

EA 6.6: Summary of the diffusion experiment results obtained on fluorite. Amount of helium is given in nano-cubic-cm at standard temperature and pressure. Uncertainties of helium given as $1 \mathrm{sd}$, in relative uncertainty $\%$. 
EA 6.7: Details of the fluorite (U-Th)/He results. Amount of helium is given in nano-cubic-cm at standard temperature and pressure. Amount of radioactive elements are given in nano-g. Uncertainties of helium and the radioactive element contents are given as $1 \sigma$ relative standard error.

**: The uncertainties from a) spike composition, b) spike concentration, c) spike dilution, d) signal detection at ICP-MS measurements and e) drift correction through the ICP-MS sequences have been propagated by the usual, quadratic method. 


\section{Further studies}

The articles presented above comprise the major findings of my PhD study. However, within the scope of my thesis a range of supplementary experiments and related results have been obtained. Some of these data can form the base for further publications, some of them bring less immediate results but they are also presented in the last part of my thesis as they contribute to the understanding of the mineralogy and diffusion behaviour of this stoichiometric simple but actually highly complex mineral. The following chapters deal with the results of these complementary studies:

I developed a helium soaking laboratory procedure that saturates helium poor mineral phases and synthetic crystals with helium. Subsequent, diffusion properties can be analysed with convenient amount of helium. Such experiments were performed on laboratory grown $\mathrm{CaF}_{2}$ crystals. Remarkably, the change in diffusion behaviour between synthetic and $\mathrm{Er}$ doped $\mathrm{CaF}_{2}$ yields differing results than in natural fluorite (Chapter 1 ).

The REE systematics study comprises over 660 single fragment analysis. This dataset allows us statistical treatment suggesting a new characterisation of fluorites due to their genesis (Chapter 2 ).

\section{Helium diffusion in synthetic $\mathrm{CaF}_{2}$}

\subsection{Abstract and introduction}

Helium diffusion experiments on pure and doped synthetic $\mathrm{CaF}_{2}$ after soaking them with helium have been performed in order to evaluate potential parameters controlling helium diffusion. Helium soaking experiments lead to homogeneous helium distribution in the $\mathrm{CaF}_{2}$ crystals. The integrity of the $\mathrm{CaF}_{2}$ crystals through temperature and pressure treatment is given, and the introduced helium is sited similar than the helium produced by natural alpha decay. In the special case of pure $\mathrm{CaF}_{2}$ we can observe diffusion in a "perfect" crystal lattice without effects like impurities, substitution, fluid and solid inclusions or zonation. Additionally, the effect of doping fluorite with $\mathrm{Ce}$ and $\mathrm{Er}, 4500 \mathrm{ppm}$ and $5000 \mathrm{ppm}$, respectively, on helium diffusion has been evaluated. The diffusion characteristics have been analysed in two laboratories and the trend in the results is in agreement. The best estimate diffusion parameters for undoped $\mathrm{CaF}_{2}$ are ranging between $\log \mathrm{D}_{0} / \mathrm{a}^{2}=4.1$ to $4.6\left[\mathrm{~s}^{-1}\right]$ and $\mathrm{E}_{\mathrm{a}}=137.6$ to $146.2[\mathrm{~kJ} / \mathrm{mol}$, Göttingen and Austin laboratory, respectively. This corresponds to a calculated closure temperature range of $c a .98 .5$ to $111.8^{\circ} \mathrm{C}$ which is $c a$. the average closure temperature of natural fluorite as discussed in the previous chapter. With increasing $\mathrm{Er}$ and Ce content, the closure temperature decreases dramatically to a calculated closure temperature range of $c a .10 .5$ to $70.8^{\circ} \mathrm{C}$. The substitution of $\mathrm{Er}$ and $\mathrm{Ce}$ for Ca probably results in a lattice deformation in $\mathrm{CaF}_{2}$ influencing the helium diffusion pathway. Remarkably, this decrease in $T_{c}$ with increasing $R E E+Y$ content has been observed in natural fluorite, vice versa. These difference suggest a comparable control effecting the helium diffusion but with differential impacts. A major effect may be due to the different formation process of laboratory grown and precipitated fluorite. 


\subsection{Sample selection}

The synthetic $\mathrm{CaF}_{2}$ and the synthetic $\mathrm{CaF}_{2}$ doped with $\mathrm{Ce}$ and $\mathrm{Er}$ was provided by the Hellma Optics Company, Germany (for details see Tab. 7.1 and EA7.1). Analysed samples are carefully crushed gem quality $\mathrm{CaF}_{2}$ made for optical lenses. The undoped synthetic $\mathrm{CaF}_{2}$ has been carefully air-abraded.

\subsection{Helium soaking experimental setting}

To perform helium diffusion experiments on synthetic $\mathrm{CaF}_{2}$ they have to be soaked with helium first. Since there is no article on soaking experiments on $\mathrm{CaF}_{2}$ a conservative time, temperature and pressure estimation for helium back diffusion has been made. The single $\mathrm{CaF}_{2} \mathrm{crystals}$ were enclosed and welded in gold capsules and heated at $700{ }^{\circ} \mathrm{C}$ for 48 days with $1034 \mathrm{MPa}$ helium atmosphere in a piston cylinder. A previous try with lower temperature $\left(500^{\circ} \mathrm{C}\right.$ ) and shorter duration (30 days) seemed not to be successful in reaching a homogeneous helium distribution in the $\mathrm{CaF}_{2}$.

\subsection{Results and discussion}

\subsubsection{Helium soaking}

An average helium amount of $239 \mathrm{ncc}$ has been soaked into an average of $9 \mu \mathrm{g} \mathrm{CaF}_{2}$. This can be calculated to $9.3 * 10^{-5}$ helium atoms per $\mathrm{CaF}_{2}$ molecule.

In case of the soaking experiments three questions have to be addressed beforehand: (i) if the soaking experiments show homogeneous helium distribution in the $\mathrm{CaF}_{2}$ crystals, (ii) if the $\mathrm{CaF}_{2}$ crystals are integer through the temperature and pressure treatment, and (iii) if the introduced Helium is sited similar than the natural (Farley, 2007). In case of synthetic $\mathrm{CaF}_{2}$ the comparability of natural hydrothermal fluorite and synthetic $\mathrm{CaF}_{2}$ from a melt has to be addressed, also.

(i) The helium concentration versus mass (calculated by Ca from ICP-MS) plot for five aliquots of sample RW-7-4 (Fig. 7.1, EA7.3) shows a linear relation which points to a homogeneous helium distribution in the $\mathrm{CaF}_{2}$ crystals after the soaking experiments.

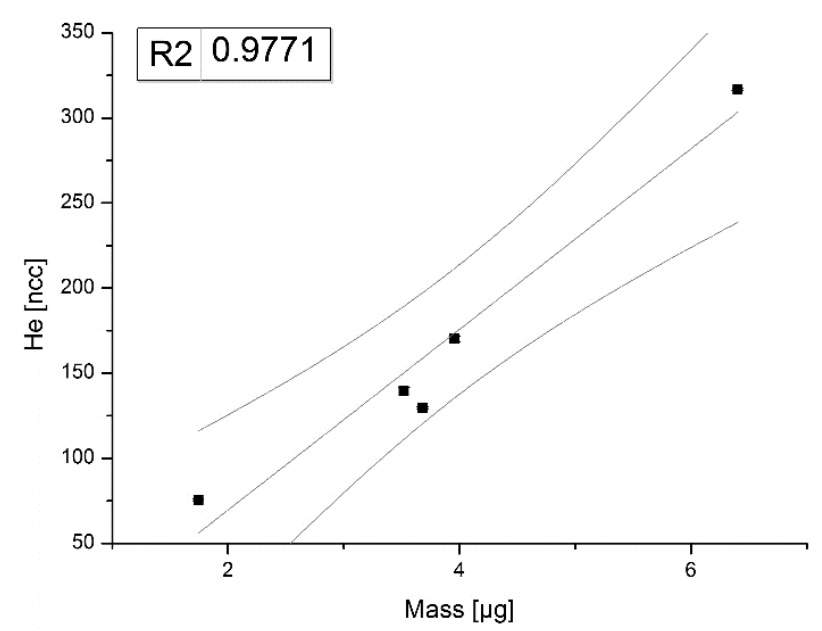

Fig. 7.1: Confidence interval of the test on homogeneous helium distribution in $\mathrm{CaF}_{2}$ after soaking by correlating helium concentration versus crystal mass estimated by ICP-MS.

(ii) The temperature, time and pressure most probably changed the crystals in case of annealing of radiation damage, annealing of lattice defects, recrystallisation and surface effects. However, the synthetic $\mathrm{CaF}_{2}$ contains much less or no radiation damage or lattice defects than natural. Therefore these effects are not changing the diffusion characteristics. However, small recrystallised $\mathrm{CaF}_{2}$ on the surface of the abraded $\mathrm{CaF}_{2}$ has been observed by microscopy. 
(iii) The diffusion experiments are comparable to experiments on natural fluorite suggesting that helium introduced by this method is sited similar than the natural produced helium or reached a similar position after the first diffusion step.

The Raman peak position and width of pure $\mathrm{CaF}_{2}$ and doped $\mathrm{CaF}_{2}$ does not change. The crystal lattice might not be deformed by REE+Y substitution. Additionally, the Raman scattering before and after the soaking experiment has been analysed. The Raman peak position and width stays stable during the soaking experiment.

\subsubsection{Diffusion characteristics of helium in synthetic $\mathrm{CaF}_{2}$}

The results of the diffusion experiments are presented as Arrhenius plots in the figures and as calculated diffusion parameters in Tab. 7.1 and details in EA7.2. In the diffusion experiments between $28 \%$ and $99 \%$ helium was released, in most cases above $45 \%$. The analysed $\mathrm{CaF}_{2}$ contained between $22 \mathrm{ncc}$ and $1476 \mathrm{ncc}$ helium with aliquot sizes between 66 to $237 \mu \mathrm{m}$ (Tab. 7.2).

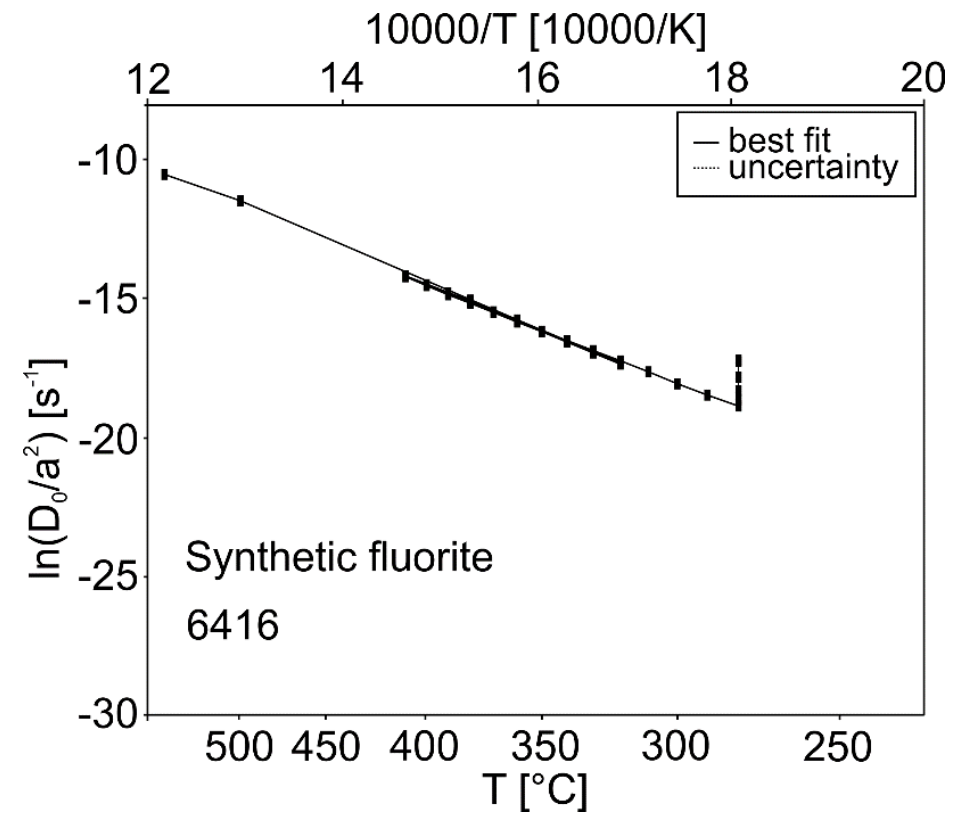

Fig. 7.2: Cycling experiment of sample 6416 showing excellent consistency.

On the first heating cycle a strong linear relationship was observed with the exception of the first degassing steps (Fig. 7.2 and Fig. 7.4) with a coefficient of determination $\left(R^{2}\right)$ between 0.9717 and 0.999 on 31 to 5 degrees of freedom with an average of 12. In the linear interpolations the first two diffusion steps were neglected because they sometimes contained unreasonable high diffusivities. The disturbed signal at the first fractional release steps, below $280^{\circ} \mathrm{C}$, can be related to surface roughness and irregularities as described by Farley (2007).

\begin{tabular}{|c|c|c|c|c|c|c|c|}
\hline \multirow[t]{2}{*}{ Sample } & & \multirow[b]{2}{*}{ abraded } & \multicolumn{5}{|c|}{ soaked with He } \\
\hline & & & Sample & $\begin{array}{c}\text { no. of aliquot } \\
\text { Goe/UT }\end{array}$ & $\begin{array}{l}\text { Tc } \\
\min \end{array}$ & $\begin{array}{l}\text { Tc } \\
\max \\
\end{array}$ & $\begin{array}{l}\text { REEY } \\
\text { ppm }\end{array}$ \\
\hline RW-2-29 & Doped with Er & $n$ & RW-7-2 & $3 / 2$ & 10.5 & 70.8 & 1065 \\
\hline RW-2-31 & CaF2 undoped & $y+n$ & RW-7-4 & $1 / 1$ & 98.5 & 111.8 & 1 \\
\hline
\end{tabular}

Tab. 7.1: Summarizing the results of the diffusion experiments and the REE+Y content. 


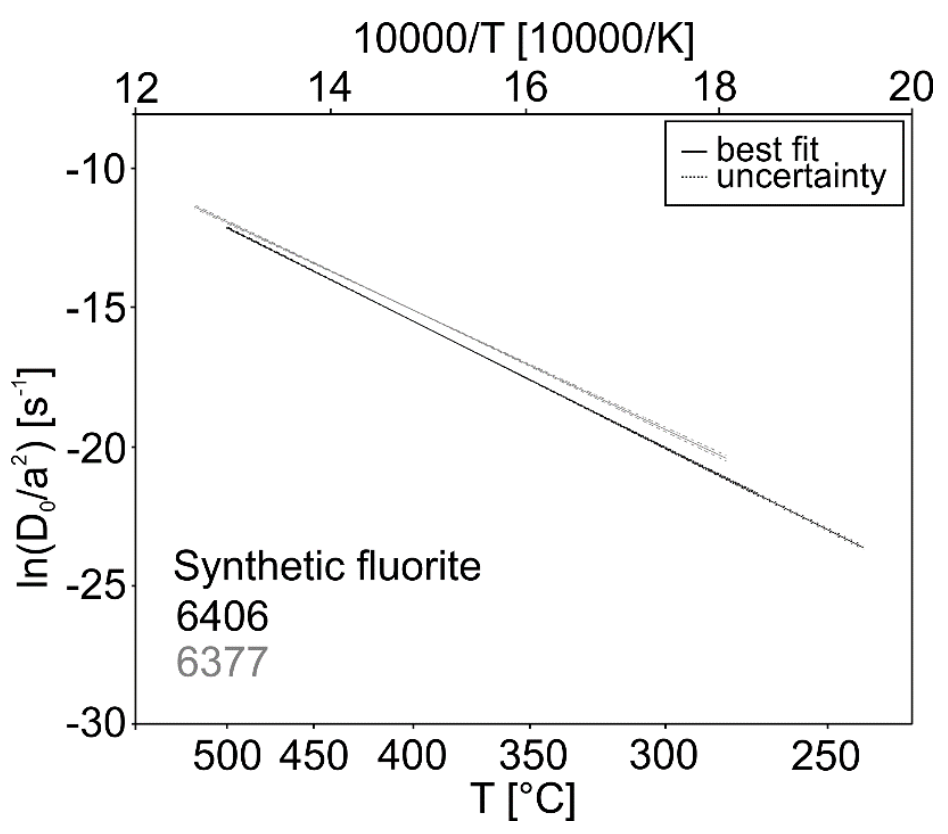

Fig. 7.3: Diffusion behaviour in pure synthetic $\mathrm{CaF}_{2}$ analysed in two laboratories yielding a $T_{c}$ of 99 and $112{ }^{\circ} \mathrm{C}$ (linear interpolation and uncertainty of the first heating cycle, black in Austin, grey in Göttingen).

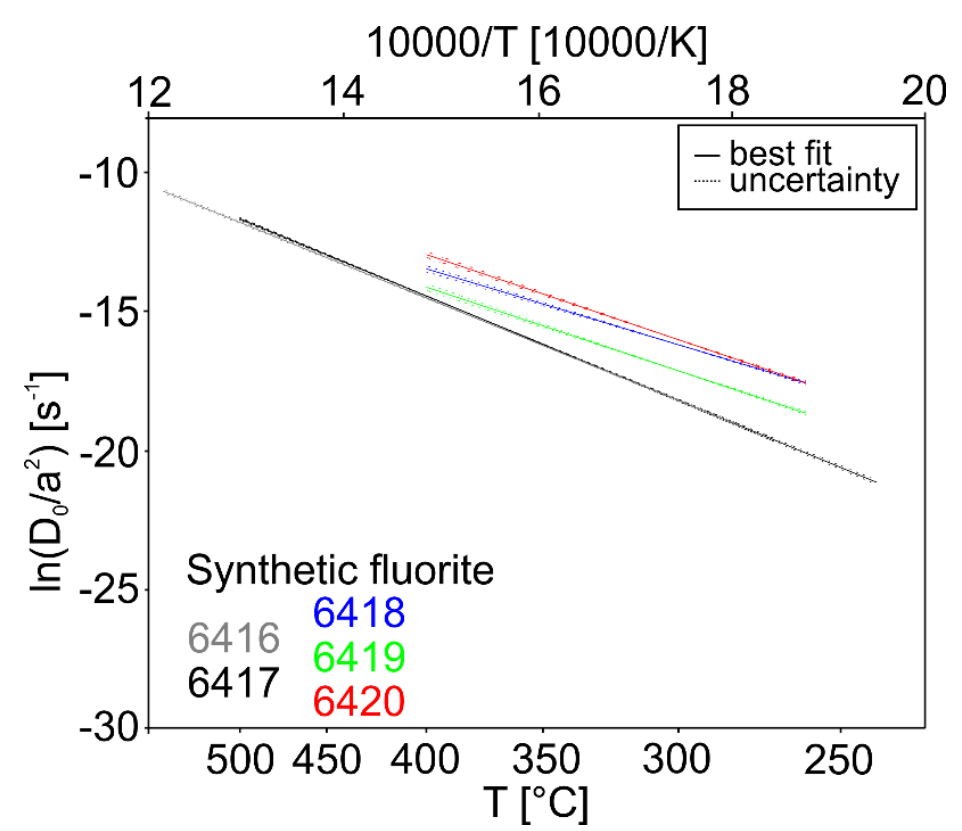

Fig. 7.4: Linear interpolation and uncertainty of the diffusion behaviour in doped synthetic CaF $F_{2}$ measured in two laboratories (grey/black in Austin, colourful in Göttingen).

The calculated helium diffusion behaviour in pure $\mathrm{CaF}_{2}$ from the linear segment (Fig. 7.3, see discussion below) of the first heating cycle yields a $\log D_{0} / a^{2}=4.1$ and $4.6\left[\mathrm{~s}^{-1}\right]$ and $E_{a}=137.6$ and $146.2[\mathrm{~kJ} / \mathrm{mol}]$ in the Göttingen and Austin labs, respectively (Tab. 7.2). This corresponds to closure temperatures of 98.5 and $111.8^{\circ} \mathrm{C}\left[10^{\circ} \mathrm{C} / \mathrm{Ma}\right.$, sphere]. In doped $\mathrm{CaF}_{2}$ the helium diffusion behaviour (Fig. 7.4) analysed in the Göttingen laboratory ranges between $\log \mathrm{D}_{0} / \mathrm{a}^{2}=1.0$ and $2.0\left[\mathrm{~s}^{-1}\right]$ and $\mathrm{E}_{\mathrm{a}}=87.6$ and $98.2[\mathrm{~kJ} / \mathrm{mol}]$. This corresponds to a range of closure temperatures of $c a .10 .5$ to $31.4{ }^{\circ} \mathrm{C}$. The calculated $T_{c}$ of the Austin laboratory are higher, 68.0 and $70.8^{\circ} \mathrm{C}$. 


\begin{tabular}{|c|c|c|c|c|c|c|c|c|c|c|c|c|}
\hline Sample No. & Sample Name & & $\begin{array}{l}\text { Seize } \\
\text { radius } \\
{[\mu \mathrm{m}]}\end{array}$ & $\begin{array}{l}\text { Final degassing } \\
\text { [ncc] }\end{array}$ & $\begin{array}{l}\text { Sum } \\
\text { [ncc] }\end{array}$ & $\begin{array}{c}\text { Percent } \\
\text { degassed } \\
{[\%]}\end{array}$ & $\begin{array}{r}\mathrm{Tc}\left({ }^{\circ} \mathrm{C}\right) \\
{\left[{ }^{\circ} \mathrm{C}\right]}\end{array}$ & \pm & $\begin{array}{l}\text { Ea } \\
{[\mathrm{kJ} / \mathrm{mol}]}\end{array}$ & \pm & $\begin{array}{l}\log (\mathrm{D} 0 / \mathrm{r} 2) \\
{[\mathrm{s}-1]}\end{array}$ & \pm \\
\hline 6416 & RW-7-2/3 f1 & $\mathrm{Er}$ & 73 & 0.868 & 119.058 & 99 & 68.0 & 4.3 & 118.0 & 0.4 & 2.9 & 0.3 UT \\
\hline 6417 & $\mathrm{RW}-7-2 / 3$ f2 & $\mathrm{Er}$ & 238 & 3.615 & 149.536 & 98 & 70.8 & 4.1 & 120.3 & 0.4 & 3.1 & 0.3 UT \\
\hline 6418 & $R W-7-2 / 3$ f3 & $\mathrm{Er}$ & 163 & 25.863 & 41.233 & 37 & 10.5 & 9.8 & 87.6 & 0.9 & 1.0 & $0.8 \mathrm{Gö}$ \\
\hline 6419 & $\mathrm{RW}-7-2 / 3 \mathrm{f} 4$ & $\mathrm{Er}$ & 127 & 127.793 & 176.702 & 28 & 31.4 & 11.4 & 96.6 & 0.9 & 1.4 & $0.8 \mathrm{Gö}$ \\
\hline 6420 & RW-7-2/3 f5 & $\mathrm{Er}$ & 144 & 37.801 & 68.391 & 45 & 25.6 & 10.1 & 98.2 & 0.8 & 2.0 & $0.7 \mathrm{Gö}$ \\
\hline 6377 & RW-7-4 f5 & pure & 68 & 19.499 & 170.209 & 89 & 98.5 & 6.6 & 137.6 & 0.6 & 4.1 & $0.4 \mathrm{Gö}$ \\
\hline 6406 & RW-7-4 f7 & pure & 96 & 1.921 & 22.263 & 91 & 111.8 & 3.2 & 146.2 & 0.3 & 4.6 & 0.2 UT \\
\hline
\end{tabular}

Tab. 7.2: Details of the diffusion measurements in synthetic $\mathrm{CaF}_{2}$. The radius is obtained by microphotographs, the laboratories are UT-Austin and Gö-Göttingen.

The second and also, if performed, the third heating cycle yield linear interpolations in agreement with the first cycle (Fig. 7.2). However, there is a strong offset between the two laboratories. The $T_{c}$ of the Austin lab are generally higher and the difference between pure and doped fluorite is smaller than the Göttingen laboratory results. This offset might be due to different heating schedules and laboratory setup used for the analysis. This discrepancy needs further studies. Nevertheless, the relative difference, the $\mathrm{T}_{c}$ decrease, between the pure and the doped $\mathrm{CaF}_{2}$ is obvious in both laboratories. This strong decrease in diffusivity and activation energy indicates a strong effect of Er and Ce substituting for $\mathrm{Ca}$ in the lattice. This points to a strong effect on the bulk diffusion by a relatively small amount of dotation. The decrease in $T_{c}$ with increasing $R E E+Y$ content has been observed in natural fluorite, vice versa. These differences suggest a comparable control on the one hand enhancing, on the other hand blocking the helium diffusion in fluorite by REE+Y. The major difference between the synthetic and natural $\mathrm{CaF}_{2}$ are their genesis. Synthetic has been laboratory grown from a $\mathrm{CaF}_{2}$ melt while natural precipitated from hydrothermal fluids.

\subsubsection{Conclusion}

(i) Helium soaking experiments are successful and valuable for analysing diffusion in synthetic $\mathrm{CaF}_{2}$ and other minerals or samples containing insufficient amount of helium for the extensive experiments. (ii) Undoped synthetic $\mathrm{CaF}_{2}$ yields comparable $T_{c}$ to natural fluorite with minor REE+Y substitution. (iii) Doping with $\mathrm{Ce}$ and $\mathrm{Er}$ significantly enhances the diffusion and therefore lowers the closure temperature of synthetic $\mathrm{CaF}_{2}$. The influence of $\mathrm{Ca}$ replacement is the opposite of the trend in natural fluorite and might be due to the different genesis of the two phases. 


\section{Fluorite classification based on rare earth element systematics}

\subsection{Abstract}

Due to the huge amount of data on fluorites (ca. 660 aliquots of 112 samples from 54 locations) statistical treatment of the database allows one to draw conclusions about the crystal chemistry of fluorite. This approach is decoupled from the outcrop- or micro-scale and therefore focus on the general overview/picture. The main suggestions from statistics are: (i) in the most common discrimination diagram for fluorite, $\mathrm{Tb} / \mathrm{Ca}$ - Tb/La diagram from Möller (1976) the green and the pegmatitic fluorites plot dominantly $(90 \%)$ in the pegmatitic field because they are enriched in REE $+\mathrm{Y}$, consequently, the colourless fluorites in the sedimentary field, and only $50 \%$ of the hydrothermal fluorites are classified correctly. (ii) Discrimination of hydrothermal and pegmatitic type fluorite using the La-Gd-Er ternary diagram described in Wolff et al. (2015a) classifies ca. $90 \%$ of all fluorites correctly.

\subsection{Introduction}

In fluorite the most prominent cations substituting $\mathrm{Ca}$ are the REE+Y. The REE pattern, even REE zoning will be retained in fluorites at and below precipitation temperature and billions of years (Cherniak et al., 2001). The REE patterns of hydrothermal minerals are a product of many factors acting during the main processes of hydrothermal mineralisation: leaching of source rock, migration of fluid phase, mineral precipitation and remobilization (Schwinn and Markl, 2005). If some determinants of these processes are known independently, the REE pattern of hydrothermal minerals can yield information about the mineral forming processes and parameters. In detail, the REE pattern is sensitive for (i) the source rock, e.g. granitic source rocks cause an enrichment of HREE and a negative Eu* anomaly while metamorphic rocks typically cause a flat REE pattern (Schwinn and Markl, 2005). (ii) Fluorites also record the REE pattern of the fluid phase from which they precipitated. Hereby, the main processes are adsorption, chemical complexation and redox reactions (Bau, 1991; Sallet et al., 2005; Schwinn and Markl, 2005): HREE are more effectively adsorbed and complexed than LREE. Fluorites precipitate because of changes in temperature and pressure along the flow path of the hydrothermal solutions or due to fluid mixing or interactions with the wall rock (Richardson and Holland, 1979a, 1979b). Because of chemical complexation LREE are enriched in the early precipitated fluorites, while HREE are enriched in late precipitated fluorites (Möller et al., 1976). The temperature of the precipitation influences the oxidation state of Eu. Above $200{ }^{\circ} \mathrm{C} \mathrm{Eu}^{2+}$ dominates over $\mathrm{Eu}^{3+}$. And because $\mathrm{Eu}^{2+}$ does not fit properly into the fluorite lattice the $\mathrm{Eu}^{*}$ anomaly changes (Schwinn and Markl, 2005). The remobilization of fluorites causes a decrease of LREE and an increase of HREE. Again this is because of chemical complexation, the REE form complexes in the fluid phase and the HREE are more effectively complexed than the LREE which for instance react with the wall rock (Möller et al., 1981; Schwinn and Markl, 2005). This behaviour of the REE leads to the Tb/Ca-Tb/La diagram by Möller et al., (1976) which is used for discriminating pegmatitic-, hydrothermal- and sedimentary fluorites. Hereby, the $\mathrm{Tb} / \mathrm{Ca}$ characterizes the chemical environment, while the $\mathrm{Tb} / \mathrm{La}$ characterizes the degree of fractionation.

\subsection{Sample selection}

The sample selection covers the broad spectrum of geological settings, colours and isotopic signatures of fluorites. The samples were classified using the different mineral colours, to be specific: colourless, yellow, honey, rosa, pink, green, blue and black (fetid fluorite), and also their relation of high to low temperature hydrothermal, plutonic, volcanic, metamorphic and sedimentary processes (hydrothermal, pegmatitic (from endo- and exocontacts), carbonate hosted, carbonatite). 


\subsection{Results and discussion}

The 660 analysed fluorites contain between 0 and $442 \mathrm{ppm} \mathrm{U,} 0$ and 5,563 ppm Th, averaging at ca. 2 ppm $U$ and 48 ppm Th (for details see EA7.4). The REE+Y content is observed between 1 and 145,500 ppm with an average of 2,248 ppm.

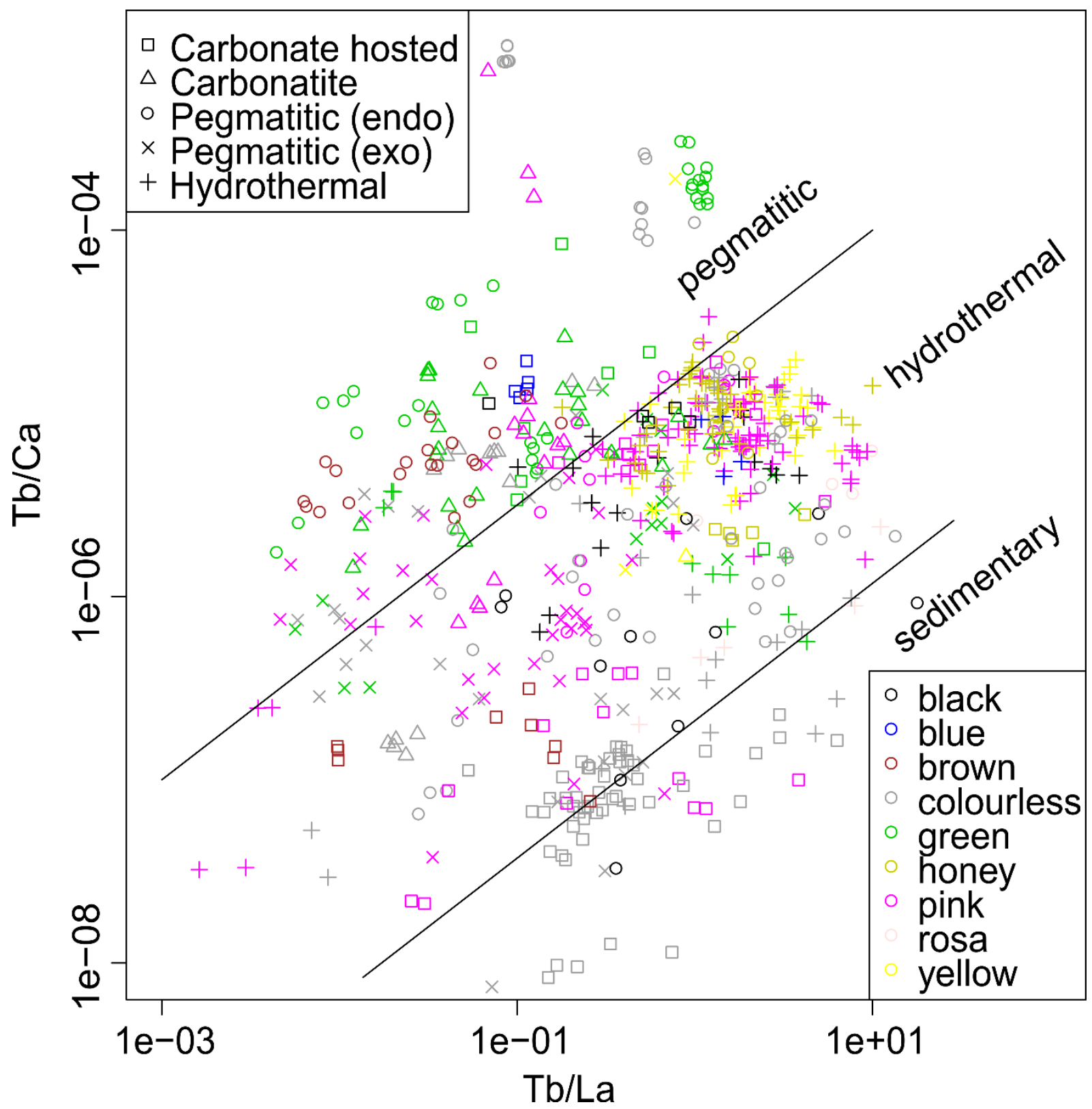

Fig. 7.5: Applying the discrimination diagram Tb/Ca-Tb/La by Möller et al. (1976) on all analysed fluorites sorted by colour and by geological setting (for explanation see text). The hydrothermal fluorites are discriminated dominantly correctly, the pegmatitic fluorites are dispersed in both, pegmatitic and hydrothermal fields. Most of the green fluorites plot in the pegmatitic field and most of the colourless fluorite in the hydrothermal field regardless of the mineral forming process. 


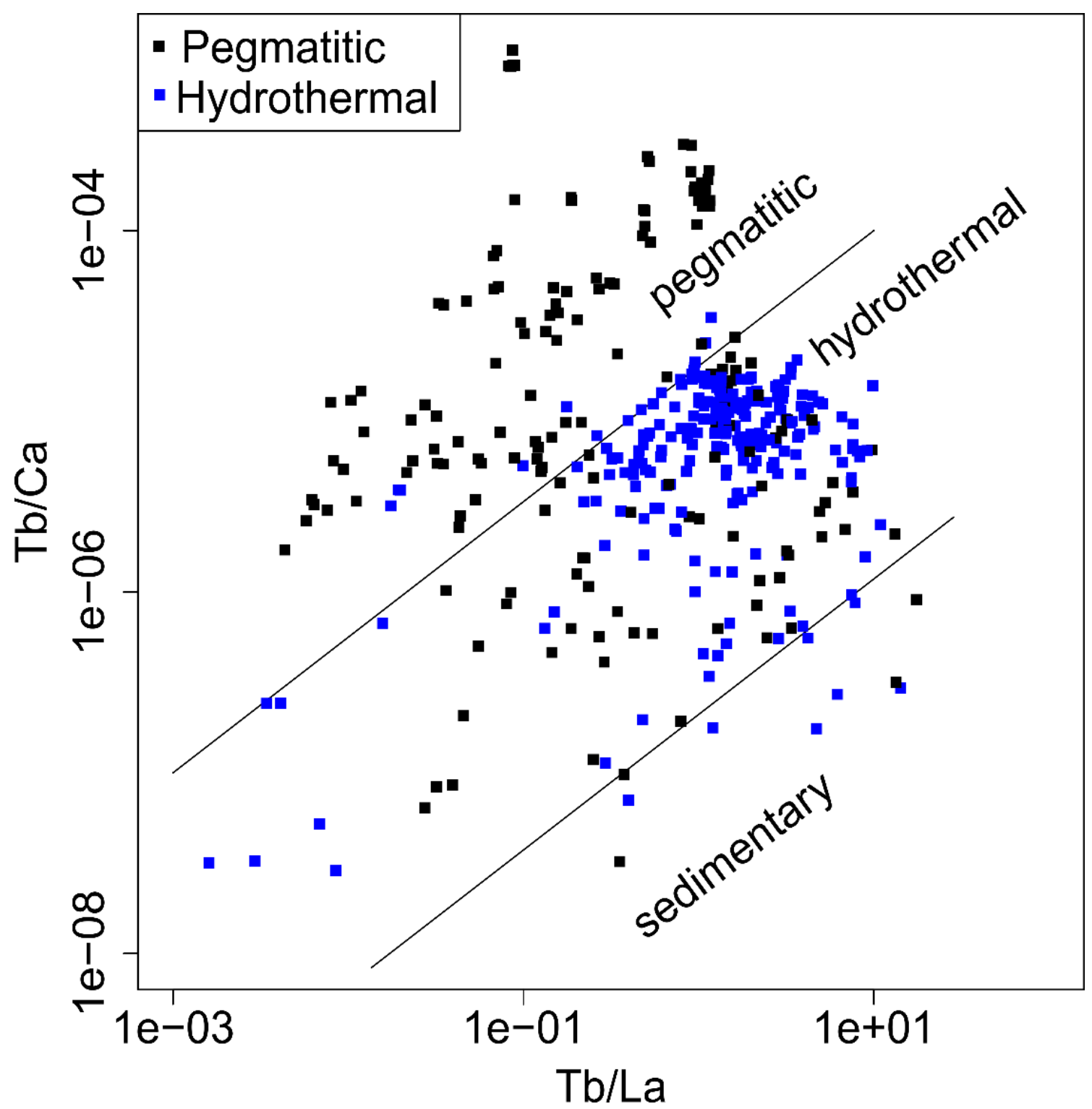

Fig. 7.6: Using the discrimination diagram Tb/Ca - Tb/La by Möller et al. (1976): $95 \%$ of the fluorites from hydrothermal type are discriminated correct (blue) but only ca. $50 \%$ of the pegmatitic fluorites are correct (black). 


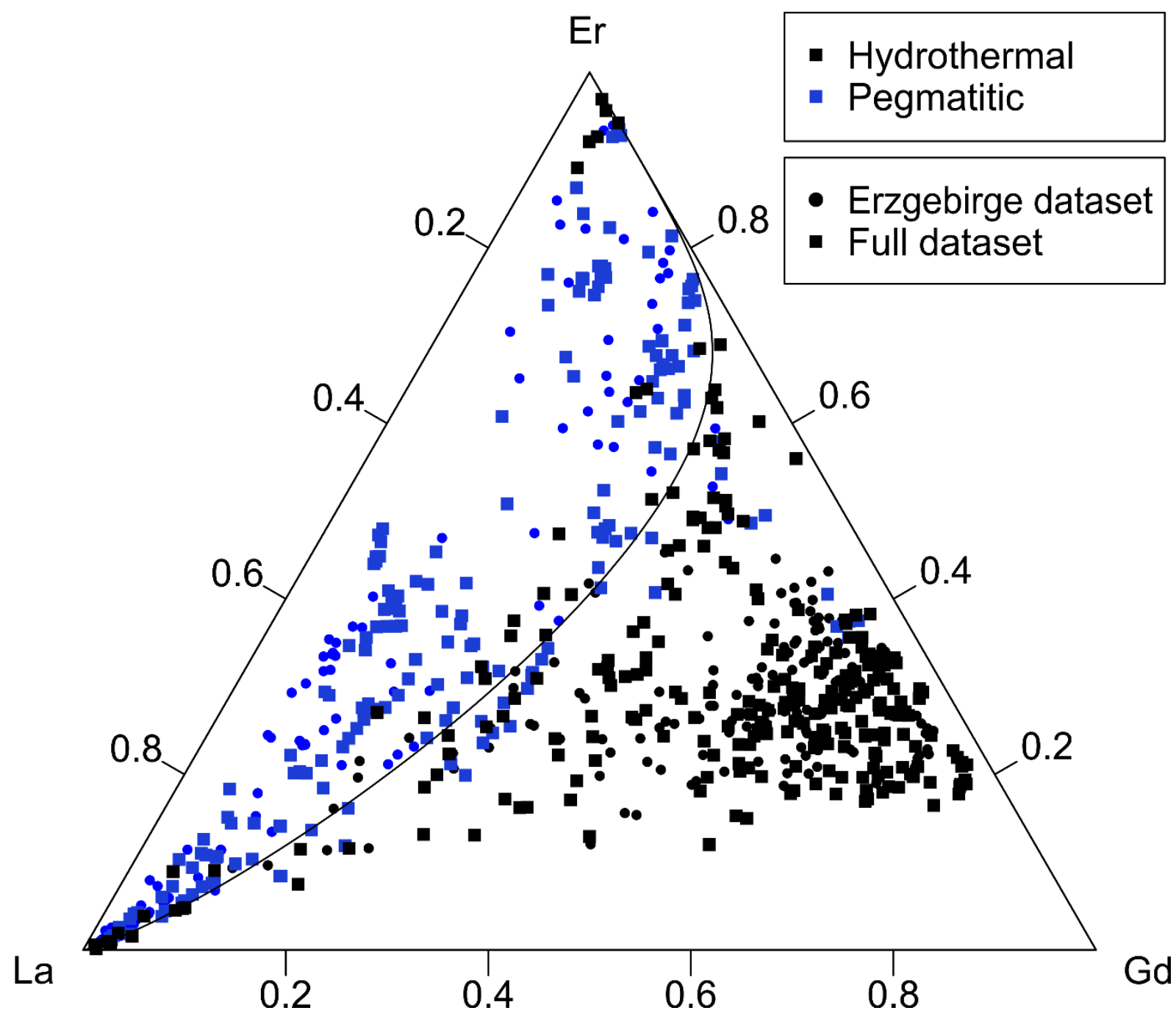

Fig. 7.7: Discrimination of hydrothermal and pegmatitic fluorites based on La-Gd-Er ternary diagram from Wolff et al. (2015a). Circles are the data from the Erzgebirge, squares are additional data (together $n=660$ ), ca. $90 \%$ of fluorites classified correctly.

\subsection{Discussion and conclusion}

The statistical evaluation of the dataset on fluorite suggests that (i) Most of the samples analysed in the frame of this thesis plot in the hydrothermal and pegmatitic field in the discrimination diagram of Möller et al. (1976). However, a clear discrimination between these fluorite types is not evident. $95 \%$ of the hydrothermal type fluorites are classified correctly but $c a .50 \%$ of the fluorites that are correlated to the field pegmatites (in this case correlated to granitoid magmatism) are classified as hydrothermal, too. This might be due to the insufficiently exact discrimination of the transition between fluorites closely related to granitoids (endocontact) and fluorites in the exocontact of the granitoid. Further, due to their enrichment in REE+Y the green fluorites plot in the pegmatitic field independently of their genesis. (ii) a discrimination between hydrothermal and pegmatitic fluorites based on their relative content of light, medium and heavy REE (La-Gd-Er) as suggested in Wolff et al. (2015a) classifies $90 \%$ of the dataset correctly. 


\section{General discussion and conclusion}

In the first step, the post Variscan thermal history of the Erzgebirge was constrained using the wellestablished methods ZHe, AFT, and AHe. Thermal modelling reveals Permo-Mesozoic burial up to temperatures of 80 to $100{ }^{\circ} \mathrm{C}$ while the sedimentary cover thins out towards the north resulting in maximum burial temperatures less than $40^{\circ} \mathrm{C}$. This thermal pattern was modified locally by Cretaceous hydrothermal activity that reset the zircon (U-Th)/He thermochronometer along ore veins. The hereby established thermal history is the basis for the second step. Herein, we compare the results of the FHe method with the independently gained information. For the purpose of comparison, the revealed thermal history is well suited because there are two separate cooling events with different peak temperatures: a pronounced late Variscan exhumation and a Late Cretaceous exhumation. Thermochronometer with higher $T_{c}$ like ZHe would retain the late Variscan signal while thermochronometer with lower $\mathrm{T}_{\mathrm{c}}$ like AHe are reset and would show the Late Cretaceous cooling signal. However, if the younger thermal event is overprinting the last hydrothermal FHe signal or if they are contemporaneous, a thermal and hydrothermal event is indistinguishable.

In the second step fluorite (U-Th-Sm)/He ages were determined in seven ore deposits of the Erzgebirge with well constrained regional cooling histories. This part of the thesis forms an empirical comparison study aiming to determine the reliability of the FHe thermochronometer. FHe is applied to two types of mineralisations with different formation ages. The two major episodes of hydrothermal activity are: a Late Carboniferous to Early Permian event associated with significant Sn-W mineralisation that is related to late Variscan granite magmatism, and a Mesozoic episode of polymetallic vein mineralisation. In contrast to the first event, the age of the younger hydrothermal activity is poorly constrained. For the latter, various geochronological methods yield a wide range of ages i.e. from Permian to early Tertiary. To validate the FHe method, the occurrence of two fluorite generations, one of known age and one of vaguely known age, is well suited. In this case, the good discrimination of the two mineralisations by the paragenesis and the La-Gd-Er diagram is important for further interpretation. If fluorites of late Variscan formation age show corresponding FHe ages, they can be interpreted as formation ages. Consequently, younger ages might be mixed or cooling ages. If the younger, Mesozoic, fluorites yield the same younger age, they can be interpreted as cooling ages indicating the last thermal overprint. And, if the fluorite generating hydrothermal phase is close to the time of thermal climax, a formation age of the Mesozoic fluorites cannot be excluded. The singlefragment $\mathrm{FHe}$ ages from the Erzgebirge show a considerable spread due to analytical errors, variable $\mathrm{T}_{c}$, fluid and solid inclusions, and zonation. This spread can be reduced by multi-aliquot analysis, further increase of sensitivity on actinide measurements and routine measurements for $T_{c}$. They are expressed by median because they do not follow a normal or log-normal distribution. This can be tested and confirmed by the shapiro test. The $p$-value after removing the significantly older ages for the samples Ehrenfriedersdorf, Horni Krupka, Sadisdorf, and Zinnwald rejects this thesis. Only Dörfl and Lauta might be log-normally distributed ( $p$-value $0.82,0.76$ ) and Frohnau might be normally distributed ( $p$-value of 0.82). Fluorite from six deposits yield Cretaceous FHe ages between 112 to $79 \mathrm{Ma}$, which are independent of their paragenesis. In contrast, fluorite from the Sadisdorf Sn-W deposit yield an age of $234 \mathrm{Ma}$. The younger ages are interpreted as cooling ages indicating the time of the last thermal 
overprint, including possible hydrothermal activity, in the Erzgebirge. The oldest, Triassic FHe ages at Sadisdorf indicate that the Mesozoic thermal overprint only partially resets the (U-Th-Sm)/He system of the late Variscan mineralisation. It is striking that the FHe age data not only overlap with the previously published AHe but also with the youngest hydrothermally reset zircon He ages in the Erzgebirge ( $c a .134$ to $112 \mathrm{Ma}$ ). This as well suggests a closure temperature for the fluorite system just within the range reported, below the zircon He system (ca. $180{ }^{\circ} \mathrm{C}$ to $160^{\circ} \mathrm{C}$, Reiners et al., 2002) and similar to or slightly higher than the apatite system (ca. $80{ }^{\circ} \mathrm{C}$ to $60{ }^{\circ} \mathrm{C}$ Farley, 2000). Furthermore, thermal modelling based on FHe ages and He diffusion parameters in fluorite results in thermal histories comparable to the results from the well-established apatite-based thermal modelling. Using only $\mathrm{FHe}$, the type of thermal overprint cannot be distinguished with certainty. On the one hand, the Cretaceous ages might reflect the Late Cretaceous exhumation of the Erzgebirge as revealed by thermal modelling of AHe and AFT. On the other hand, they might indicate the vanishing superimposed hydrothermal activity. A later thermal overprint can be excluded.

The major part of the thesis comprises numerous laboratory experiments constraining the diffusion characteristics of helium in fluorite. The most prominent results revealed by diffusion experiments are (i) a linear Arrhenius relationship (ii) the diffusion domain is the crystal (iii) a variable helium diffusion in fluorite (iv) with increasing REE $+Y$ content a higher $T_{c}$ is to be expected. The first two findings ( $\left.i+i i\right)$ are very important for the feasibility of the FHe method. They suggest that the results can be extrapolated to geological time scales and lower temperatures. This is in good agreement with the empirical case study which proves that the method yields geologically meaningful ages. Moreover, the FHe method can be combined with other low-temperature chronometer to multi-method geochronology and the data can be used for thermal modelling. The variable $T_{c}$ and its dependence on the $R E E+Y$ content (iii + iv) as suggested by the diffusion analysis is also in agreement with results of an empirical case study which reveals fluorites from the same ore deposit yielding a bimodal age distribution. The temperature range between $46 \pm 14{ }^{\circ} \mathrm{C}$ and $169 \pm 9{ }^{\circ} \mathrm{C}$, considering a $125 \mu \mathrm{m}$ fragment size, spans between $\mathrm{ZHe}$ and $\mathrm{AHe}$ and fills the existing gap. It is well suited for low-temperature thermochronology, e.g. burial, exhumation, and hydrothermal events.

The variability of both, diffusivity and activation energy, $\log D_{0} / a^{2}=0.30 \pm 0.27$ to $7.27 \pm 0.46 \mathrm{~s}^{-1}$ and $E_{a}=96 \pm 3.5$ to $182 \pm 3.8 \mathrm{~kJ} / \mathrm{mol}$, respectively, and the amount of variation is surprising but wellestablished with repeated measurements. Moreover, the amount of variation could be reproduced in a second laboratory. Even though diffusion experiments are needed to estimate the $T_{c}$ on every fluorite sample beforehand, the opportunity to reveal a thermal history between 169 and $46^{\circ} \mathrm{C}$ using only one mineral is valuable. This is comparable with zircons having variable radiation damage within one sample and therefore a $T_{c}$ range between $c a .180$ to $0{ }^{\circ} \mathrm{C}$. In this case thermal modelling allows one to estimate the thermal history, too. As shown by the empirical case study, fluorites with differing $T_{c}$ might be capable of covering the span between formation age and later low-thermal overprint. The control of the helium diffusion in fluorite by lattice ordering is an indication that diffusion in more complex minerals should be handled with care.

The general trend in the data suggests that a higher $T_{c}$ can be expected with increasing REE+Y content. Hereby, the REE $+Y$ might not directly influence the diffusion of helium themselves because they have almost identical ionic radii but trigger several charge compensation processes because of their different charges. Most probably, substitution of $\mathrm{F}^{-}$by $\mathrm{O}^{2-}$ or $\mathrm{Ca}^{2+}$ by $\mathrm{Na}^{+}$not compensated by $\mathrm{REE}+\mathrm{Y}$ is resulting in $\mathrm{F}$ vacancies which significantly enhance diffusion paths and lower the $\mathrm{T}_{\mathrm{c}}$. 


\section{The general conclusions:}

1) Further development of the fluorite (U-Th-Sm)/He method has increased and proven its routine applicability that might lead to establishing the method among AHe, AFT, ZHe and ZFT thermochronology.

2) FHe thermochronology has been successfully validated by revealing known and unknown thermal histories and also by using thermal modelling.

3) The FHe method is well-suited for ore deposits and hydrothermally altered regions where the wellestablished apatite-based low-T thermochronometers cannot be applied due to the high solubility of apatite in acid environments.

4) Diffusion experiments yield robust results, although minor differences were detected between the laboratories using different analytical designs. This underlines the need for further cross-calibrations of different laboratory techniques.

5) The linearity of the Arrhenius plots indicate a thermally activated volume diffusion.

6) Diffusivity of helium in different fluorite samples is highly variable and the determined closure temperatures range from 169 to $46^{\circ} \mathrm{C}$, considering a $125 \mu \mathrm{m}$ fragment size of all studied fluorite.

7) Fluorite formed in differing environments and with differing parageneses has variable degree of $\mathrm{Ca}$ $\rightarrow$ REE+Y substitution, but typically less than 1 weight percent. Further, the detected closure temperatures show a general correlation with the REE $+Y$ contents. Therefore, the REE $Y$ content can be used as a proxy for the closure temperature.

8) Most likely the decrease in closure temperature brought about by substitution not charge compensated by $R E E+Y$ results in increasing $F$ vacancies probably enhancing the diffusion within the fluorite lattice. Additionally, the increasing proportion of the third fluorine ion is blocking the helium diffusion pathways due to its body centred position in the cubic $\mathrm{YF}_{3}$-type crystal lattice. Further, I assume that substitution generated vacancies can have the effect of trapping $\mathrm{He}$ in the fluorite lattice.

9) Laboratory-determined closure temperatures have been verified by an empirical case study: from one deposit two fluorites with different compositions and closure temperatures yielded different $\mathrm{FHe}$ ages. The $290 \mathrm{Ma}$ and the $79 \mathrm{Ma}$ data coincide with the Permian and Cretaceous cooling periods, which have been well-established for the region.

10) According to thermal modelling of $\mathrm{ZHe}, \mathrm{AHe}$ and AFT data, the Erzgebirge is dissected by two roughly NE-SW aligned fault zones leading to three structural blocks that experienced different postVariscan thermal histories.

11) Basement rocks experienced cooling to near-surface temperatures shortly after the Variscan orogeny and were then buried by Permian to Jurassic sediments. Thermal modelling suggests that the pre-Cretaceous burial was deeper in the southern to central parts of the Erzgebirge compared to its northern part.

12) Local thermal anomalies resetting all applied thermochronometers were generated by Cretaceous hydrothermal ore-forming fluids.

13) AHe and FHe data indicate that the thermal activity in the studied area terminated before latest Cretaceous; both show no detectable regional exhumation since Late Cretaceous. 


\section{Outlook}

The thesis proves that the fluorite (U-Th-Sm)/He thermochronometer provides geologically meaningful ages using a feasible technique. Additionally, thermal modelling of the FHe data succeeds in revealing a feasible thermal history. The data suggests that the $T_{c}$ of the fluorite (U-Th-Sm)/He thermochronometer is variable. The REE+Y content plays a leading role in controlling this systematics and might be useful for the understanding of the diffusion process. However, they might not directly influence the diffusion themselves but trigger several processes. A closer look at these processes, especially the ionic porosity, is needed to fully understand this systematics. Further diffusion experiments in combination with mineralogical and crystallographical constraints, e.g. x-ray, EBSD and Raman analysis can yield precise information on the fluorite lattice and vacancy density. Hereby, the effect of REE+Y clusters might play a key role. Together with analysis of the compensation mechanisms, using CL spectroscopy in fluorite, this complex multi-dimensional problem might be solvable. Firstly, more routinely applied diffusion experiments shall establish or broaden the confirmed closure temperature range. Moreover, the question arises, if fluorite has such a variable helium diffusivity caused by chemical composition, what are the consequences for thermochronology using chemically and mineralogically more complex minerals, e.g. zircon, apatite, goethite, feldspar and garnet?

In future, the routine application of FHe together with $\mathrm{T}_{\mathrm{c}}$ estimation and cation analysis might yield valuable information on low-temperature geological and economic geological problems as neotectonics and the timing and duration of hydrothermal events. This should especially be the case in geological settings where apatite and zircon is lacking, e.g. in greisen, carbonate hosted, and MVT ore deposits.

Research on synthetic $\mathrm{CaF}_{2}$ in combination with soaking experiments seems to be very promising. Even though the opposite trend has been suggested by the data on synthetic and natural $\mathrm{CaF}_{2}$, there is a significant effect of doping on diffusion. Further application of this method to other synthetic materials, doped materials, and minerals poor in helium, might help one to understand the fundamentals of diffusion of noble gasses in solids.

The results of the regional study in the Erzgebirge begs the question, where nowadays are the relicts of the predicted Mesozoic sedimentary cover? A provenance study in the Sächsische Schweiz and beyond combined with additional studies in the Thüringer Becken might yield further conclusions. A comparison of the Erzgebirge to the Lausitz block with a focus on the Lausitz thrust might yield further information on the exhumation of Variscan basement blocks in Cenomanian times. The FHe study in the Erzgebirge raised the question, if the fluorites addressed as Mesozoic in formation age might have kept a memory on late-Variscan mineralisation? The question of formation ages might be a focus on further research including extensive Sm-Nd dating of fluorite. By increasing the accuracy of the FHe method, it might also be possible to divide different hydrothermal pulses, e.g. the multiple Mesozoic hydrothermal events in the Erzgebirge. This combination might be capable of answering important questions on the timing and lifespan of hydrothermal systems in general. By application to more ore deposits, the very good correlation between REE systematics and mineralisation type might reveal its potential. 


\section{Acknowledgement}

My special gratitude goes to István Dunkl and Hilmar von Eynatten for the possibility of doing research together, science talks, discussions on many ideas and the warm family-like atmosphere.

Special thanks to my wife Katharina, my son Leonard, and my twins for never ending support, love and joy.

Many thanks for a lot of help in the lab to Judit Dunkl, Keno Lünsdorf, and Thilo Hartung and the workshop of the GZG.

It was a great opportunity to visit the labs and discuss my thesis with Prof. Dr. Danny Stockli, Adam Goldsmith, Dr. Burkhard Schmidt, Dr. Volker Karius, Prof. Dr. Andreas Pack.

More thanks for help discussing my data and sampling to Dr. Ulf Kempe, Dr. Thomas Voigt, Dr. JanMichael Lange, Dr. Christian Tonk.

Thank you very much for reflections, hints and advices: Prof. Dr. Gregor Markl, Prof. Dr. Noreen Evans, Dr. Martin Danišík, Dr. Teresa Pi, Prof. Dr. H.G. Dill, Dr. Raimon Tolosana-Delgado, Prof. Dr. Igor Villa, Dr. Volker Lüders, Prof. Dr. István Dódony.

More thanks for helping me sampling and collecting samples to Prof. Dr. Hans Jürgen Franzke, Prof. Dr. Gerhard Heide, Dr. Karin Rank, Dr. Michel Picard, Dr. Paula C. Piilonen, Dr. Kingsley Burlinson, Dr. Ulrich Hein, Hans-Jürgen Schneider, Geowissenschaftliches Museum der Universität Göttingen. 


\section{References}

Arehart, G.B., Chakurian, A.M., Tretbar, D.R., Christensen, J.N., Mclnnes, B.A., Donelick, R.A., 2003, Evaluation of radioisotope dating of Carlin-type deposits in the Great Basin, western North America, and implications for deposit genesis: Economic Geology, v. 92, p. 235-248.

Bau, M., 1991, Rare-earth element mobility during hydrothermal and metamorphic fluid-rock interaction and the significance of the oxidation state of europium: Chemical Geology, v. 93, p. 219-230.

Baumann, L., 1967, Zur Frage der varistischen und postvaristischen Mineralisation im sächsischen Erzgebirge: Freiberger Forschungshefte C, v. 209, p. 15-38.

Baumann, L., 1994a, Ore parageneses of the Erzgebirge-history, results and problems: Monograph series on mineral deposits, v. 31, p. 25-46.

Baumann, L., 1994b, The vein deposits of Freiberg, Saxony: Monograph series on mineral deposits, v. 31, p. 149-167.

Baumann, L., and Weber, W., 1996, Crust Activation in Central Europe and their metallogenetic importance for the Erzgebirge: Freiberger Forschungshefte C, v. 467, p. 27-58.

Baumann, L., Kuschka, E., Seifert, T., 2000, Lagerstätten des Erzgebirges: Stuttgart, Enke im Thieme Verlag, $300 \mathrm{p}$.

Bengston, A., Ewing, R. C. and Becker, U., 2012, He diffusion and closure temperatures in apatite and zircon: A density functional theory investigation. Geochim. et Cosmochim. Acta 86, 228-238.

Bonett, D.G., and Price, R.M., 2002, Statistical inference for a linear function of medians: Confidence intervals, hypothesis testing and sample size requirements: Psychological methods, v. 7(3), p. 370-383.

Brause, H., 1988, Beiträge zur Geodynamik des Saxothuringikums: Geoprofil, v. 2, p. 1-88.

Bühn, B., 2003. Fluid-rock interaction during progressive migration of carbonatitic fluids, derived from small-scale trace element and $\mathrm{Sr}, \mathrm{Pb}$ isotope distribution in hydrothermal fluorite. Geochim. et Cosmochim. Acta, 67(23), 4577-4595.

Bühn, B., Rankin, A. H., Schneider, H.-J. and Dulski, P., 2002, The nature of orthomagmatic, carbonatitic $f$ luids precipitating REE,Sr-rich f luorite: $\mathrm{f}$ luid-inclusion evidence from the Okorusu $\mathrm{f}$ luorite deposit, Namibia. Chemical Geology, 186, 75-98.

Burlinson, K., 1991, Decrepitation in gold exploration. A case history from the Cotan prospect, N.T. Journal of Geochemical Exploration, 42, 143-156.

Carslaw, H. S. and Jaeger, J. C., 1959. Conduction of heat in solids. Clarendon Press, Oxford, $510 \mathrm{~S}$.

Cathelineau, M., Boiron, M., Holliger, P., Poty, B., 1990, Metallogenesis of the French part of the Variscan orogen. Part II: Time-space relationships between $\mathrm{U}, \mathrm{Au}$ and $\mathrm{Sn}-\mathrm{W}$ ore deposition and geodynamic events - mineralogical and U-Pb data. International IGCP Conference Project 233: Tectonophysics, v. 177(1-3), p. 59-79.

Chesley, J., Halliday, A. N. and Scrivener, R. C., 1991, Samarium-Neodymium Direct Dating of Fluorite Mineralisation. Science, 252(5008), 949-951. 
Chesley, J., Halliday, A. N., Kyser, T. K. and Spry, P. G., 1994, Direct dating of Mississippi valley-type mineralisation; use of Sm-Nd in fluorite. Economic Geology, 89(5), 1192-1199.

Cressie, N.A.C., 1993, Statistics for spatial data. Wiley series in probability and mathematical statistics: Applied probability and statistics, New York, 900 pp.

Dahl, P. S., 1997, A crystal-chemical basis for Pb retention and fission-track annealing systematics in U-bearing minerals, with implications for geochronology. Earth and Planetary Science Letters, 150(3-4), 277-290.

Danišík, M., Migoń, P., Kuhlemann, J., Evans, N.J., Dunkl, I. and Frisch, W., 2010, Thermochronological constraints on the long-term erosional history of the Karkonosze Mts., Central Europe. Geomorphology, 117(1-2), 78-89.

Dill, H. G., Weber, B., 2010, Accessory minerals of fluorite and their implication regarding the environment of formation (Nabburg-Wölsendorf fluorite district, SE Germany), with special reference to fetid fluorite ("Stinkspat"). Ore Geology Reviews 37(2), 65-86.

Dodson, M. H., 1973, Closure Temperature in Cooling Geochronological and Petrological Systems. Contrib Mineral Petrol, 40(3), 259-274.

Dolejs, D., and Štemprok, M., 2001, Magmatic and hydrothermal evolution of Li-F granites: Cinovec and Krasno intrusions, Krusne hory batholith: Czech Republic Bulletin of Geoscience, v. 76(2), p. 77-99.

Dudek, A., Frolíková, I. and Nekovarík, Č., 1991, The depth of intrusion of Hercynian granitoid plutons in the Bohemian Massif. Acta Univ. Carol. Geol., 3, 4.

Dunkl, I., Mikes, T., Simon, K. and von Eynatten, H., 2008, Brief introduction to the Windows program Pepita: data visualization, and reduction, outlier rejection, calculation of trace element ratios and concentrations from LA-ICP-MS data. In Laser ablation ICP-MS in the Earth Sciences: Current practices and outstanding issues (ed. P. Sylvester). Mineralogical Association of Canada Short Course 40, Vancouver, B.C., p. 334-340.

Ehlers, T.A., Chaudhri, S.K., Fuller, C.W., Willett, S.D., Ketcham, R.A., Brandon, M.T., Belton, D., Kohn, B.P., Gleadow, A.J.W., Dunai, T.J. and Fu, F.Q., 2005, Computational Tools for Low-Temperature Thermochronometer Interpretation. In: Low-Temperature Thermochronology. Techniques, Interpretations, and Applications (P.W. Reiners and T.A. Ehlers, eds.) Reviews in Mineralogy \& Geochemistry, Mineralogical Society of America Geochemical Society, 58, 589-622.

Eikenberg, J., 1991, Application of the U-Xe-Kr and U-Pb systems for dating U-minerals, in Pagel, M., and Leroy, L., eds, Source, transport and deposition of metals. Rotterdam, Balkema, p. 385390.

Eissmann, L., 1997, Die ältesten Berge Sachsens oder die morphologische Beharrlichkeit geologischer Strukturen, mit 2 Tabellen: Altenburger naturwissenschaftliche Forschungen. Naturkundliches Museum, Altenburg, $56 \mathrm{p}$.

Evans, N. J., Wilson, N., Cline, J., McInnes, B. I. A. and Byrne, J., 2005, Fluorite (U-Th)/He thermochronology: Constraints on the low temperature history of Yucca Mountain, Nevada. Applied Geochemistry, 20(6), 1099-1105.

Farley, K. A., 2000, Helium diffusion from apatite: General behavior as illustrated by Durango fluorapatite. J. Geophys. Res, 105(B2), 2903-2914.

Farley, K. A., 2007, He diffusion systematics in minerals: Evidence from synthetic monazite and zircon structure phosphates. Geochim. et Cosmochim. Acta, 71(16), 4015-4024.

Farley, K. A., Wolf, R. A. and Silver, L., 1996, The effects of long alpha-stopping distances on (UTh)/He ages. Geochim. et Cosmochim. Acta, 60(21), 4223-4229.

Farley, K. A., Reiners, P. W. and Nenow, V., 1999, An Apparatus for High-Precision Helium Diffusion Measurements from Minerals. Anal. Chem, 71(10), 2059-2061. 
Fechtig, H. and Kalbitzer, S., 1966, The diffusion of argon in potassium-bearing solids. In: Potassium argon dating (A. O. Schaeffer and J. Zähringer, eds.), Springer-Verlag. New York., pp. 68-106.

Fitzgerald, P.G., Baldwin, S.L., Webb, L.E., O'Sullivan, P.B., 2006, Interpretation of (U-Th)/He single grain ages from slowly cooled crustal terranes: A case study from the Transantarctic Mountains of southern Victoria Land: Chemical Geology, v. 225, p. 91-120.

Flowers, R.M., Ketcham, R.A., Shuster, D.L. and Farley, K.A., 2009, Apatite (U-Th)/He thermochronometry using a radiation damage accumulation and annealing model. Geochim. et Cosmochim. Acta, 73(8), 2347-2365.

Förster, B., 1996, U/Pb-Datierungen an Pechblenden der U-Lagerstätte Aue-Niederschlema (Erzgebirge). Unpubl. doctoral dissertation, Justus Liebig-Universität Giessen.

Förster, B., and Haack, U., 1996, Multistage evolution of the Aue-Niederschlema uranium vein deposit (Erzgebirge, Germany): evidence from pitchblende dating: Journal of Conference Abstracts, v. 1, p. 173.

Förster, H.-J., Gottesmann, B., Tischendorf, G., Siebel, W., Rhede, D., Seltmann, R. and Wasternack, J., 2007, Permo-Carboniferous subvolcanic rhyolitic dikes in the western Erzgebirge/Vogtland, Germany: a record of source heterogeneity of post-collisional felsic magmatism. N. Jb. Miner. Abh., 183(2), 123-147.

Galbraith, R.F. and Laslett, G.M., 1993, Statistical models for mixed fission track ages. Nucl. Tracks Radiat. meas., 21(4), 459-470.

Gautheron, C., Tassan-Got, L., Barbarand, J. and Pagel, M., 2009, Effect of alpha-damage annealing on apatite (U-Th)/He thermochronology. Chemical Geology, 266(3-4), 157-170.

Gavrilenko, V., Morozov, M., Kempe, U., Smolenskiy, V., Wolf, D., 1997, Unusual REE distribution patterns in fluorites from $\mathrm{Sn}-\mathrm{W}$ deposits of the quartz-cassiterite and quartz-wolframite type [abstract]: Journal of Czech Geological Society, v. 42(3), p. 36.

Gigoux, M., Delpech, G., Guerrot, C., Pagel, M., Augé, T., Négrel, P., Brigaud, B., 2015, Evidence for an Early Cretaceous mineralizing event above the basement/sediment unconformity in the intracratonic Paris Basin: paragenetic sequence and Sm-Nd dating of the world-class PierrePerthuis stratabound fluorite deposit. Miner. Deposita 50, 455-463.

Gleadow, J.W., Duddy, I.R., Green, P.F. and Hegarty, K.A., 1986, Fission track lengths in the apatite annealing zone and the interpretation of mixed ages. Earth Planet Sci. Lett., 78(2-3), 245-254.

Götze, J., 1998, Geochemistry and provenance of the Altendorf feldspathic sandstone in the Middle Bunter of the Thuringian basin (Germany). Chemical Geology, 150(1-2), 43-61.

Goldfarb, R.J., Snee, L.W., Miller, L.D., 1991, Rapid dewatering of the crust deduced from ages of mesothermal gold deposits: Nature, v. 354, p. 296-298.

Gradstein, F. and Ogg, J., 2004, Geologic time scale 2004 - why, how, and where next! Lethaia, 37(2), 175-181.

Grønlie, A., Harder, V.M., Roberts, D., 1990, Preliminary fission-track ages of fluorite mineralisation along fracture zones, inner Trondheimsfjord, Central Norway: Norsk geologisk tidsskrift, v. 70(3), p. 173-178.

Guenthner, W.R., Reiners, P.W., Ketcham, R.A., Nasdala, L. and Giester, G., 2013, Helium diffusion in natural zircon: Radiation damage, anisotropy, and the interpretation of zircon (U-Th)/He thermochronology. American Journal of Science, 313(3), 145-198.

Halliday, A.N., and Mitchell, J.G., 1984, K-Ar ages of clay-size concentrates from the mineralisation of the Pedroches Batholith, Spain, and evidence for Mesozoic hydrothermal activity associated with the break up of Pangaea: Earth and Planetary Science Letters, v. 68(2), p. 229-239.

Höhndorf, A., Kämpf, H., Dulski, P., 1994, Sm/Nd and Rb/Sr isotopic investigations on fluorite mineralisation of the eastern Erzgebirge, in Seltmann, R., Kämpf, H., Möller, P., eds, Metallogeny 
of Collisional Orogens Focussed on the Erzgebirge and Comparable Metallogenic Settings: Czech Geological Survey, Prague, Czech Republic, p 116-128.

Hösel, G., Meyer, H., Tägl, U., 1994, Sauberg/Westfeld, in Hösel, G., ed, Das ZinnerzLagerstättengebiet Ehrenfriedersdorf/Erzgebirge: Freiberg, Bergbau in Sachsen, Landesamt für Umwelt und Geologie und Oberbergamt, v. 1, p 42-58.

Hofstra, A. H., Premo, W. R., Emsbo, P., Cline, J. S. and Aleinikoff, J. N., 2000, U-Th-Pb dating of hydrothermal minerals from Carlin-type gold deposits: results and evaluation. In: Geology and Ore Deposits 2000: The Great Basin and Beyond. Symp. Proc. (J. K. Cluer, J. G. Price, E. M. Struhsacker, R. F. Hardyman and C. L. Morris, eds.) vol. 1, pp. 61-65.

Janetschke, N., and Wilmsen, M., 2014, Sequence stratigraphy of the lower Upper Cretaceous Elbtal Group (Cenomanian-Turonian of Saxony, Germany): Zeitschrift der Deutschen Gesellschaft für Geowissenschaften, v. 165(2), p. 179-207.

Jung, D., and Meyer, H., 1991, Zur Geologie der Lagerstätte Röhrenbohrer, Geoprofil, v. 3, p. 21-27. Kazanskii, S. A., Ryskin, A. I., Nikiforov, A. E., Zaharov, Y., Ougrumov, M. and Shakurov, G. S., 2005, EPR spectra and crystal field of hexamer rare-earth clusters in fluorites. Phys. Rev. B, 72(1), 014127.

Kempe, U., 2003, Precise electron microprobe age determination in altered uraninite: consequences on the intrusion age and the metallogenic significance of the Kirchberg granite (Erzgebirge, Germany). Contrib. Mineral. Petr., 145(1), 107-118.

Kempe, U., Trinkler, M. and Brachmann, A., 1994, Brauner Fluorit aus Sn-W-Lagerstätten Chemismus und Farbursachen. Beih. z. Eur. J. Mineral., 6(Beiheft 1).

Kempe, U., Wolf, D., Ebermann, U. and Bombach, K., 1999, $330 \mathrm{Ma} \mathrm{Pb/Pb} \mathrm{single} \mathrm{zircon} \mathrm{evaporation}$ ages for the Altenberg Granite Porphyry, Eastern Erzgebirge (Germany): implications for Hercynian granite magmatism and tin mineralisation. Z. geol. Wiss., 27(5/6), 385-400.

Kempe, U. and Belyatsky, B. V., 2000, Direct Isotope Dating of W(-Y) Mineralisation at Kyzyltau (Mongolian Altai): Preliminary Results: International Geology Review. International Geology Review, 42(5), 470-480.

Kempe, U. and Götze, J., 2002, Cathodoluminescence (CL) behaviour and crystal chemistry of apatite from rare-metal deposits. Mineralogical Magazine, 66(1), 151-172.

Kempe, U., Plötze, M., Brachmann, A. and Böttcher, R., 2002, Stabilisation of divalent rare earth elements in natural fluorite. Mineralogy and Petrology, 76, 213-234.

Kempe, U., Bombach, K., Matukov, D., Schlothauer, T., Hutschenreuter, J., Wolf, D., Sergeev, S., 2004, $\mathrm{Pb} / \mathrm{Pb}$ and $\mathrm{U} / \mathrm{Pb}$ zircon dating of subvolcanic rhyolite as a time marker for Hercynian granite magmatism and Sn mineralisation in the Eibenstock granite, Erzgebirge, Germany: Considering effects of zircon alteration: Mineralium Deposita, v. 39, p. 646-669.

Ketcham, R.A., 2005, Forward and inverse modeling of low-temperature thermochronometry data. In: Low-Temperature Thermochronology. Techniques, Interpretations, and Applications (P.W. Reiners and T.A. Ehlers, eds.) Reviews in Mineralogy \& Geochemistry, Mineralogical Society of America Geochemical Society, 58, 275-314.

Ketcham, R. A., Guenthner, W. R. and Reiners, P. W., 2013, Geometric analysis of radiation damage connectivity in zircon, and its implications for helium diffusion. American Mineralogist, 98(2-3), 350-360.

Klemm, W., 1994, Review of data on the composition of hydrothermal solutions during the Variscan and post Variscan mineralisations in the Erzgebirge, Germany: Monograph Series, Mineral

Deposits, v. 31, p. 61-69.

Kley, J., 2013, Saxonian tectonics in the 21st century. ZDGG, 164(2), 295-311.

Knobloch, E., Konzalová, M., Kvacek, Z., 1996, Die obereozäne Flora der Staré Sedlo-Schichtenfolge in Böhmen (Mitteleuropa): Rozpravy Česke Geologicke Ustavu Svazek, v. 49, p. 1-260. 
Knobloch, E. and Konzalová, M., 1998, Comparison of the Eocene plant assemblages of Bohemia (Czech Republic) and Saxony (Germany). Review of Palaeobotany and Palynology, 101(1-4), 2941.

Komínek, J., Chrt, J. and Landa, O., 1994, Uranium mineralisation in the western Krušné hory Mts.(Erzgebirge) and the Slavkovský les region, Czech Republic. In: Mineral deposits of the Erzgebirge/Krušné hory-Germany/Czech Republic (K.v. Gehlen and D.D. Klemm, eds.). Monograph Series on Mineral Deposits, 31, 209-230.

Kossmat, F., 1925, Übersicht der Geologie von Sachsen. Sächsisches Geologisches Landesamt, Leipzig, $129 \mathrm{pp}$.

Kroner, U., Hahn, T., Romer, R.L., Linnemann, U., 2007, The Variscan orogeny in the Saxo-Thuringian zone-heterogeneous overprint of Cadomian/Palaeozoic peri-Gondwana crust, in Linnemann, U., Nance, R.D., Kraft, P. and Zulauf, G., eds, The evolution of the Rheic Ocean: From AvalonianCadomian active margin to Alleghenian-Variscan collision: Geological Society of America, Special Paper, v. 423, p. 153-172.

Kumann, R., and Leeder, O., 1994, On the relations between granite and ore in the Ehrenfriedersdorf tin deposit, Erzgebirge, in Seltmann, R., Kämpf, H., Möller, P., eds, Metallogeny of Collisional Orogens Focussed on the Erzgebirge and Comparable Metallogenic Settings: Czech Geological Survey, Prague, Czech Republic, p 166-173.

Kuschka, E., 1996, Hydrothermalite des Schwarzwaldes und Erzgebirges im paragenetischen Vergleich: Freiberger Forschungshefte C, v. 467, p. 177-200.

Kuschka, E., 1997, Atlas der hydrothermalite des Vogtlandes, Erzgebirges und Granulitgebirges. Sächsisches Landesamt für Umwelt und Geologie, Bereich Boden und Geologie: Geoprofil, v. (10), p. 1-151.

Lange, J.-M., Tonk, C. and Wagner, G.A., 2008, Apatite fission track data for the Postvariscan thermotectonic evolution of the Saxon basement - first results. ZDGG, 159(1), 123-132.

Linnemann, U., and Romer, R.L., 2002, The Cadomian Orogeny in Saxo-Thuringia, Germany: geochemical and $\mathrm{Nd}-\mathrm{Sr}-\mathrm{Pb}$ isotopic characterization of marginal basins with constraints to geotectonic setting and provenance: Massifs and correlations across the Cadomo-Avalonian orogens: Tectonophysics, v. 352(1-2), p. 33-64.

Linnemann, U. and Romer, R.L., 2010, Pre-Mesozoic geology of Saxo-Thuringia: From the Cadomian active margin to the Variscan Orogen. Schweizerbart, Stuttgart, $485 \mathrm{pp}$.

Lovera, O. M., Richter, F. M. and Harrison, T. M., 1989, The 40 Ar/ 39 Ar Thermochronometry for Slowly Cooled Samples Having a Distribution of Diffusion Domain Sizes. J. Geophys. Res., 94(B12), 17917-17935.

Mai, D.H. and Walther, H., 2000, Die Fundstellen eozäner Floren des Weißelsterbeckens und seiner Randgebiete. Altenburger Naturwiss. Forsch., 13, 1-59.

McDougall, I., and Harrison, T.M., 1988, Geochronology and thermochronology by the ${ }^{40} \mathrm{Ar} /{ }^{39} \mathrm{Ar}$ method: New York, Oxford University Press, xi, 212 p.

Migoń, P. and Lidmar-Bergström, K., 2001, Weathering mantles and their significance for geomorphological evolution of central and northern Europe since the Mesozoic. Earth-Science Reviews, 56(1-4), 285-324.

Mitchell, J.G., and Halliday, A.N., 1976, Extent of Triassic/Jurassic hydrothermal ore deposits on the North Atlantic margins: Transactions of the Institution of Mining and Metallurgy B, v. 85, p. 159161.

Möller, P., Parekh, P. and Schneider, H.-J., 1976, The application of Tb/Ca-Tb/La abundance ratios to problems of fluorspar genesis. Miner Deposita, 11, 111-116.

Möller, P., Bau, M., Dulski, P. and Lüders, V., 1998, REE and yttrium fractionation in fluorite and their bearing on fluorite formation. In: Proceedings of the Ninth Quadrennial IAGOD Symposium. Held 
in Beijing, China, August 12-18, 1994. Papers presented at the Symposium on topics related to general problems on the genesis of ore deposits and on studies of the ore geology of specific districts or deposits (R. D. Hagni, ed.), E. Schweizerbart'sche, Stuttgart.

Monecke, T., Kempe, U., Monecke, J., Sala, M., Wolf, D., 2002, Tetrad effect in rare earth element distribution patterns: A method of quantification with application to rock and mineral samples from granite-related rare metal deposits: Geochimica et Cosmochimica Acta, v. 66(7), p. 11851196.

Monecke, T., Kempe, U., Trinkler, M., Thomas, R., Dulski, P., Wagner, T., 2011, Unusual rare earth element fractionation in a tin-bearing magmatic-hydrothermal system: Geology, v. 39(4), p. 295298.

Moore, D. S. and Wright, J. C., 1981, Laser spectroscopy of defect chemistry in CaF2:Er3+. J. Chem. Phys., 74(3), 1626.

Morozov, M., Trinkler, M., Plötze, M., Kempe, U., 1996, Spectroscopic studies on fluorites from Li-F and alkaline granite systems in Central Kazakhstan, in Shatov, V., Seltmann, R., Kremenetsky, A., Lehmann, B., Popov, V., Ermolov, P., eds, Granite-related ore deposits of Central Kazakhstan and adjacent areas. Project, St. Petersburg, p 359-369.

Nasdala, L., Irmer, G. and Wolf, D., 1995, The degree of metamictization in zircon: a Raman spectroscopic study. Eur.J.Mineral., 7, 471-478.

Nasdala, L., Reiners, P.W., Garver, J.I., Kennedy, A.K., Stern, R.A., Balan, E. and Wirth, R., 2004, Incomplete retention of radiation damage in zircon from Sri Lanka. American Mineralogist, 89(1), 291-231.

Nekrasov, K.A. and Kupryashkin, A.Ya., 2001, Recovery of the potential of interaction between helium atoms and fluorine ions using the data on interstitial diffusion and solubility of helium in fluorides of alkaline earth metals. HighTemperature 39, 229-234.

Nowacki, W., 1938, Die Kristallstruktur des kubischen Yttriumfluorids YF3. Zeitschrift fuer Kristallographie, Kristallgeometrie, Kristallphysik, Kristallchemie, 100, 242-250.

Ostendorf, J., Henjes-Kunst, F., Seifert, T., Gutzmer, J., 2014, Rb-Sr geochronology of sphalerite from fluorite-barite-sulfide veins of the Freiberg ore district, Erzgebirge (Germany). 21st General Meeting of the International Mineralogical Association (IMA) 2014 in Johannesburg, South Africa, abstract ID: 664.

Paton, C., Hellstrom, J., Paul, B., Woodhead, J., Hergt, J., 2011, Iolite: freeware for the visualisation and processing of mass spectrometric data. J Anal At Spectrom 26 (12), 2508-2518.

Pi, T., Solé, J. and Taran, Y., 2005, (U-Th)/He dating of fluorite: application to the La Azul fluorspar deposit in the Taxco mining district, Mexico. Mineralium Deposita, 39(8), 976-982.

Pietzsch, K., 1913. Verwitterungserscheinungen der Auflagerungsfläche des sächsischen Cenomans. ZDGG, 65, 594-602.

Prazak, J., 1994, Cretaceous, in: Klomínský, J., ed, Geologický atlas České Republiky, stratigrafie. Geological atlas of the Czech Republic, stratigraphy, 1st edn, Český geologický ústav, Kutná Hora.

Presser, V. and Glotzbach, C., 2009, Metamictization in zircon: Raman investigation following a Rietveld approach. Part II: Sampling depth implication and experimental data. J. Raman Spectrosc., 40(5), 499-508.

Reiners, P. W., Farley, K. A. and Hickes, H., 2002, He diffusion and (U-Th)/He thermochronometry of zircon: initial results from Fish Canyon Tuff and Gold Butte. Tectonophysics, 349(1-4), 297-308.

Richardson, J. and Blenkinsop, J., 1989. Dissolution of Fluorite (CaF,) for Isotope Geochemistry. Journal of Fluorine Chemistry, 43, 145-149.

Romer, R.L., Thomas, R., Stein, H. and Rhede, D., 2007, Dating multiply overprinted Sn-mineralized granites - examples from the Erzgebirge, Germany. Mineralium Deposita, 42(4), 337-359. 
Romer, R.L., Förster, H.-J. and Štemprok, M., 2010a, Age constraints for the late-Variscan magmatism in the Altenberg-Teplice Caldera (Eastern Erzgebirge/Krušné hory). N. Jb. Miner. Abh., 187(3), 289-305.

Romer, R.L., Schneider, J. and Linnemann, U., 2010b, Post-Variscan deformation and hydrothermal mineralisation in Saxo-Thuringia and beyond: a review. In: Pre-Mesozoic geology of SaxoThuringia. From the Cadomian active margin to the Variscan Orogen (U. Linnemann and R.L. Romer, eds.) Schweizerbart, Stuttgart, 347-360.

Schröder, B., 1976, Saxonische Tektonik im Ostteil der Süddeutschen Scholle. Geol. Rundsch., 65(1), 34-54.

Schröder, B., 1987, Inversion tectonics along the Western margin of the Bohemian Massif: Compressional Intra-Plate Deformations in the Alpine Foreland. Tectonophysics, 137(1-4), 93100.

Schröder, B. and Peterek, A., 2001, Cenozoic degradation history of basement units in the surroundings of the western Eger (Ohre) Rift. ZDGG, 152(2-4), 387-403.

Schwinn, G. and Markl, G., 2005, REE systematics in hydrothermal fluorite. Chemical Geology, 216(34), 225-248.

Seifert, T., 2008, Metallogeny and petrogenesis of lampophyres in the Mid-European variscides: Postcollosional magmatism and its relationship to late-variscan ore forming processes in the Erzgebirge (Bohemian Massiv). IOS Press, Rotterdam, 303 pp.

Seifert, T., Baumann L., Leeder O., 1992, Contribution to the paragenetic characterization of mineralisations of the $\mathrm{Sn}(-\mathrm{W})$, quartz-polymetal and fluorite-quartz association in the E part of the Central Erzgebirge anticlinal area: Neues Jahrbuch für Mineralogie Abhandlungen, v. 165, p. 65-81.

Seifert, T., Wendebaum, G., Trinkler, M., Baumann, L., 1994, Geochemische und thermometrische Untersuchungen an hydrothermalen Mineralisationen im Mittleren Erzgebirge: European Journal of Mineralogy, v. 6(1), p. 261.

Seifert, T., Atanasova, P., Gutzmer, J. and Pfänder, J., 2011, Mineralogy, geochemistry and age of greisen mineralisation in the Li-Rb-Cs-Sn-W deposit Zinnwald, Erzgebirge, Germany. Mineralogical Magazine, 75(3), 1833.

Shuster, D.L. and Farley, K.A., 2003, 4He/3He thermochronometry. Earth Planet. Sc. Lett. 217, 1-17.

Shuster, D. L., Flowers, R. M. and Farley, K. A., 2006a, Radiation damage and helium diffusion kinetics in apatite. Geochim. et Cosmochim. Acta, 70(18), A590.

Shuster, D. L., Flowers, R. M. and Farley, K. A., 2006b, The influence of natural radiation damage on helium diffusion kinetics in apatite. Earth and Planetary Science Letters, 249(3-4), 148-161.

Shuster, D. L. and Farley, K. A., 2009, The influence of artificial radiation damage and thermal annealing on helium diffusion kinetics in apatite. Geochim. et Cosmochim. Acta, 73(1), 183-196.

Siebel, W., Hann, H. P., Danišík, M., Shang, C. K., Berthold, C., Rohrmüller, J., Wemmer, K. and Evans, N. J., 2009, Age constraints on faulting and fault reactivation: a multi-chronological approach. Int J Earth Sci (Geol Rundsch), 99(6), 1187-1197.

Stemprok, M. and Sulcek, Z., 1969, Geochemical profile through an ore-bearing lithium granite. Economic Geology, 64(4), 392-404.

Stockli, D., Farley, K. A., 2004, Empirical constraints on the titanite (U-Th)/He partial retention zone from the KTB drill hole. Chem. Geol. 207, 223-236.

Suhr, P., 2003, The Bohemian Massif as a catchment area for the NW European Tertiary Basin. Geolines, 15, 147-159.

Sun, S., and McDonough, W.F., 1989, Chemical and isotopic systematics of oceanic basalts: implications for mantle composition and processes: Geological Society, London, Special Publications, v.42(1), p. 313-345. 
Thomson, S.N., and Zeh, A., 2000, Fission-track thermochronology of the Ruhla Crystalline Complex: new constraints on the post-Variscan thermal evolution of the NW Saxo-Bohemian Massif: Tectonophysics, v. 324(1-2), p. 17-35.

Tischendorf, G., 1989, Silicic magmatism and metallogenesis of the Erzgebirge [compiled]: Veröffentlichungen des Zentralinstitutes für Physik der Erde, v. 107, Potsdam, 316 p.

Tischendorf, G., and Förster, H., 1990, Acid magmatism and related metallogenesis in the Erzgebirge: Geological Journal, v. 25(3-4), p. 443-454.

Trinkler, M., Monecke, J. and Thomas, R., 2005, Constraints on the genesis of yellow fluorite in hydrothermal barite-fluorite veins of the Erzgebirge, eastern Germany: Evidence from optical absorption spectroscopy, rare-earth-element data, and fluid-inclusion investigations. The Canadian Mineralogist, 43, 883-898.

Tripathy-Lang, A., Fox, M. and Shuster, D. L., 2015, Zircon 4He/3He thermochronometry. Geochim. et Cosmochim. Acta 166, 1-14.

Ventura, B. and Lisker, F., 2003, Long-term landscape evolution of the northeastern margin of the Bohemian Massif: apatite fission-track data from the Erzgebirge (Germany). International Journal of Earth Sciences, 92(5), 691-700.

Voigt, T., 1995, Faziesentwicklung und Ablagerungssequenzen am Rand eines Epikontinentalmeeres die Sedimentationsgeschichte der Sächsischen Kreide. Unpubl. doctoral dissertation, Geotechnik und Bergbau der Technischen Universität Bergakademie Freiberg.

Voigt, T., 1998, Entwicklung und Architektur einer fluviatilen Talfüllung - die Niederschöna Formation im Sächsischen Kreidebecken. Abhandl. Staatl. Museum Min. Geol. Dresden, 43/44, 121-139.

Voigt, T., 2009, The Lusatia-Krkonoše High as a late Cretaceous inversion structure: evidence from the surrounding Cretaceous basins. Z. geol. Wiss., 37, 15-39.

von Eynatten, H., Voigt, T., Meier, A., Franzke, H., Gaupp, R., 2008, Provenance of Cretaceous clastics in the Subhercynian Basin: constraints to exhumation of the Harz Mountains and timing of inversion tectonics in Central Europe: International Journal of Earth Sciences (Geol Rundsch), v. 97(6), p. 1315-1330.

Wagner, G.A., 1972, The geological interpretation of fission track ages: Trans American Nuclear Society, v. 15(1), p. 1-117.

Werner, O., and Lippolt, H.J., 2000, White mica 40Ar/39Ar ages of Erzgebirge metamorphic rocks: simulating the chronological results by a model of Variscan crustal imbrication, in Franke, W., Haak, V., Oncken, O., Tanner, D., eds, Orogenic Processes: Quantification and Modelling in the Variscan Belt: Geological Society London, Special Publications, v. 179, p. 323-336.

Wolf, L., Steding, D., Schubert, G., Alexowsky, W., Leonhardt, D., Hoth, K., Eilers, H. and Fritzsche, H., 1992, Geologische Übersichtskarte des Freistaates Sachsen: 1:400 000. Sächsisches Landesamt für Umwelt und Geologie, Freiberg.

Wolf, R.A., Farley, K.A. and Silver, L., 1996, Helium diffusion and low-temperature thermochronometry of apatite. Geochim. et Cosmochim. Acta, 60,(21), 4231-4240.

Wolff, R., Dunkl, I., Kiesselbach, G., Wemmer, K. and Siegesmund, S., 2012, Thermochronological constraints on the multiphase exhumation history of the Ivrea-Verbano Zone of the Southern Alps. Tectonophysics, 579, 104-117.

Wolff, R., Dunkl, I., Kempe, U. and Eynatten, H. von, 2015a, The age of the latest hydrothermal overprint of tin and polymetallic deposits in the Erzgebirge, Germany: constraints from fluorite (U-Th-Sm)/He thermochronology. Economic Geology, 110, 2025-2040.

Wolff, R., Dunkl, I., Lange, J.-M., Tonk, C., Voigt, T. and Eynatten, H. von, 2015b, Superposition of burial and hydrothermal events: post-Variscan thermal evolution of the Erzgebirge, Germany. Terra Nova, 27(4), 292-299. 
Wolff, R., Dunkl, I., Kempe, U., Stockli, D. F., Wiedenbeck, M. and Eynatten, H. von, 2016, Variable helium diffusion characteristics in fluorite. Geochim. et Cosmochim. Acta, 188, 21-34.

Yardley, B.W.D., and Cleverley, J.S., 2013, The role of metamorphic fluids in the formation of ore deposits, in Jenkin, G.R.T., Lusty, P.A.J., Mcdonald, I., Smith, M.P., Boyce, A.J., Wilkinson, J.J., eds, Ore Deposits in an Evolving Earth: Geological Society, London, Special Publications, 393 p.

Ziegler, P.A., 1990, Geological atlas of Western and Central Europe. Shell Internationale Petroleum Mij. B.V, The Hague, Netherlands, dist. by Geol. Soc. Publ. House, Bath, 239 pp.

Ziegler, P.A. and Dèzes, P., 2007, Cenozoic uplift of Variscan Massifs in the Alpine foreland: Timing and controlling mechanisms. TOPO-EUROPE: the Geoscience of Coupled Deep Earth-Surface Processes, 58(1-4), 237-269.

Ziegler, J.F., Ziegler, M.D., Biersack, J.P., 2010, SRIM-The stopping and range of ions in matter: Nuclear Instruments and Methods in Physics Research Section B: Beam Interactions with Materials and Atoms, v. 268(11), p. 1818-1823. 


\section{CURRICULUM VITAE}

Reinhard Wolff

\section{Kegelskamp 12 \\ 48153 Münster \\ rwolff@uni-muenster.de \\ +49 179-5022260}

\section{CV}

Münster, $2^{\text {nd }}$ June 2016

10.05.1982

25.09.2009

08.08 .2013
Born in Spaichingen/Tuttlingen, Germany

Married to Katharina Wolff

Birth of son Leonard Wolff

\section{Professional EXPERIENCE}

\section{Research assistant}

08.2015 - recent

$03.2011-08.2015$

$03.2010-03.2011$

$2005-03.2010$

\section{Teaching}

2010 - recent
Institute of Geology and Palaeontology, Westfälische Wilhelms-University Münster Structural geology and tectonics, thermochronology

Geoscience Center Göttingen (GZG), Georg-August-University of Göttingen, dep. Sedimentology Thermochronological research, developments in (U-Th)/He method, helium diffusion experiments, ICPMS lab, Raman lab, petrological and geochemical analysis, sedimentology

GZG, University of Göttingen

Conodont (U-Th)/He thermochronology

GZG, University of Göttingen

Isotope geology, K/Ar lab, Attaberg lab

University of Münster and University of Göttingen

Physical Geography, special methods in tectonics (PECUBE \& ArcGIS), rock and mineral identification, field camp, Assistant teaching in advanced thermochronology, rock and mineral identification, excursion: „Western Alps“،, mapping 1,

\section{EdUCATION}

\section{PhD thesis}

$03.2011-08.2015$

University of Göttingen, "Fluorite (U-Th-Sm)/He thermochronology“", supervisors: Prof. Dr. H.v. Eynatten, Dr. I. Dunk1

\section{Diploma of Geoscience}

$04.2007-03.2010$

University of Göttingen, Grade: 1.15, Diploma thesis: "Thermochronology and exhumation of the IvreaVerbano zone using (U-Th)/He and K-Ar dating methods.”, supervisors: Prof. Dr. S. Siegesmund, Dr. I. Dunk1

\section{Diploma mapping}

2010

\section{Bachelor of Science}

$10.2003-04.2007$

University of Göttingen, "Geological mapping of metamorphic and granitoid rocks south of Snåret, Västervik, southeast Sweden.“

University of Göttingen, Grade: 2, Bachelor thesis: "Geochemistry and trace element geochemistry to classify the main sequences of the Huab Complex and the adjacent Fransfontein Suite, Namibia“ 


\section{Reinhard Wolff}

\section{DAAD funding}

$02.2012-04.2012$ Jackson School of Geosciences at the University of Texas at Austin, USA

(U-Th)/He thermochronology and diffusion experiments in the lab of Prof. Dr. D. Stockli, Advanced thermochronology class

\section{AWARDS}

2010

"Adolf von Koehnen" award for an outstanding diploma thesis

\section{HONORARY}

1998 - recent

Member and scout leader at the german christian scout accosiation CPD eV.

\section{LANGUAGE SKILLS}

$\begin{array}{ll}\text { German } & \text { Mother tongue } \\ \text { English } & \text { C1.1, Grade: } 1.6 \\ \text { Spanish } & \text { beginners }\end{array}$

\section{FURTher Professional ExPERIENCE}

2015

2014

2013

2013

2012

2012

2012

2011

2010

2006

$1999-2000$
Abstract and oral accepted at the "The 25 ${ }^{\text {nd }}$ V.M. Goldschmidt Conference" in Prague, Czech Republic Abstract and poster at the „14th international conference on thermochronology“ in France

Advanced statistics and programming in R, R. Tolosana

Abstract and oral at the DMG\&GV at the "Geofluids" in Tübingen, Germany

Short course "Diffusion in geological materials“, Rainer Abart, Wien

Abstract and oral at the "The $22^{\text {nd }}$ V.M. Goldschmidt Conference" in Montreal, Canada

Abstract and poster at the "GeoResources for the $21^{\text {th }}$ century", Hannover, Germany

Abstract and poster at the " $10^{\text {th }}$ Alpine Workshop CorseAlp 2011" in Corsica, France

Abstract and poster at the " $12^{\text {th }}$ International Conference on Thermochronology" in Glasgow, UK

Excursion: "Rio de la Plata" in Argentinia and Uruguay

1/2 year exchange to the Zillah High School, WA, USA

\section{FURTHER EXPERIENCE}

ESRI ArcGIS, Java, Visual Basic, R, HeFTy, Igor (Iolite), MS-Office, CorelDraw, PetroMod, MATLAB, PECUBE, QTQt

Member of Geochemical Society, German Mineralogical Society (DMG eV.)

Driver license 


\section{Publications Reinhard Wolff}

\section{PAPER}

Wolff, R., Dunkl, I., Kempe, U., Stockli, D.,Wiedenbeck, M., Eynatten, H.v. (2016) Variable helium diffusion in fluorite. Geochimica et Cosmochimica Acta 188, 21-34.

Wolff, R.; Dunkl, I.; Lange, J-M.; Tonk, Ch.; Voigt, T.; Eynatten, H.v. (2015) Superposition of burial, tectonics and hydrothermal events: post-Variscan thermal evolution of Erzgebirge, Germany. TerraNova 27 (4), 292-299.

Wolff, R., Dunkl, I., Kempe, U., Eynatten, H.v. (2015) The age of the latest hydrothermal overprint of tin and polymetallic deposits in the Erzgebirge, Germany: constraints from fluorite (U-Th-Sm)/He thermochronology. Economic Geology 110, 2025-2040.

Wolff, R., Dunkl, I., Kiesselbach, G., Wemmer, K., Siegesmund, S. (2012) Thermochronological constraints on the multiphase exhumation history of the Ivrea-Verbano Zone of the Southern Alps. Tectonophysics 579, 104-117.

\section{Abstracts}

Wolff, R., Dunkl, I., Eynatten, H.v. (2015) Variable Helium Diffusion in Fluorite. The 25nd V.M. Goldschmidt Conference. Prague, Czech Republic. 16.-21.8.2015

Wolff, R., Dunkl, I., Eynatten, H.v. (2014) Fluorite (U-Th)/He thermochronology: what do we really date? Thermo2014, 14th International Conference on Thermochronology, Chamonix, 8.-14.9.2014

Wolff, R., Dunkl, I., Lange, J.-M., Tonk, Ch., Voigt, T., Eynatten, H.v. (2013) Superposition of burial and hydrothermal events: Post Variscan thermal evolution of the Erzgebirge, Germany. Geofluids, Tübingen, Germany. 15.-19.9.2013

Wolff, R., Dunkl, I., Eynatten, H.v. (2012) Fluorite (U-Th)/He thermochronology. The 22nd V.M. Goldschmidt Conference. Montreal, Canada. 24.-29.6.2012

Wolff, R., Dunkl, I., Eynatten, H.v. (2012) Rare Earth Elements in Fluorite. GeoResources for the $21^{\text {th }}$ century, Hannover, Germany. SDGG. 1.-03.10.2012

Wolff, R., Dunkl, I., Kiesselbach, G., Siegesmund, S., Eynatten, H.v. (2011) Refined Exhumation History of the Ivrea-Verbano Zone, Southern Alps. CorseAlp2011, 10th Alpine Workshop, Corsica, 10.16.4.2011

Wolff,R., Kiesselbach, G., Dunkl, I., Siegesmund, S., Eynatten, H.v. (2010) Thermochronology of the Ivrea-Verbano Zone of the Western Alps using zircon fission track, (U-Th)/He and K/Ar dating. Thermo2010, 12th International Conference on Thermochronology, Glasgow, 16.-20.8.2010

\section{THESIS}

Wolff, R., (2009) Thermochronology and exhumation of the Ivrea-Verbano zone using (U-Th)/He and KAr dating methods. Diploma thesis.

Wolff, R., (2008) Geological mapping of metamorphic and granitoid rocks south of Snåret, Västervik, southeast Sweden. Diploma mapping.

Wolff, R., (2007) Geochemistry and trace element geochemistry to classify the main sequences of the Huab Complex and the adjacent Fransfontein Suite, Namibia. Bachelor thesis. 